University of Louisville

ThinkIR: The University of Louisville's Institutional Repository

Electronic Theses and Dissertations

8-2017

\title{
The roles of anxious rearing, negative affect, and effortful control in a model of risk for child perfectionism.
}

Nicholas William Affrunti

University of Louisville

Follow this and additional works at: https://ir.library.louisville.edu/etd

Part of the Clinical Psychology Commons

\section{Recommended Citation}

Affrunti, Nicholas William, "The roles of anxious rearing, negative affect, and effortful control in a model of risk for child perfectionism." (2017). Electronic Theses and Dissertations. Paper 2739.

https://doi.org/10.18297/etd/2739

This Doctoral Dissertation is brought to you for free and open access by ThinkIR: The University of Louisville's Institutional Repository. It has been accepted for inclusion in Electronic Theses and Dissertations by an authorized administrator of ThinkIR: The University of Louisville's Institutional Repository. This title appears here courtesy of the author, who has retained all other copyrights. For more information, please contact thinkir@louisville.edu. 
THE ROLES OF ANXIOUS REARING, NEGATIVE AFFECT, AND EFFORTFUL CONTROL IN A MODEL OF RISK FOR CHILD PERFECTIONISM

\author{
By \\ Nicholas William Affrunti \\ B.S., Fordham University, 2007 \\ M.A., Catholic University of America, 2010
}

\begin{abstract}
A Dissertation
Submitted to the Faculty of the

College of Arts and Sciences of the University of Louisville

in Partial Fulfillment of the Requirements

for the degree of
\end{abstract}

Doctor of Philosophy in Clinical Psychology

Department of Psychological and Brain Sciences

University of Louisville

Louisville, KY

August 2017 

THE ROLES OF ANXIOUS REARING, NEGATIVE AFFECT, AND EFFORTFUL CONTROL IN A MODEL OF RISK FOR CHILD PERFECTIONISM

\author{
By
}

Nicholas William Affrunti

B.S., Fordham University, 2007

M.A., Catholic University of America, 2010

A Dissertation Approved on

July 29,2016

By the following Dissertation Committee

Dissertation Director
Janet Woodruff-Borden, Ph.D.,

Jill Adelson, Ph.D.

Cara Cashon, Ph.D.

Paul Salmon, Ph.D.

Paul Rosen, Ph.D. 


\section{ACKNOWLEDGMENTS}

I would first like to thank Dr. Janet Woodruff-Borden whose mentorship and counsel throughout my graduate training has been invaluable. Without her unending support for my academic development and this dissertation, this project would not have been possible. I would also like to thank my committee members, Drs. Jill Adelson, Cara Cashon, Paul Rosen, and Paul Salmon for their time and thoughtful feedback on this

project. Additionally, thank you to my lab mates, Elena Geronimi, Colette Gramszlo, and Brenda Arellano whose friendship, support, and assistance over the past four years have been irreplaceable. Finally, I want to thank all the families that participated in this project. Their time, energy, and effort are much appreciated and have helped advance our understanding of child perfectionism. 


\title{
ABSTRACT \\ THE ROLES OF ANXIOUS REARING, NEGATIVE AFFECT, AND EFFORTFUL CONTROL IN A MODEL OF RISK FOR CHILD PERFECTIONISM
}

\author{
Nicholas W. Affrunti
}

July 29, 2016

Our understanding of perfectionism and its developmental trajectory and impact on children has experienced a recent growth. Research has shown that child perfectionism is associated with a number of negative outcomes including anxiety and depressive disorders, hopelessness, poor psychosocial treatment outcomes, and researchers have not found it to be associated with actual achievement. As such, research has begun to examine the developmental risk factors that predict for its development. The current study proposes utilizing a developmental psychopathology approach, one that purports a complex interaction among internal, external, risk and protective processes in the developmental of perfectionism. Specifically, the study examined whether negative affect, effortful control, and anxious rearing would predict levels of perfectionism in children using path analysis. Effortful control and negative affect were measured using parent-report, anxious rearing was measured by parent- and child-report, and perfectionism was measured through self-report and a behavioral task. It was hypothesized that child-reported anxious rearing and perfectionism measured with a behavioral task would provide the best fitting model and provide at least an adequate fit for the data. Additionally, it was hypothesized that in this model anxious rearing and 
negative affect would predict increased levels of child perfectionism, that there would be a significant indirect effect of anxious rearing on the association between negative affect and perfectionism, and that effortful control would interact with negative affect and anxious rearing in the prediction of child perfectionism. Participants were 60 parent-child dyads with children between the ages of 7 and 13 recruited from the community. Overall, results partially supported the hypotheses. The best fitting model used child-reported anxious rearing and behaviorally assessed perfectionism. Within this model, anxious rearing and effortful control significantly predicted for child perfectionism. However, negative affect did not predict child perfectionism. Additionally, there was a significant indirect effect of anxious rearing. Lastly, the interaction between effortful control and anxious rearing and, separately, negative affect did not significantly predict for child perfectionism. Findings are discussed in terms of theoretical and conceptual implications for the study of child perfectionism and suggestions for future research are presented. 


\section{TABLE OF CONTENTS}

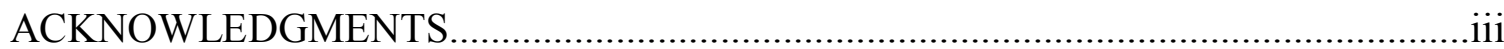

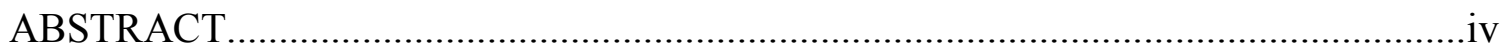

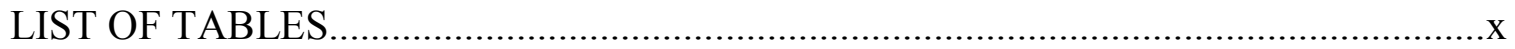

INTRODUCTION

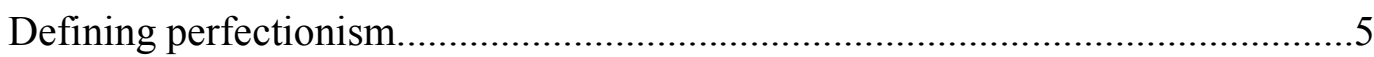

Adaptive vs. maladaptive approaches.......................................................

The dimensionality of perfectionism.........................................................

Development of perfectionism: Cognitive-affective development.........................10

Cognitive development............................................................................ 10

Affective development........................................................................... 14

Development of perfectionism: Risk factors.......................................................17

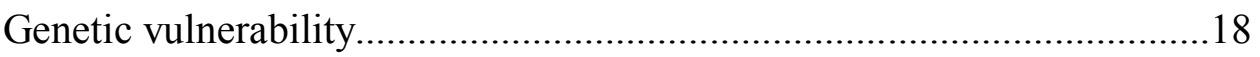

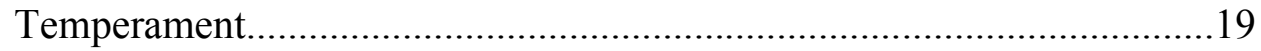

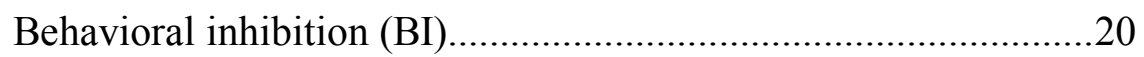

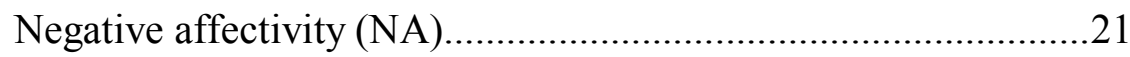

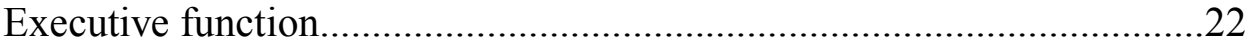

Development of perfectionism: Parental risk factors............................................25

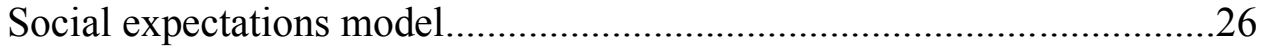

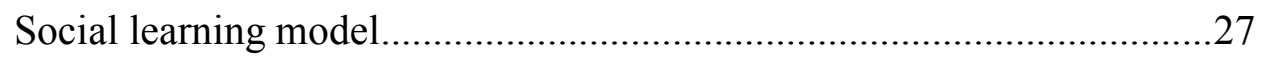

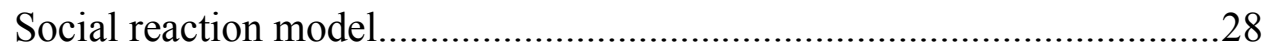


Anxious rearing model.................................................................29

Development of perfectionism: Protective factors........................................... 31

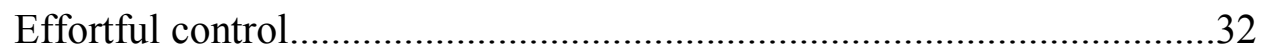

Emotion regulation............................................................................33

Perfectionism in the development of internalizing disorders.............................35

Associations with internalizing symptoms and disorders.......................36

Mediators of perfectionism and internalizing disorders........................42

Intolerance of uncertainty....................................................42

Perceived competence.......................................................44

"Not just right experiences" ".................................................4 47

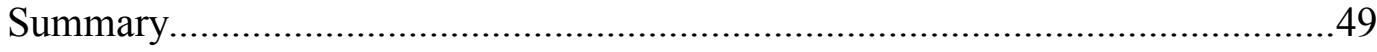

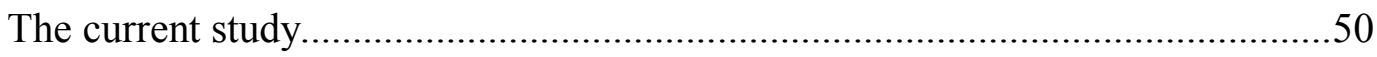

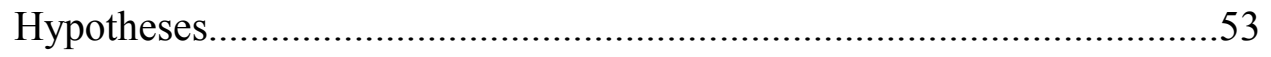

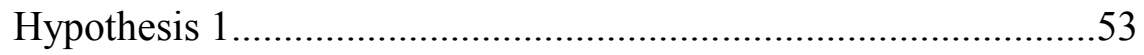

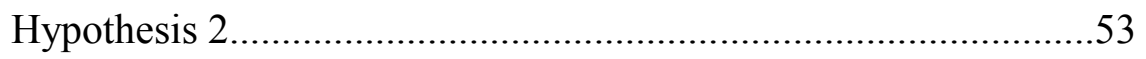

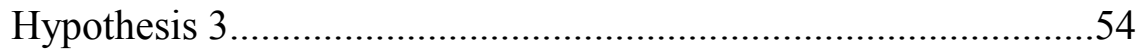

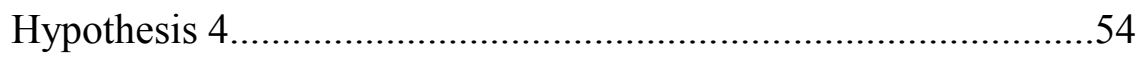

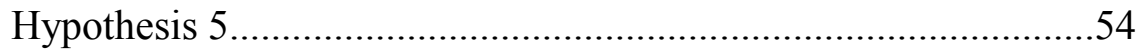

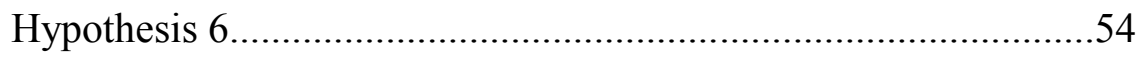

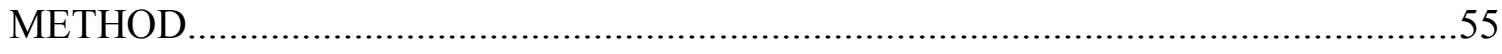

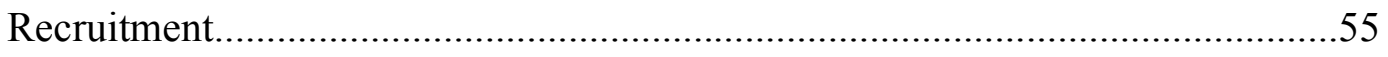

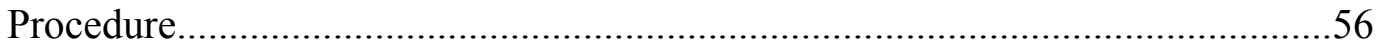


Participants

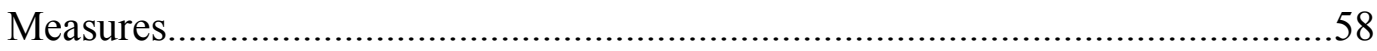

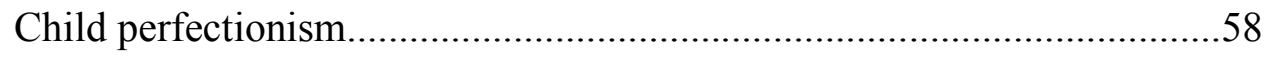

Figure copy task...........................................................58

Child and adolescent perfectionism scale................................61

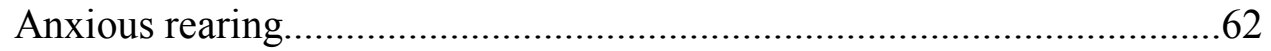

Child Temperament...................................................................63

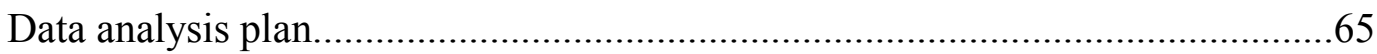

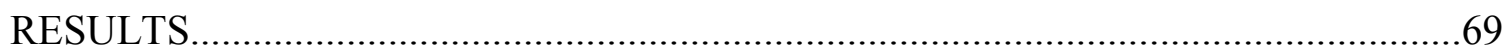

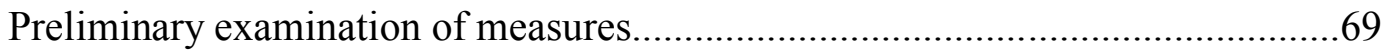

Descriptive statistics and correlations..................................................... 70

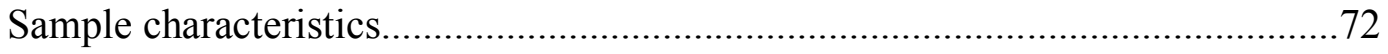

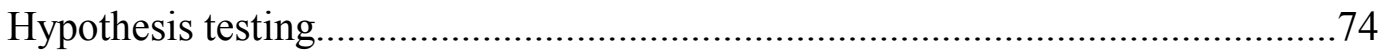

Hypothesis one: Examination of various models.................................74

Hypothesis two: Model fit........................................................75

Hypothesis three: Effects of negative affect and anxious rearing on

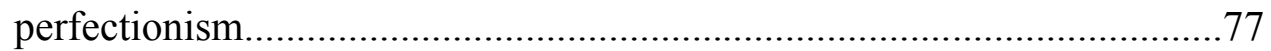

Hypothesis four: Indirect effect of anxious rearing.............................78

Hypothesis five: Interaction of effortful control and negative affect........79

Hypothesis six: Interaction of effortful control and anxious rearing.........79

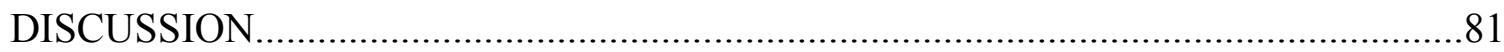




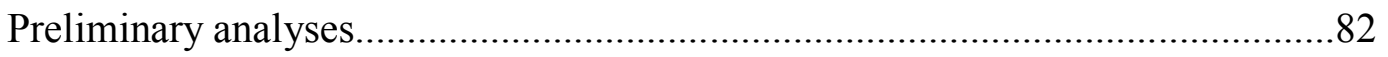

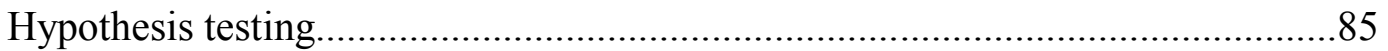

Implications for a conceptual model..........................................................94

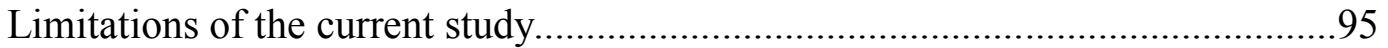

Summary and future directions.............................................................97

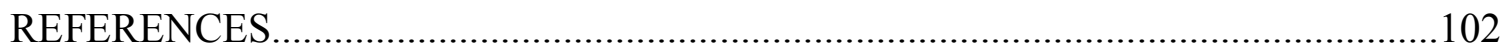

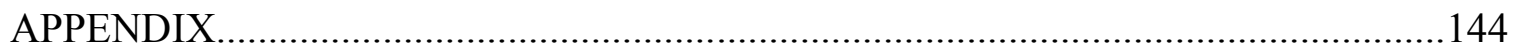

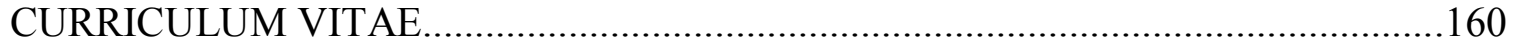




\section{LIST OF TABLES}

TABLE

PAGE

1. Summary of relevant studies connecting perfectionism with internalizing disorders in

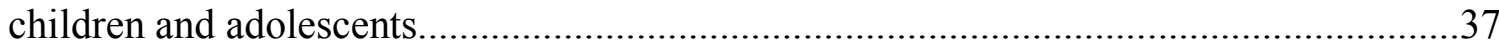

2. Descriptive statistics and Pearson correlation coefficients for all variables..................70

3. Associations between study variables and child age and gender...............................73

4. Model fit statistics for all models.................................................................. 74

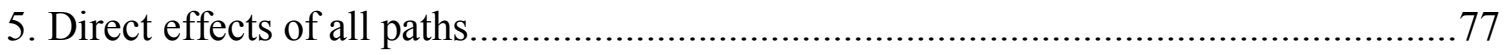




\section{INTRODUCTION}

Perfectionism, or a striving for high, strict standards regardless of their appropriateness and paired with self-criticism and/or distress, has been implicated as a risk factor for internalizing disorders throughout the lifespan (Egan, Wade, \& Shafran, 2011). In adults, perfectionism has been strongly linked with obsessive compulsive disorder (Antony, Purdon, Huta, \& Swinson, 1998; Sassaroli et al., 2008), major depressive disorder (Blatt, Quinlan, Pilkonis, \& Shea, 1995; Sassaroli et al., 2008), suicidality (Hamilton \& Schweitzer, 2000), social phobia (Heimberg, Juster, Hope, \& Mattia, 1995; Lundh \& Öst, 1996), and panic disorder (Antony et al., 1998). Systematic reviews of perfectionism and psychopathology (e.g., Egan et al., 2011; Harvey, Watkins, Mansell, \& Shafran, 2004; Shafran, Cooper, \& Fairburn, 2002) have suggested that perfectionism may be involved in the development and maintenance of internalizing disorders. That is, it may not only be a construct that occurs across disorders, but a construct that also acts in the etiology and maintenance of internalizing psychopathologies.

In order to provide support for the theory that perfectionism is a risk and maintenance factor for internalizing disorders, research has begun to examine perfectionism across development. Research focused on child perfectionism has increased over the past two decades and has shown the applicability of some adult research to children (see Affrunti \& Woodruff-Borden, 2014; Hewitt et al., 2002 for reviews). However, research with children remains relatively uncommon. Further, the 
impact of development on perfectionism remains unclear. Although the majority of this research has omitted developmental factors, it has become clear that perfectionism influences internalizing psychopathology in a reciprocal, dynamic fashion across development (Flett, Hewitt, Oliver, \& Macdonald, 2002). This notion fits well within the major tenets of the developmental psychopathology perspective (Cicchetti \& Cohen, 1995; Cicchetti \& Rogosch, 1996). Developmental psychopathology models espouse that (a) processes in a system interact in complex ways and change as a function of other variables in that system; (b) most forms of psychopathology are the result of multiple causal influences; (c) both successful and unsuccessful adaptation are important in understanding the origins of psychopathology; (d) psychopathology occurs within a developmental context of growth and change. These views emphasize multiple risk and protective processes that interact and evolve over time. Indeed, this is consistent with recent examinations of perfectionism (Herman, Wang, Trotter, Reinke, \& Ialongo, 2013). As such, incorporating a developmental psychopathology perspective allows for greater understanding of the development and maintenance of perfectionism in children and a more sophisticated process-based account of internalizing disorders.

The current study focused on child perfectionism in internalizing disorders from a developmental psychopathology perspective. The introduction will explore two aims: (1) a developmental conceptualization of child perfectionism and (2) the role child perfectionism can play in the development of internalizing disorders. Developmental literature will be the primary focus; however, because developmental research on perfectionism is limited, adult research will be integrated where necessary. First, common definitions and conceptualizations of perfectionism will be presented to operationalize the 
construct for this review. Then, the developmental context of perfectionism will be considered. Next, key risk and protective factors thought to influence the development of perfectionism will be reviewed. Then, parental variables which may play a role in the development and maintenance of perfectionism will be outlined. Subsequently, evidence linking perfectionism to child internalizing disorders will be reviewed. This includes evidence for the role of perfectionism in the development and maintenance of internalizing disorders, as well as its links with other implicated pathological processes, such as intolerance of uncertainty and perceived competence.

Based on this extant literature, a developmental psychopathology model for perfectionism was examined. The model serves both of the above aims, outlining the possible paths to child perfectionism and the effect of child perfectionism on internalizing disorders. The model is presented in Figure 1. As noted above, the model includes multiple domains of risk and protective factors for the development of perfectionism including temperament, parenting, and executive function. Within these domains, individual factors (e.g., negative affect temperament) are hypothesized to contribute to the development of perfectionism in the context of other factors (e.g., effortful control). Additionally, the developmental psychopathology model includes possible mechanisms through which perfectionism exerts its effects on internalizing disorders, including intolerance of uncertainty, self-competence, and "not just right experiences" (NJREs). In sum, the model provides a framework for exploring the roles of temperament, executive function, and parenting as predictors of perfectionism and various paths from perfectionism towards internalizing disorders. 


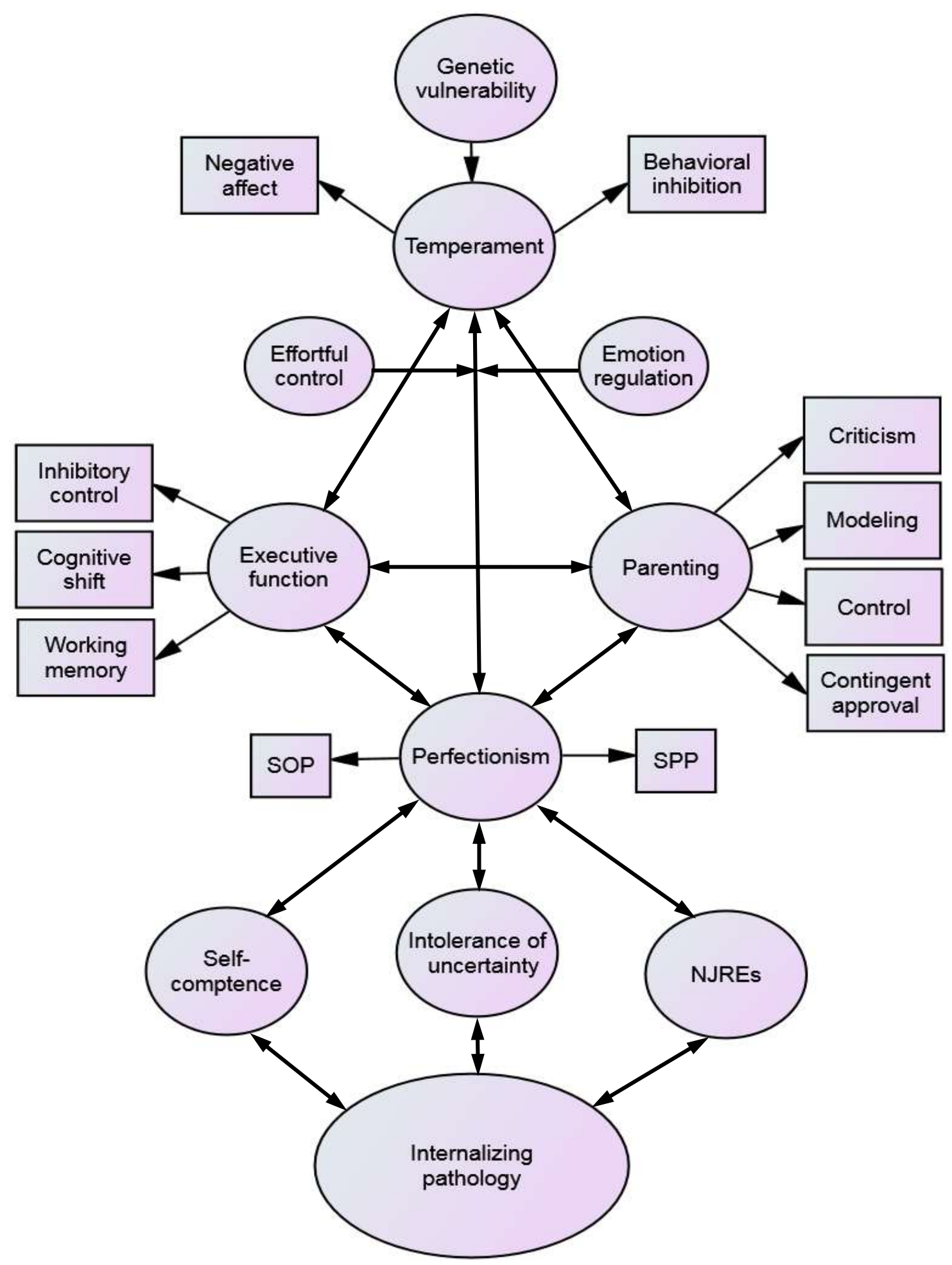

Figure 1. Proposed model of the developmental psychopathology of perfectionism in internalizing disorders. Note. Square processes represent variables that are subsumed by larger constructs. 
Though intricate, developmental psychopathology models do not espouse any singular path to the development of perfectionism, and subsequent internalizing pathology. The model of perfectionism is similar in complexity to developmental models of anxiety, worry, and depression (Garber, 2010; Kertz \& Woodruff-Borden, 2011; Vasey \& Dadds, 2001). In such models, tests of singular paths may represent important steps in confirming the larger model. The current study tested a portion of the larger developmental psychopathology model presented above. The following sections will provide evidence for the chosen variables and their hypothesized relations with perfectionism, as a part of the larger developmental psychopathology approach to perfectionism.

\section{Defining Perfectionism}

In order to best examine perfectionism in a developmental context an appropriate definition of perfectionism must be presented. Although early research is rife with various definitions of perfectionism (Beck, 1976), recent research suggests that perfectionism includes multiple related parts (Frost, Marten, Lahart, \& Rosenblate, 1990; Hewitt et al., 1991). The two primary approaches, which are not mutually exclusive, divide perfectionism into adaptive and maladaptive features and into multiple related dimensions. These approaches are essential in demonstrating that successful and unsuccessful adaptation is important for understanding the origin of dysfunctional perfectionism and subsequent pathology. This section reviews both approaches towards perfectionism and concludes with a working definition for the current study.

\section{Adaptive vs. Maladaptive Approaches}


There is growing empirical support for the distinction between adaptive and maladaptive perfectionism (Bieling, Israeli, \& Antony, 2004; Enns, Cox, Saren, \& Freeman, 2001; Herman, Trotter, Reinke, \& Ialongo, 2011). This split is also consistent with early hypotheses on the nature of perfectionism (Hamachek, 1978). Statistical procedures such as factor or cluster analysis have also revealed that perfectionism can be separated into adaptive and maladaptive types (Frost, Heimberg, Holt, Mattia, \& Neubauer, 1993; Rice, Ashby, \& Slaney, 1998; Rice \& Slaney, 2002). These studies have shown that adults elevated on the perfectionism dimension of positive striving do not show high levels of depression, anxiety, and stress. Similar results have been found for children. For example, in a sample of $4816^{\text {th }}$ grade children, positive striving was not associated with internalizing pathology (McCreary, Joiner, Schmidt, \& Ialongo, 2004). Conversely, evaluative concerns or self-criticism dimensions of perfectionism did show significant associations with stress, anxiety, and depression. That is, adaptive perfectionism, or appropriate and healthy striving for excellence, holds little clinical relevance. Maladaptive perfectionism threatens the ability to succeed and is not related to actual achievement (Stornelli, Flett, \& Hewitt, 2009). It is maladaptive perfectionism that has been linked to the development of internalizing disorders (Bieling et al., 2004; Herman et al., 2011).

Importantly, limitations exist in this literature. First, the operationalized definition of maladaptive perfectionism, even when using the same measure, may be different across studies (see Soenens et al., 2005; Turner \& Turner, 2011). This can obfuscate comparisons made across studies. Second, despite its importance, there is no universally accepted method of operationalizing the split between adaptive and maladaptive 
perfectionism. Indeed, many studies use continuous levels of perfectionism without denoting adaptive or maladaptive categories. Lastly, it has been argued that adaptive perfectionism reflects a separate process that lacks utility in a clinical context (Shafran et al., 2002).

Despite limitations, there is strong evidence that perfectionism encompasses both maladaptive and adaptive processes. As such, it follows that factors interacting and evolving over time determine whether perfectionism is functional or dysfunctional. Indeed, the study of maladaptive perfectionism will involve risk and vulnerability factors, while adaptive perfectionism will call attention to resilience and protective factors across development.

\section{The Dimensionality of Perfectionism}

In addition to the conceptualization of perfectionism into adaptive and maladaptive types, perfectionism has been defined as a multidimensional process. According to Flett, Coulter, Hewitt, and Nepon (2011), perfectionism is a multidimensional construct made up of the intra-individual and inter-individual components. These components are: self-oriented perfectionism (SOP), requirements imposed by the individual on him/herself to be perfect; socially prescribed perfectionism (SPP), requirements perceived by the individual that others require him/her to be perfect; and other-prescribed perfectionism (OPP), requirements imposed by the individual on others to be perfect (Hewitt \& Flett, 1991b). A separate multidimensional view of perfectionism further distinguishes these into specific content areas (Frost et al., 1990). That is, SOP consists of content about personal standards or doubts about one's actions, whereas SPP can consist of parental expectations or criticisms. Although unidimensional 
definitions exist (Shafran et al., 2002), much of the previous research on perfectionism has used a multidimensional approach.

Dimensions in multidimensional approaches often show relations to each other and to internalizing disorders in both children and adults (e.g., Blatt, Quinlan, Chevron, McDonald, \& Zuroff, 1982; Cox et al., 2000). Yet, different dimensions of perfectionism have shown different associations with disorders and symptoms (see Donaldson, Spirito, \& Farnett, 2000; Huggins, Davis, Rooney, \& Kane, 2008). For example, Huggins et al. (2008) found that SPP, but not SOP, was a significant predictor of depression diagnostic status in a sample of 786 children, ages 10 to 11 years. Separately, SPP was found to predict depression symptoms and SOP was found to predict anxiety symptoms over a 6month period in a sample of 737 children (O’Connor, Rasmussen, \& Hawton, 2010). As such, a multidimensional approach may better describe the various paths to dysfunction as a result of perfectionism. For example, in certain situations, high standards set by parents may precede the development of self-imposed standards (Affrunti \& WoodruffBorden, 2014). Or, those factors which are salient in the development of SPP, and subsequent depression, may be different than those in the development of SOP and anxiety. Unidimensional models of perfectionism may miss such nuanced effects in the development of perfectionism. In other words, multidimensional approaches better account for the various effects of salient factors (e.g., parenting or temperament) on perfectionism and subsequent internalizing disorders.

Previous research on perfectionism has indicated that it is a complex process encompassing multiple dimensions and both adaptive and maladaptive aspects. Although much of this research has been with adults, rather than children, a growing body of child 
literature suggests similar definitions may be appropriate. However, there is a need to better account for developmental effects within this definition. For the purposes of this study, perfectionism will be defined as the setting of rigidly high standards that are adhered to regardless of appropriateness or ability to achieve them and are paired with criticism and/or distress. It is a multidimensional construct that encompasses both SOP, or the setting of high personal standards and valuing only successful attainment of goals, and SPP, or the expectations and criticisms of others (i.e., parents). These are the two most salient dimensions for children (Flett \& Hewitt, 1990). Furthermore, the overarching process of perfectionism exists on a continuum from functional to dysfunctional. That is, striving to achieve highly is, by itself, not maladaptive. However, as standards become more rigid and paired with more criticism and/or distress, perfectionism becomes less functional (McCreary et al., 2004). The interaction of perfectionism with other contextual factors determines whether the process is adaptive or maladaptive. The result is a cognitive-affective process that plays an etiological and maintaining role in internalizing disorders across development (see Fig. 1). This definition is consistent with previous research using children (Huggins et al., 2008; Stornelli et al., 2009). It incorporates both cognitive and affective factors that are integral to perfectionism (Flett et al., 2002) and allows for the importance of development in these areas to be explored. That is, cognitive and affective development is theorized to be essential to the development of perfectionism.

For ease of understanding, perfectionism will refer to the broader process incorporating both SPP and SOP, while dimensions will be specified when appropriate. 
Previous research using both unidimensional and multidimensional approaches will be reviewed in order to provide a comprehensive background of the concept.

\section{Development of Perfectionism: Cognitive-Affective Development}

The development of perfectionism happens within the greater context of the

developing individual. Cognitive and affective development is a crucial part of how perfectionism develops in children (Evans et al., 1997; Flett et al., 2002). Importantly, cognitive and affective development is interrelated (Steinberg, 2005). A complete review of research on cognitive and affective development in children is outside the scope of this paper. However, this section will focus on research that serves to inform the development of perfectionism within the larger developing individual. That is, what cognitive and affective requirements are necessary for perfectionism to develop and does perfectionism have different manifestations based on development? For example, there are accounts of rigidity and repetition in typically developing children 2 to 3 years old (Leekam et al., 2007). Further, perfectionistic rituals, as measured by the childhood routines inventory, peaked at 24 to 47 months with lower levels shown from 48 to 72 months in a sample of 150 children (Evans et al., 1997). These findings seem to suggest that perfectionism may decrease throughout early childhood. However, understanding the findings in the context of the child's normal development is vital to appreciating the development of perfectionism. That is, in order for the development of perfectionism to be understood, it must be examined relative to normal cognitive and affective development.

\section{Cognitive Development}

Cognitive processes have long been hypothesized to influence perfectionism (Hamachek, 1978). Perfectionism is conceptualized as a partly cognitive process that 
requires a child to know, set, and hold standards in his/her mind. Further, children must understand when they have and have not met those standards or must project the negative consequences of future errors. For the SPP domain, a child must be aware that others are setting standards for him/her. In maintaining perfectionism, a child may selectively attend to what is wrong, rather than what is right. These processes require an ability to retain information in one's mind, compare that information, selectively attend to stimuli, and extrapolate into the future.

The ability to retain information in one's mind is directly linked to working memory (Baddeley \& Hitch, 1994; Smith \& Jonides, 1999). Working memory is a foundational executive function and refers to the ability to maintain and manipulate information in one's mind. Working memory develops early in infancy (Diamond, 2013; Diamond, 1995) and can be updated systematically with new information in infants as young as 9 months (Bell, 2012; Diamond, 1985). However, the ability to perform mental operations begins to develop later and progresses at a slower pace (Cowan, Saults, \& Elliott, 2002; Luciana, Conklin, Hooper, \& Yarger, 2005). One such manipulation needed for the development of perfectionism is a comparison. This comparison may be between the right and wrong answers on a test or expected and unexpected outcomes. Regardless of the specific comparison made, in order to make a comparison the child must hold both sets of information in his/her mind. This has been displayed in children as young as 3.5 years, but increases linearly through adolescence (Best \& Miller, 2010). As such, as children develop they may become better at retaining standards and comparing them to the current state, a vital part of perfectionism. 
In order to retain information, the child must attend to that information. Although this ability is influenced by working memory, it also requires inhibitory control. Inhibitory control refers to the ability to control one's attention, behavior, and thoughts and relates strongly to idea of effortful control detailed later (Miyake et al., 2000). Both inhibitory control and working memory influence the development of the other over time (Fry \& Hale, 2000; Garon, Bryson, \& Smith, 2008). Inhibition develops rapidly in early childhood across a variety of tasks (Hughes, 1998; Lehto \& Uusitalo, 2006; Sabbagh, Xu, Carlson, Moses, \& Lee, 2006). However, children show differential competence in inhibition tasks even at the same age. For example, 3 to 4 year olds have a difficult time with tasks requiring the inhibition and activation of verbal responses (Diamond \& Taylor, 1996). Yet, in a card sorting task children show marked improvement around years 3 to 4 , whereas younger children are poor at adapting to new rules (Carlson, 2005; Zelazo, Frye, \& Rapus, 1996). This suggests that inhibitory skills are not acquired all at the same time. Indeed, inhibitory control continues to show development into middle adolescence (Brocki \& Bohlin, 2004).

Cognitive flexibility, or the ability to switch cognitive sets, also may be implicated in perfectionism. Being able to flexibly switch cognitive sets may act as a protective factor against the development of maladaptive perfectionism. However, cognitive flexibility comes later in development because, it builds upon other cognitive components (Davidson, Amso, Anderson, \& Diamond, 2006; Garon, Bryson, \& Smith, 2008). Children show this ability as early as 3 or 4 (Rennie, Bull, \& Diamond, 2004) but do not reach more advanced levels until 15 years of age (Huizinga, Dolan, \& van der Molen, 2006). Similarly, data suggest that 3-and 4-year-olds are able to learn and 
integrate rules of when to switch sets based on environmental feedback (Hughes, 1998a; 1998b). This suggests that perseveration may represent a failure to develop normative skills of cognitive flexibility. Little is known, however, about the developmental course of cognitive flexibility (Garon et al., 2008). Delayed acquisition of this ability may be an important risk factor in the development of perfectionism. That is, children who develop this ability later than 3 or 4 years may have difficulty appropriately using cognitive flexibility to switch from early normal routine and rigidity, leading to dysfunctional rigidity.

Perfectionistic children who feel anxious or depressed at the prospect of making errors need an awareness of their reaction to future events. According to Povinelli and colleagues (1996), children are unable to integrate a future self until age 4 . That is, children may not be able to understand the negative outcome associated with errors until this period of development. This ability increases as the child ages (Wallace \& Rabin, 1960). Further, children as young as 4 years are able to make connections between the past and future (Lagattuta, 2007), suggesting that they have the capacity to understand the negative consequences of past failures. Reasoning about causal relationships also appears to be present in children as young as 3 years (Flavell, Green, \& Flavell, 2004; Harris, German, \& Mills, 1996). This may allow children to become aware of negative consequences of mistakes and errors, and to internalize high, rigid standards.

In sum, it is likely that 3 - to 4-year-old children have the cognitive abilities to engage in perfectionism, separate from normal routine. Prior to this, children may often engage in normal ritual and rigidity, which explains well the findings of Evans and colleagues (1997) described above. That is, children from ages 2 to 4 tend to engage in 
high amounts of ritualistic behaviors, which have been theorized to serve as a child's attempts to gain self-control and regulate his/her emotional states (Kopp, 1989). Further, these early routines may serve adaptive functions to increase affiliation and attachment with caregivers (Albert, Amgott, Krakow, \& Howard, 1979; Leckman, Mayes, \& Insel, 1996). Children from 3 to 4 years develop the ability to hold and manipulate information,

allowing them to gain more control over the demands of their environment (Kopp, 1989). However, development of this ability also allows a child to set and compare high, rigid standards to the current state, a necessary precursor to perfectionism. Similarly, children ages 3 to 4 years are able to attend to selective information in their environment and exert control over their attention, allowing them continued focus on their goal (Posner \& DiGirolamo, 1998). Stimuli not relevant to this goal can then be denied. As noted above, cognitive development is necessary, though not sufficient to develop perfectionism. Further, these abilities impact the development of each another, suggesting that no single ability is sufficient. For example, cognitive flexibility requires inhibitory control (Davidson et al., 2006). For most children, as they age, their abilities in these areas advance and ritualistic or rigid behaviors typically decrease (Evans et al., 1997). For other children, as they develop cognitively, these abilities may be used to develop more complex rules, standards, and adhere more strictly to routine and rituals. As such, they are at risk of developing perfectionism beyond normal routine.

\section{Affective Development}

Similar to the research on cognitive development, there exists an extensive literature on affective development. As perfectionism includes an affective aspect (Hollender, 1965; Pacht, 1984), understanding emotional development is key in 
understanding the development of perfectionism. Perfectionism also includes an emotional component as it requires a child to experience some level of distress. This distress may present as frustration, anger, embarrassment, sadness, or anxiety. In order for this to occur the child must experience the distress and fail to effectively regulate his/her emotions.

Basic emotions such as fear, disgust, joy, and anger, are present in infants as young as 6 months old (Izard, 2007; Lewis, 2008; Saarni et al., 1998). As such, children at this age are able to experience the distress associated with perfectionism. By age 3 years, children are able to experience embarrassment, guilt, and shame (Lewis, 2008), which may all be associated emotions experienced by perfectionists (Beck, 1976). Embarrassment may be especially relevant to the SPP domain of perfectionism. Children often fear embarrassment as a negative outcome when standards set by others are not met (Tangney, 2002). Similarly, shame is often the result of failure to achieve self-made standards and is perhaps more relevant to the SOP domain of perfectionism. Although the ability to experience distress occurs at a young age, the regulation of these emotions shows far greater variability across development.

Although emotion regulation has been defined in various ways, the focus has often been on internal and external processes that serve to modulate one or more components of emotion by modifying the experience, intensity, and expression of emotions (Diamond \& Aspinwall, 2003; Eisenberg, Fabes, Guthrie, \& Reiser, 2000; Gross, 1999). Emotion regulation as a developmental process has been written about at length (see Diamond \& Aspinwall, 2003; Eisneberg \& Fabes, 1992; Fox, 1994; Fox \& Calkins, 2003 for reviews). Early in development, children use actions and interventions 
of others to regulate their emotions (Morris, Silk, Steinberg, Myers, \& Robinson, 2007; Thompson, 1994). However, research also suggests that emotion regulation, particularly the ability to regulate negative emotions, develops early over the first years of life (Eisenberg et al., 1996). The ability to use focused attention to decrease distress develops by 6 months (Rothbart, 1986). Regulating self-soothing motor responses, such as thumbsucking or reaching for a caregiver, appears to occur during the second and third years of life (Diamond, 1991). As children become more sophisticated in their emotional skills, they gradually become more independent in regulating and managing their own emotions (Eisenberg \& Morris, 2002; Kopp, 1989). Emotion regulation, specifically arousal modulation, continues to develop throughout preschool years (Fox \& Calkins, 2003). By 4.5 years, children who are successful at regulating their emotional experience towards emotionally challenging tasks show less negative emotionality and fewer behavior problems (Calkins \& Keane, 2004). Those children unable to regulate their emotional experience showed more behavior problems and negative emotionality. Negative emotionality and behavior difficulties during tasks may influence the development of perfectionism. That is, children who are unable to regulate their emotional experience may be at risk of developing perfectionism as a way to cope with negative affect experienced during challenging tasks. Those children who develop successful emotion regulation abilities may be protected from dysfunction associated with perfectionism.

Affective development begins early in life with the development of simple emotions such as fear or disgust. However, by age 3 to 4 years, children begin to develop more complex emotions such as embarrassment or guilt. Both simple and complex emotions are experienced by perfectionists (Besharat \& Shahidi, 2010; Tangney, 2002). 
Yet at a similar age, 3 to 4 years, emotion regulation abilities begin to develop. These abilities may guard against maladaptive perfectionism, while delayed or deficient development of emotion regulation may be a risk factor for maladaptive perfectionism. That is, in order for maladaptive perfectionism to develop children must experience negative emotion and fail to regulate it. The development of emotion and emotion regulation may also be involved in domains of perfectionism. For example, the development of embarrassment without associated regulation skills may lead to maladaptive perfectionism, particularly the SPP domain.

Importantly, cognitive and affective development are interrelated (Eisenberg \& Morris, 2002; Fox \& Calkins, 2003). However, early in life and throughout childhood and adolescence individuals develop cognitive and affective abilities (e.g., inhibitory control, emotion regulation) that are necessary, though not sufficient, for the development of perfectionism. That is, certain cognitive and affective developmental trajectories may influence the development of, or protection from, perfectionism. Normal routine and rigidity is common in children below age 4 (Evans et al., 1997) prior to the development of many of these abilities. After approximately 4 years of age, children may have skills that protect them from harmful effects of perfectionism. Children with delayed or deficient development of cognitive flexibility or emotion regulation may be at greater risk of such harmful effects. Further, different patterns, deficits, and trajectories of development after 4 years of age may lead to separate outcomes. Yet, more research is needed on how the development of perfectionism occurs within the developing individual.

\section{Development of Perfectionism: Risk Factors}


The development of perfectionism is impacted by a number of risk factors. Specifically implicated in this process are genetic vulnerabilities, temperament, and executive function deficits. Yet, these factors do not develop in isolation and they interact in complex ways across development (Morasch \& Bell, 2011). This results in numerous pathways leading to the development of perfectionism. Importantly, these factors vary in the extent to which they have been studied in the context of perfectionism. Some have shown strong relations to perfectionism in adolescents or adults, but lack support in children. Others have limited or no empirical support. In this case, hypothetical effects will be reviewed with a consideration towards why these factors may put children at risk of developing perfectionism.

\section{Genetic Vulnerability}

There is preliminary evidence that genetic factors may influence the development of perfectionism (Bachner-Melman et al., 2007; Tozzi et al., 2004). In a study of 1022 twins (no ages were provided) from the Mid-Atlantic Twin Registry, Tozzi and colleagues (2004) found that shared genetic factors significantly related to domains of perfectionism. Specific domains were: personal standards, doubts about actions, and concern over mistakes. The authors state that perfectionism may be moderately heritable with different domains of perfectionism showing varying amounts of heritability. For example, the personal standards domain of perfectionism, which is closely related to SOP, showed the highest heritability factor. No information is presented on SPP domains of perfectionism. A study by Bachner-Melman et al. (2007) evaluated genes that confer risk for anorexia nervosa and their relation to perfectionism across 202 anorexia nervosa 
and 408 control families. They found that genes previously identified as related to disordered eating were also related to perfectionism scores.

Despite the preliminary evidence of a genetic influence of perfectionism, these studies are limited in their conclusions. First, Bachner-Melman et al. (2007) found genes associated with eating disorders to also be associated with perfectionism, but cannot conclude to what extent the genes represent the disordered eating, perfectionism, or both. Indeed, high rates of heritability of eating disorders likely confound this finding (Thornton, Mazzeo, \& Bulik, 2011). Environmental factors may also be underlying apparent genetic relations. Indeed, Tozzi et al. (2004) found that non-shared and shared environmental factors were stronger predictors of different domains of perfectionism than genetic factors. Furthermore, epigenetic phenomena (see Feil, 2006 for a review) are not accounted for in either of these studies. It seems likely that the genetic influence found in these studies represents the transmission of broad risk factors, rather than the specific transmission of perfectionism. This broad genetic factor may manifest itself in children as specific temperamental characteristics (Ormel et al., 2005). Indeed, previous research has provided strong evidence that genetics influence temperament. For example, genetics are estimated to account for between $20 \%$ and $60 \%$ of the heritability of temperament (Cyphers, Phillips, Fulker, \& Mrazek, 1990; Stevenson \& Fielding, 1985; Saudino, McGuire, Reiss, Hetherington, \& Plomin, 1995).

\section{Temperament}

The development of perfectionism is likely influenced by temperament. Temperament is a multi-level construct including genetic, psychological, physiological, neural, and behavioral components that react to and regulate experience (Derryberry \& 
Rothbart, 1997; Nigg, 2006; Rothbart, 2011). Though partially stable, it is plastic to maturation and experience (Rimm-Kaufman \& Kagan, 2005). This is important as temperament may provide an early developmental point of reference for future outcomes. For example, inhibited toddlers are unlikely to become gregarious children. Although a complete review of temperamental models in development is beyond the scope of this introduction, temperamental dimensions that may play a role in the development of perfectionism are addressed. These models include behavioral inhibition and negative affectivity or reactivity. Importantly, though self-regulation aspects such as effortful control are temperamental constructs, they will be discussed later as hypothesized protective factors.

Behavioral inhibition (BI). BI is a temperamental dimension characterized by uncertainty, withdrawal, fear, and distress in the presence of novel or unfamiliar situations (Kagan, 1997). Theoretically, BI influences maladaptive perfectionism through increased perceptions of threat in novel situations. The individual responds to this increased threat with high, rigid standards in order to cope with perceived distress. Preliminary evidence has provided support for this theory. In separate studies of undergraduates, perfectionism was shown to be related to behavioral inhibition (Chang et al., 2007; Kobori, Yamagata, \& Kijima, 2005; Turner \& Turner, 2011). However, associations with SOP and SPP dimensions were absent. O'Connor and Forgan (2007) found that both SOP and SPP were moderately correlated with BI in a sample of 255 undergraduates. Similar findings were reported by Randles, Flett, Nash, McGregor, and Hewitt (2010). However, these studies are all limited by their use of undergraduate 
samples. Further, no information as to whether BI moderates, mediates, predicts, or is developed in concert with perfectionism is provided.

Interestingly, O'Connor and Forgan (2007) also reported a significant, though small, correlation between behavioral approach and SOP. Approach systems, which act opposite to inhibition and withdrawal, may lead to adaptive perfectionism. Indeed, some research suggests that perfectionism is associated with approach systems in community samples (Kaye, Conroy, \& Fifer, 2008). Approach systems may allow perfectionists to engage with tasks that are new and challenging in an effort to achieve highly without the need to cope with distress. BI may also interact with other temperamental risk factors, increasing the likelihood of maladaptive perfectionism. One such temperamental dimension is negative affect.

Negative affectivity (NA). Although NA is closely linked to BI (Gable, Reis, \& Elliot, 2000), it is a separate temperamental domain. NA is characterized by anger, fear, discomfort, and reactivity towards distress with an associated difficulty in being soothed (Gartstein \& Rothbart, 2003). High, rigid standards may be developed by individuals with NA as a way to cope with intense distress expected during a future situation. As long as standards are met, the child may not experience distress. NA may further impact perfectionism by creating increased distress and an inability to alleviate distress in the presence of unmet standards. Indeed, NA is commonly observed in individuals who are perfectionistic (Downey \& Chang, 2007; Flett, Molnar, Nepon, \& Hewitt, 2012).

DiBartolo and Varner (2012) examined NA in sample of 157 children with a mean age of approximately 10 years. Children with elevated levels of SPP, regardless of their performance on a task or the standard set (experimenter set standard, self-set standard) 
for the task, had higher levels of NA. SPP may be especially impacted by levels of NA. Children with higher levels of NA may feel that standards set unattainably high by social or parental forces are cause for distress. This distress is not soothed even when performance is high. Indeed, in a sample of 309 children ages 7 to 12 years, maladaptive perfectionism was correlated with emotional reactivity in low, standard, and high achievers (Bouffard, Roy, \& Vezeau, 2005). No information was provided on domains of perfectionism. However, the results suggest that NA may relate strongly to maladaptive levels of perfectionism rather than more adaptive levels. This would be consistent with theory proposed by Bouffard et al. (2005); children who are more reactive and unable to cope effectively with their distress may be more likely to experience negative outcomes as a result of their perfectionism (Boisseau, Thompson-Brenner, Pratt, Farchione, \& Barlow, 2013; Rhéaume et al., 2000).

Together, the literature suggests that children who exhibit BI, NA, or characteristics of both may be at increased likelihood of developing maladaptive perfectionism (Bouffard et al., 2005; O’Connor \& Forgan, 2007). Further, BI and NA may show different links with different dimensions of perfectionism, though research is not yet conclusive in this area. Lastly, temperament is plastic to other key variables in the developmental context (Rothbart, Sheese, \& Posner, 2007). The above research has examined perfectionism and temperament in isolation of other processes. Key developmental variables should not be ignored, as they likely exert influence on the developmental trajectory of individuals with BI and NA.

\section{Executive Function}


Executive function refers to a family of processes that are needed to concentrate, think, and control one's behaviors (Diamond, 2012). Although executive functioning has an effect on temperament (Degnan \& Fox, 2007; Kochanska \& Knaack, 2003), it likely also has a direct effect on perfectionism. There are three such core systems: inhibitory control, working memory, and cognitive flexibility. These are separate but interrelated processes (Miyake et al., 2000).

Executive function difficulties likely put a child at risk of developing maladaptive perfectionism (Affrunti \& Woodruff-Borden, 2014). Given a specific task, a child who has an inability to inhibit his/her thoughts and is unable to switch cognitive sets, may ruminate on certain standards or rules. A greater working memory capacity may allow standards, rules, and expected outcomes to exist simultaneously in mind, without impairing the child's performance, leading to more adaptive perfectionism. Those children with lower working memory may experience performance deficits as a result. Therefore, it may be expected that a child who has low inhibitory control, low working memory ability, and cognitive flexibility deficits, in the presence of other risk factors such as temperament, may have an increased risk of maladaptive perfectionism. Executive function deficits may affect the SOP and SPP domains similarly.

Despite this, few studies have investigated executive functioning difficulties in perfectionism. In a small sample of 34 adults, deficits in set shifting were significantly correlated with retrospective reports of perfectionism in children (Tchanturia et al., 2004). In a study of undergraduates, individuals with higher perfectionism, rated as part of obsessive-compulsive personality traits, had increased deficits in working memory and inhibitory control (Aycicegi-Dinn, Dinn, \& Caldwell-Harris, 2009). Yet, methodology, 
such as the use of cross-sectional and retrospective data, limits conclusions about directionality and development. No results on domains of perfectionism are provided. In samples of individuals with anxiety disorders, obsessive-compulsive disorder (OCD), obsessive-compulsive personality disorder, and eating disorders (i.e., clinical disorders associated with perfectionism), executive functioning deficits have been observed (Brand \& Altstötter-Gleich, 2008; Greisberg \& McKay, 2003; Lauer, 2002; Nigg, 2006; Slade, Coppel, \& Townes, 2009). Results of these studies suggest that individuals diagnosed with these disorders have difficulty inhibiting responses, retaining information in working memory, and shifting cognitive sets. Deficits in executive functioning domains may place a child at risk of developing perfectionism by impeding their ability to flexibly apply rules and increasing perseveration on standards. For example, a child with difficulty inhibiting responses may apply strict, rigid standards regardless of whether doing so is appropriate for the situation. Deficits in shifting cognitive sets may cause the child to perseverate on these standards and not responsively adapt to the environmental demands. Although previous studies are consistent with this theory, they are all limited and inconclusive. For example, studies such as Lauer (2002) and Slade et al (2009) present results pertaining to clinical disorders associated with perfectionism, but not perfectionism itself, limiting conclusions regarding it. However, executive function deficits may explain help explain findings that maladaptive perfectionism is associated with impaired decision making (Boisseau et al., 2013).

Risk factors such as executive function, temperament, and genetic vulnerabilities do not exist in isolation and are affected by multiple processes across development. For example, research has repeatedly shown that high levels of negative affect are related to 
deficits in executive function in children (Healey, Marks, \& Halperin, 2011; Ursache, Blair, Stifter, Voegtline, \& The Family Life Project Investigators, 2013). Further, increased negative affect and executive function deficits have shown to increase internalizing symptoms in children (Anthony, Lonigan, Hooe, \& Phillips, 2002; Eisenberg et al., 2001). Yet, perfectionism may be one mechanism through which risk factors such as negative affect and executive function exert their effects on internalizing disorders. That is, risk factors may contribute to the development of perfectionism, which contributes to the development of internalizing disorders. Although research is not yet advanced enough to examine effect sizes for these processes, genetic vulnerabilities, temperament, and executive function deficits are all salient risk factors for the development of perfectionism.

\section{Development of Perfectionism: Parental Risk Factors}

Parental factors are also thought to be involved in the etiology and maintenance of perfectionism. Indeed, original theories on perfectionism postulated that perfectionism grew out of a need to gain approval from critical, rigid, or controlling parents (Hamachek, 1978; Missildine, 1963). However, the association between parental factors in the development and maintenance of perfectionism is far more nuanced. There are multiple reasons for this. First, there exists a complex dynamic between parenting and multiple key developmental factors. For example, parental behaviors have been found to predict executive function abilities longitudinally (Bernier, Carlson, \& Whipple, 2010). Similarly, studies have shown that parental variables predict for temperament and emotion regulation as well (see Lengua, Honorado, \& Bush, 2007; Melnick \& Hinshaw, 2000; Stright, Gallagher, \& Kelley, 2008; Zeman, Penza, Shipman, \& Young, 1997 for 
examples). Second, parent and child behaviors are likely transactional, each influencing the other over time (Pardini, 2008). Lastly, multiple parental factors may lead to the development of similar outcomes (e.g., Wood, McLeod, Sigman, Hwang, \& Chu, 2003).

In order to account for multiple paths of development, models outlining the impact of different parenting factors on the development of perfectionism have been postulated (Flett et al., 2002). Four specific models are summarized below. Empirical evidence for these models is limited, which restricts conclusions drawn about directionality and strengths of relations observed. Further, little evidence exists for which dimensions of perfectionism, SPP and SOP, are impacted by parenting behaviors. Hypothetically, different parenting behaviors may exert stronger effects on different domains of perfectionism, which when combined with other risk factors, results in maladaptive perfectionism.

\section{Social Expectations Model}

The social expectations model posits that perfectionism grows out of contingent parental approval and meeting parental expectations (Flett et al., 2002). That is, children are only reinforced when they meet high standards set by their parents, learning that they must be perfect to obtain parental affection. Behaviorally, parents may use controlling or rejection behaviors to convey stringent goals for their child. In a longitudinal study of 381 adolescents 15 to 19 years, perceived parental expectations predicted for increases in SPP but not SOP over 7 to 9 months (Damian, Stoeber, Negru, \& Băban, 2013). SPP is likely directly impacted by parental expectations, as they create the perception that others demand perfection. However, it may also have an indirect effect on SOP. 
Theoretically, contingent approval by parents may lead a child to develop perfectionism through the feedback the parents provide. Research has shown that feedback focusing on personal characteristics (e.g., intelligence), rather than the achievement process, can foster contingent self-worth (Kamins \& Dweck, 1999; Mueller \& Dweck, 1998). When positive feedback about personal characteristics is no longer presented by the parent, the child may be at risk of developing adjustment problems. Indeed, this may be one pathway by which adaptive perfectionism becomes maladaptive. This is supported by findings that individuals high in SOP are prone to depressive episodes in the presence of achievement failure (Hewitt, Flett, \& Ediger, 1996). Further, contingent self-worth and helplessness have been shown to commonly occur in children who are perfectionistic (Hewitt \& Flett, 1991a; Hewitt et al., 1997). In sum, the presence of high parental expectations may increase child levels of SPP, leading to the development of contingent self-worth and higher levels of SOP. However, contingent approval is not the only parental behavior involved in perfectionism.

\section{Social Learning Model}

The social learning model of perfectionism development focuses on imitation and modeling of perfectionistic parents (Flett et al., 2002). Early social learning experiments performed by Bandura, Grusec, and Menlove (1967) found that children who had adult models with unrealistic standards and who did not readily provide reinforcement developed the most stringent style of self-reward. This may indicate that children aim to imitate the perfectionistic behaviors of their parents. More recent research has consistently shown there are small to moderate correlations between child and parent levels of perfectionism (Chang, 2000; Cook \& Kearney, 2009, 2014; Vieth \& Trull, 
1999). Further, research found that a child's own level of perfectionism correlated most strongly with the child's perceived level of parental perfectionism (Flett et al., 2002).

Despite empirical support for the concordance between parental and child perfectionism levels, it is has not been tested whether modeling and imitation are the mechanisms by which this concordance occurs. Genetic factors may represent one alternative explanation. Hypothetically, modeling and imitation may serve to increase SOP without increases in SPP. That is, parents who model perfectionism may not necessarily hold high expectations for their children. This would provide one explanation for why levels of SOP and SPP are not consistently highly correlated (Flett \& Hewitt, 1990).

\section{Social Reaction Model}

The social reaction model of perfectionism suggests that children who develop perfectionism are exposed to particularly harsh environments (e.g., exposure to physical or psychological abuse, rejection, or a chaotic family environment). Behaviorally, parents may be overly punitive, critical, and hostile towards their children. Children develop perfectionism as a reaction to this environment in order to minimize further abuse, reduce shame or humiliation, or establish a sense of control and predictability in an unpredictable situation. Indeed, there is research that suggests people develop perfectionistic tendencies as an attempt to cope with hostile environments (Kinzl, Traweger, Guenther, \& Biebl, 1994; Tobin \& Griffing, 1996). Though perfectionism may appear as a coping mechanism in a harsh environment, it may be a maladaptive. Studies show that maternal harshness and criticism are associated with levels of maladaptive perfectionism in children (Clark \& Coker, 2009; Frost, Lahart, \& Rosenblate, 1991). This 
may be due to harshness and criticism that is persistent even when children achieve high standards. Further, harsh and critical parenting may exert effects on both SOP and SPP. Inflexible standards developed in such an environment would likely require a child to impose high standards on themselves, while also feeling as if the environment necessitates those high standards in order to escape abuse.

\section{Anxious Rearing Model}

The final model of perfectionism development, the anxious rearing model, posits that parental worry about being imperfect may cause parents to promote a focus on the negative consequences of making mistakes. Parents may use controlling behaviors to promote vigilance for possible mistakes that pose a threat for the child (Flett et al., 2002). Rigid standards are developed by the child as a result of consistent reminders from the parent that failure, mistakes, and negative judgments are threats with which the child cannot cope.

Research has begun to provide support for the anxious rearing model. Soenens and colleagues (2005) found, in a sample of 155 female undergraduates, that parent maladaptive perfectionism was significantly related to the use of psychological control. Further, psychological control completely mediated the relation between parent and child maladaptive perfectionism. Similar results were reported in a separate study of undergraduates (Turner \& Tuner, 2011). Further, increased use of parental control has been separately shown to be associated with increased parental and child perfectionism, using child samples (Affrunti \& Woodruff-Borden, 2015; Kenney-Benson \& Pomerantz, 2005). This is consistent with research examining the role of parental control in pediatric anxiety disorders (Chorpita \& Barlow, 1998; Ginsburg, Siqueland, Masia-Warner, \& 
Hedtke, 2004). Most convincingly, however, is an experimental manipulation of perfectionistic parenting behaviors. Perfectionistic parenting behaviors, consistent with the anxious rearing model, are those that focus on mistakes, the negative consequences of mistakes, and overprotection from mistakes through verbal and non-verbal behaviors. Children, 7 to 12 years, exposed to the perfectionistic parenting condition displayed increases in SOP, regardless of anxiety level (Mitchell, Broeren, Newall, \& Hudson, 2013).

According to the anxious rearing model, perfectionistic parenting behaviors communicate that failure and mistakes result in negative consequences. Though Mitchell et al. (2013) did not use a measure of SPP, it is likely that anxious rearing behaviors affect both levels of SOP and SPP. These behaviors may convey to the child that his/her parents require high standards or the child will be judged negatively. Furthermore, the child may develop high standards in order to minimize perceived threats associated with failure and mistakes.

Taken together, empirical evidence suggests that parental behaviors likely play a role in the development and maintenance of both SOP and SPP (Flett et al., 2002; Maloney, Egan, Kane, \& Rees, 2014). They may also contribute to the development of maladaptive perfectionism from adaptive perfectionism. Research has most often implicated parental control (Kenney-Benson \& Pomerantz, 2005; Mitchell et al., 2013; Turner \& Turner, 2011), though there is evidence that parental criticism, modeling, and communication style may be other mechanisms relevant in the development of perfectionism (Affrunti, Geronimi, \& Woodruff-Borden, 2014; Biran \& Reese, 2007; Miller-Day \& Marks, 2006). 
Yet, the above models show that the association between parental behaviors and dimensions of perfectionism is highly complex. Parenting behaviors may exert effects on different dimensions of perfectionism at different time points, in different settings, and at different intensities. For example, it is plausible that parents who set high expectations for their child also may be overly critical at times. Or a parent may be controlling early in a child's life but grant more autonomy to the child as he/she ages. The dynamic process of parenting is not well captured by current research. As noted earlier, parent-child interactions are likely reciprocal. As such, perfectionistic children may elicit certain behaviors from parents in order to decrease distress associated with mistakes and failure. Further, little is known about the relative strength of these associations in larger models of perfectionism development.

\section{Development of Perfectionism: Protective Factors}

As noted earlier, understanding both the successful and unsuccessful adaptation of a process is vital in a developmental psychopathology perspective. As it pertains to perfectionism, risk factors contribute to the development of maladaptive aspects, while protective factors may lower the risk that a child develops dysfunction. That is, protective factors may allow a child to develop a more adaptive form of perfectionism or shield a child from the dysfunction associated with maladaptive perfectionism. Similar to research on risk factors, studies for protective processes in perfectionism are limited. However, research on resilience in children has identified self-regulatory processes as foundational in the protection from dysfunction (see Masten \& Coatsworth, 1998 for a review). Two such processes, effortful control and emotion regulation, are hypothesized as protective factors in the development of perfectionism. 


\section{Effortful Control}

Effortful control is the ability to suppress a dominant response in order to perform a subdominant response. It often is conceptualized as a temperament factor and refers to the focusing and shifting of attention and inhibiting behavior when appropriate (Rothbart, Ellis, \& Posner, 2004). That is, it is a combination of attentional and inhibitory control that acts to regulate experience and overlaps with executive function, temperament, and self-regulation (Kochanska, Murray, \& Harlan, 2000). Effortful control emerges early in infancy, between 6 to 12 months, in tandem with attentional mechanisms (Rothbart, Derryberry, \& Posner, 1994). By approximately 4 years of age, effortful control is stable (Kochanska \& Knaack, 2003). Effortful control may protect children from developing maladaptive perfectionism by allowing them to regulate their behavior, inhibit an emotional response, and shift their attention away from the unmet standards.

Only a single study has looked at effortful control and perfectionism. In a sample of 229 undergraduates SPP was negatively associated with effortful control and SOP was not significantly associated with effortful control (Tangney, Baumeister, \& Boone, 2004). The results are partially consistent with the hypothesized relation between perfectionism and effortful control. That is, individuals who have high levels of effortful control may be able to manage the standards set by those around them without difficulty. It may those with low effortful control that experience distress by the high, rigid standards of parents, partners, teachers and other social figures. The lack of a significant association between SOP and effortful control may due to adaptive perfectionism. That is, SOP can involve positive goal striving and self-criticism factors that may have skewed results (McCreary et al., 2004). Indeed, it would be expected that effortful control would be positively 
associated with positive goal striving but negatively associated with self-criticism factors. Future studies should examine this possibility. Importantly, the sample consisted of undergraduates and different relations may be observed in children. Further, no claims towards directionality can be made. Effortful control may also interact with other temperamental factors to create distress (Lonigan \& Vasey, 2009). It remains plausible that successful development of effortful control abilities protect children from the development of maladaptive perfectionism.

\section{Emotion Regulation}

As noted earlier, emotion regulation is likely an important construct in the development of perfectionism. Theoretically, emotion regulation may moderate the experience and expression of distress associated with perfectionism and failed expectations. Indeed, Flett et al. (2002) hypothesized that emotion regulation may allow those with high standards to respond to failure with appropriate coping rather than depressed affect. Conversely, those with low emotion regulation abilities may be at risk for internalizing disorders when experiencing unmet standards. Despite this theory, research is sparse investigating the effect of emotion regulation on levels of perfectionism. This is true for both maladaptive and adaptive levels, SOP and SPP. No such research has investigated this across development.

However, in a sample of 100 undergraduates, the majority of whom were women, levels of SPP and SOP were associated with dysfunctional cognitive emotion regulation strategies measured using self-report questionnaires (Rudolph, Flett, \& Hewitt, 2007). This is consistent with the theory that emotion regulation difficulties are associated with perfectionism, but is limited by its overuse use of undergraduate women, self-report, and 
cross-sectional nature. Further, the study does not provide any insight into how emotion regulation may contribute to perfectionistic distress. Aldea and Rice (2006) provided compelling evidence that emotion regulation may affect the expression of distress in perfectionism using a large sample of 349 undergraduates. They found that maladaptive perfectionism was positively and significantly related to distress, while adaptive perfectionism was negatively and significantly related to distress. Further, they found that emotion dysregulation mediated these relations. That is, emotion dysregulation partially explains the associations observed between perfectionism and distress. The findings suggest that perfectionists who can regulate their emotions may experience less dysfunction.

Emotion regulation abilities may also explain physiological reactivity differences observed in perfectionistic individuals. Children found to have a stronger ability to regulate emotional experience and expression have a specific physiological profile in response to stress. This profile is marked by higher vagal tone (a marker for parasympathetic activation; Fox, 1989; Porges, Doussard-Roosevelt, \& Maiti, 1994) and HPA down-regulation (Blair, Granger, \& Razza, 2005; Gunnar, Tout, de Haan, Pierce, \& Stansbury, 1997). Although regulation in early infants is associated with lower reactivity (Calkins \& Fox, 1992), in children both high vagal tone and HPA regulation are characteristics of individuals who flexibly react and recover from environmental stressors (Diamond, 2002). Maladaptive perfectionists show the opposite physiological profile. For example, systolic blood pressure, used as a measure of vagal tone, was found to be stable over the course of difficult tasks for perfectionists, while it declined for those with lower levels of standards (Albert, Rice, \& Caffee, 2014; Besser, Flett, Hewitt, \& Guez, 2008). 
Further, focus on perfectionistic irrational beliefs (e.g., "I must perform well") was associated with elevated systolic blood pressure outside of specific stress tasks (Harris, Davies, \& Dryden, 2006). Perfectionistic individuals have also shown higher levels of cortisol reactivity, a measure of HPA activation, in response to stressful tasks (Wirtz et al., 2007). Importantly, the samples in these studies were adults and need replication in children to determine if similar effects are shown. However, the results do provide preliminary evidence that perfectionists may lack the ability to regulate their physiological states in the presence of unmet standards. Conversely, successful development of emotion regulation abilities may reduce physiological reactivity and defend against maladaptive perfectionism development.

Protective factors such as effortful control and emotion regulation may play instrumental roles in shielding children from developing maladaptive perfectionism. Further, deficits in these processes may allow risk factors to contribute more strongly to maladaptive developmental trajectories that lead to perfectionism. Yet, other key factors play instrumental roles in the development of effortful control and emotion regulation (e.g., executive function, parenting; Morris et al., 2007; Simonds, Kieras, Rueda, \& Rothbart, 2007). Further research needs to examine these associations in the development of perfectionism.

\section{Perfectionism in the Development of Internalizing Disorders}

In addition to the developmental aspects preceding the development of perfectionism, it is important to review literature examining those factors which follow from the development of perfectionism. Given high rates of comorbities among internalizing disorders (Kendler et al., 2011; Kessler, Chiu, Demler, \& Walters, 2005), it 
has been proposed that they share common liabilities (e.g., temperament traits, parenting styles; Eaton et al., 2013). These liabilities provide important etiological information about these disorders. Perfectionism has been theorized as one such process that influences the development of internalizing disorders through mediators detailed later (Affrunti \& Woodruff-Borden, 2014; Egan et al., 2011; Wheeler, Blankstein, Antony, McCabe, \& Bieling, 2011). However, consistent with the developmental psychopathology approach, there are multiple paths, involving multiple factors that influence the etiology of internalizing disorders. Perfectionism represents one risk factor that dynamically interacts with others (e.g., temperament, executive function, and parenting) to put individuals at risk of developing or maintaining internalizing pathology. Indeed, Bieling, Summerfeldt, Israeli and Antony (2004) found that SOP and SPP explained a significant amount of the variance in comorbid diagnoses in patients with anxiety and mood disorders. Further, perfectionism predicted for higher comorbidity even after controlling for current symptoms. Thus, the value of examining perfectionism becomes clear; targeting perfectionism directly in individuals with an internalizing disorder, or comorbid disorders, may lead to relief across multiple domains.

\section{Associations with Internalizing Symptoms and Disorders}

Evidence from numerous studies supports the notion that perfectionism is a risk and maintenance factor for the development of internalizing disorders in children. Individual studies are summarized in Table 1. 
Table 1.

Summary of relevant studies connecting perfectionism with internalizing disorders in children and adolescents

\begin{tabular}{|c|c|c|c|c|}
\hline Citation & $\begin{array}{l}\text { Outcome } \\
\text { variable }\end{array}$ & $\begin{array}{l}\text { Sample } \\
\text { characteristics }\end{array}$ & $\begin{array}{l}\text { Domains of } \\
\text { perfectionism }\end{array}$ & Key Findings \\
\hline $\begin{array}{l}\text { Asseraf \& Vaillancourt, } \\
2014\end{array}$ & $\begin{array}{l}\text { Depressive } \\
\text { symptoms }\end{array}$ & $\begin{array}{l}\mathrm{N}=653 ; \text { mean } \\
\text { age }=12.18 \\
\text { years }\end{array}$ & SOP; SPP & $\begin{array}{l}\text { Depressive symptoms predicted subsequent } \\
\text { increase in SPP; SOP predicted for } \\
\text { subsequent SPP }\end{array}$ \\
\hline $\begin{array}{l}\text { Boergers, Spirito, \& } \\
\text { Donaldson, } 1998\end{array}$ & Suicide reason & $\begin{array}{l}\mathrm{N}=120 ; \\
\text { suicide } \\
\text { attempters; } \\
\text { ages } 12-17 \\
\text { years }\end{array}$ & SOP; SPP & $\begin{array}{l}\text { SPP predicted for death as reason for } \\
\text { suicide attempt }\end{array}$ \\
\hline $\begin{array}{l}\text { Donaldson, Spirito, \& } \\
\text { Farnett, } 2000\end{array}$ & Hopelessness & $\begin{array}{l}\mathrm{N}=68 \text {; suicide } \\
\text { attempters; } \\
\text { ages } 11-17 \\
\text { years }\end{array}$ & SOP; SPP & $\begin{array}{l}\text { Both SOP and SPP predicted increased } \\
\text { hopelessness; SPP stronger predictor }\end{array}$ \\
\hline $\begin{array}{l}\text { Enns, Cox, \& } \\
\text { Inayatulla, } 2003\end{array}$ & $\begin{array}{l}\text { Depression; } \\
\text { Suicidal ideation }\end{array}$ & $\begin{array}{l}\mathrm{N}=78 \\
\text { psychiatric } \\
\text { inpatients; ages } \\
12-18 \text { years }\end{array}$ & SOP; SPP & $\begin{array}{l}\text { SOP predicted increased hopelessness over } \\
\text { time during inpatient hospital stay }\end{array}$ \\
\hline $\begin{array}{l}\text { Essau, Conradt, } \\
\text { Sasagawa, \& Ollendick, } \\
2012\end{array}$ & $\begin{array}{l}\text { Perfectionism; } \\
\text { Anxiety } \\
\text { symptoms }\end{array}$ & $\begin{array}{l}\mathrm{N}=632 ; \text { ages } \\
6-12 \text { years }\end{array}$ & Perfectionism & $\begin{array}{l}\text { Perfectionism decreased during anxiety } \\
\text { prevention program; Perfectionism } \\
\text { predicted lower treatment gains }\end{array}$ \\
\hline $\begin{array}{l}\text { Essau, Leung, Conradt, } \\
\text { Cheng, \& Wong, } 2008\end{array}$ & $\begin{array}{l}\text { Anxiety } \\
\text { symptoms }\end{array}$ & $\begin{array}{l}N=1022 ; \text { ages } \\
12-17 \text { years }\end{array}$ & SOP; SPP & $\begin{array}{l}\text { SOP and SPP associated with increased } \\
\text { anxiety symptoms }\end{array}$ \\
\hline Flett, Coulter, Hewitt, & $\begin{array}{l}\text { Worry; } \\
\text { Rumination; }\end{array}$ & $\begin{array}{l}\mathrm{N}=81 ; \text { mean } \\
\text { age }=12.8\end{array}$ & SOP; SPP & $\begin{array}{l}\text { SOP associated with worry, depression, and } \\
\text { rumination; SPP associated with worry, }\end{array}$ \\
\hline
\end{tabular}


\& Nepon, 2011

Flett, Hewitt, \& Cheng, 2008

Hewitt et al., 2002

Hewitt, Newton, Flett, \& Callander, 1997

Huggins, Davis,

Rooney, \& Kane, 2008

$w$

Jacobs et al., 2009

\section{Depression}

Kenney-Benson \& Pomerantz, 2005

Leon, Kendall, \& Garber, 1980

Libby, Reynolds,

Derisley, \& Clark, 2004

\section{Depression}

Depressive symptoms

Anxiety and depression symptoms

Hopelessness;

Suicidal ideation

diagnosis

\section{years}

$\mathrm{N}=250$; ages $15-18$ years

$\mathrm{N}=114$; ages

$10-15$ years

$\mathrm{N}=66$;

psychiatric

inpatients;

grades 6-12

$\mathrm{N}=786 ; 50$

diagnosed

depressed;

ages 10-11

years

Depression
severity

$\mathrm{N}=439$;

diagnosed

depressed;

ages 12-17

years

Depressive symptoms

Depressive symptoms

OCD diagnosis
$\mathrm{N}=104 ;$ ages

7-10 years

$\mathrm{N}=138 ; 21$

diagnosed

depressed;

grades 3-6

$\mathrm{N}=118 ; 28$

diagnosed

OCD; ages 11-

18 years depression

SOP and SPP correlated with depressive symptoms

SOP and SPP correlated with anxiety and depression symptoms

SOP; SPP

SOP correlated with increased hopelessness; SPP correlated with increased hopelessness, suicidal ideation

SOP; SPP SOP and SPP higher in depressed group than non-depressed controls; SPP predicted depression diagnosis

Perfectionism Perfectionism correlated with more severe depression; Perfectionism predicted less improvement in treatment

SOP; SPP $\quad$ SPP predicted for depressive symptoms

Perfectionism Perfectionism correlated with depression symptoms

PS, CM, PE, CM, PS, and ORG correlated with OCD $\mathrm{PC}, \mathrm{ORG}$ diagnosis 
McCreary, Joiner, Schmidt, \& Ialongo, 2004
Anxiety and depression symptoms

Mitchell, Newall, Broeren, \& Hudson, 2013

Nobel, Manassis, \& Wilansky-Traynor, 2012

O'Connor, Rasmussen, \& Hawton, 2010

Rice, Leever, Noggle, \& Lapsley, 2007

Rogers et al., 2009

Soenens et al., 2008

Soreni et al., 2014

\section{Perfectionism; \\ Anxiety \\ symptoms}

Anxiety and

depression

symptoms

Anxiety and

depression

symptoms

Depressive

symptoms

Depression

severity

Depressive symptoms

OCD severity; Depression symptoms
$\mathrm{N}=481$;

African

American

sample; mean

age 11.8 years

$\mathrm{N}=67 ;$
diagnosed
anxiety

disordered;

ages 9-12 years

$\mathrm{N}=78$; ages 8- SOP; SPP

11 years

$\mathrm{N}=737$; mean age $=15.2$

years

$\mathrm{N}=141$; ages

12-16 years

$\mathrm{N}=422$;

diagnosed

depressed;

ages 12-17

years

$\mathrm{N}=677$; ages

15-18 years

$\mathrm{N}=94$; diagnosed OCD; ages 917 ;

SOP; SPP SPP

SM; CE;
SOP-critical; SOP-critical and SPP predicted increased SOP-striving; anxiety and depression symptoms over 1 SPP year

SOP decreased during anxiety treatment; Pre-treatment SOP predicted lower posttreatment gains

SOP correlated with anxiety and depression symptoms; Pre-treatment SOP predicted increased post-treatment depression symptoms

SOP-critical; SOP-critical and SPP predicted anxiety and SOP-striving; depression symptoms over 6 months COM; NFA

SM interacted with NFA to predict depressive symptoms

Perfectionism

Perfectionism correlated with increased depression symptom severity

Maladaptive perfectionism

Maladaptive perfectionism predicted for depressive symptoms at 1 year

SOP-critical; SOP-critical and COM predicted OCD SOP-striving; symptom severity; SOP-critical and SPP SPP; SM; CE; predicted increased depressive symptoms; COM; NFA SOP-striving was associated with lower 
Ye, Rice, \& Storch, 2008

OC symptoms;

Depression

symptoms
$\mathrm{N}=31$

diagnosed

OCD; age 7-18

years depressive symptoms

$\mathrm{SM}, \mathrm{CE}$, COM, NFA

SM associated with OC symptoms, depression; CE linked with depression

Note: SPP = Socially Prescribed Perfectionism; SOP = Self-Oriented Perfectionism; $\mathrm{SM}=$ Sensitivity to mistakes; $\mathrm{CE}=$

Contingent self-esteem; $\mathrm{COM}=$ Compulsiveness; NFA = Need for admiration; PS = Personal standards; $\mathrm{CM}=\mathrm{Concern}$ over mistakes $; \mathrm{PE}=$ Parental expectations $; \mathrm{PC}=$ Parental criticism; $\mathrm{ORG}=$ Organization; $\mathrm{OCD}=$ Obsessive-compulsive disorder;

Perfectionism $=$ single dimension of perfectionism used; 
First, perfectionism has been repeatedly linked with increased anxiety and depressive symptoms and diagnoses, including suicidality, in children (Asseraf \& Vaillancourt, 2014; Castro \& Rice, 2003; Donaldson et al., 2000; Enns, Cox, \& Inayatulla, 2003; Essau, Leung, Conradt, Cheng, \& Wong, 2008; Flett et al., 2011; Hewitt et al., 1997; 2002; Huggins et al., 2008; Kenney-Benson \& Pomerantz, 2005; Leon, Kendall, \& Garber, 1980; Rice, Leever, Noggle, \& Lapsley, 2007; Soreni et al., 2014; Ye, Rice, \& Storch, 2008). Second, longitudinal studies have shown that perfectionism is a strong predictor of subsequent anxiety and depression diagnoses in early development (McCreary et al., 2004; O'Connor et al., 2010; Soenens et al., 2008). Third, perfectionism has often been linked with the severity of disorder or symptom in children (Boergers, Spirito, \& Donaldson, 1998; Libby, Reynolds, Derisley, \& Clark, 2004; Rogers et al., 2009). Fourth, adaptive levels of perfectionism are associated with non-distressed or non-disordered individuals (DiPrima, Ashby, Gnilka, \& Noble, 2011; Cox, Enns, \& Clara, 2002; Soreni et al., 2014). Fifth, higher levels of perfectionism impede treatment of child internalizing disorders (Essau, Conradt, Sasagawa, \& Ollendick, 2012; Jacobs et al., 2009; Mitchell, Newall, Broeren, \& Hudson, 2013; Nobel, Manassis, \& Wilansky-Traynor, 2012) and treatment of perfectionism directly reduces internalizing symptoms in adults (Egan et al., 2014; Steele et al., 2013).

As such, the growing body of literature linking perfectionism with internalizing disorders lends support to perfectionism as a risk and maintenance factor for the development of these disorders. Despite this, the individual contributions of perfectionism to these disorders over such developmental factors as temperament, executive function, and parenting is not well known. Further, mediating processes likely 
help explain how and why perfectionism exerts its effects on the development of internalizing disorders.

\section{Mediators of Perfectionism and Internalizing Disorders}

Clarifying the link between perfectionism and internalizing disorders is not easy given the dynamic fashion in which it develops and affects outcomes. However, research and theory have implicated multiple clinical processes linking perfectionism and internalizing disorders (Hill, Hall, \& Appleton, 2011; Libby et al., 2004; Moretz \& McKay, 2009). Intolerance of uncertainty, lowered perceived competence, and "not just right experiences" (NJREs), have all shown associations with perfectionism and internalizing disorders. Indeed, these factors have been theorized as ways maladaptive perfectionism effects the development of internalizing disorders (Affrunti \& WoodruffBorden, 2014). They also may provide support for the notion that perfectionism is an etiological and maintaining factor across internalizing disorders. As such, these represent possible paths that are part of multiple causal routes within the development of these disorders. Importantly, much of this research remains preliminary, limiting our understanding of the exact nature of the relations observed across development.

Intolerance of uncertainty. "Intolerance of uncertainty" is the concept that ambiguity in situations is inherently threatening or negative and should be avoided (Dugas, Buhr, \& Ladouceur, 2004), and it has been implicated in disorders such as generalized anxiety disorder, OCD, obsessive-compulsive personality disorder, and depression (Buhr \& Dugas, 2006; Dugas, Schwartz, \& Francis, 2004; Gallagher, South, \& Oltmanns, 2003; Gentes \& Ruscio, 2011; Tolin, Abramowitz, Brigidi, \& Foa, 2003). Intolerance of uncertainty may link perfectionism with internalizing disorders as the high, 
rigid standards and perceived negative consequences that occur in perfectionism make uncertainty a fearful prospect. This would likely occur regardless of perfectionism domain, SPP or SOP. That is, perfectionism may result in children developing distress towards uncertain, unexpected situations that may in turn increase the risk of developing an internalizing disorder. Research examining the relationship of intolerance of uncertainty and perfectionism has only been correlational. Buhr and Dugas (2006) reported significant correlations between intolerance of uncertainty and perfectionism in 197 undergraduates. Similar significant correlations were shown in a sample of 191 adolescents, 14 to 18 years of age (Boelen, Vrinssen, \& van Tulder, 2010). No conclusions can be drawn about directionality or specific domains. Yet, these findings are consistent with the theory that perfectionism and intolerance of uncertainty may be associated in the development of internalizing disorders.

In some contemporary cognitive models of $\mathrm{OCD}$, intolerance of uncertainty, and perfectionism are conceptualized as specific dysfunctional beliefs that give rise to obsessive-compulsive symptoms (Clark, 2004; Libby et al., 2004; Frost \& Steketee, 2002). Indeed, in factor analytic studies, perfectionism and intolerance of uncertainty have been combined into a single factor in adults (Taylor, Afifi, Stein, Asmundson, \& Jang, 2010). This may suggest that those who are highly perfectionistic are likely to develop intolerance of uncertainty in the context of OCD. Longitudinal studies are needed to determine directionality and strengths of effects of these relations across development. Convincing evidence for intolerance of uncertainty as a mediator between perfectionism and internalizing disorders comes from a sample of 475 undergraduates (Reuther et al., 2013). Researchers found that intolerance of uncertainty mediated the 
relation between perfectionism and obsessive-compulsive symptoms. Although the data was not longitudinal, this provides support for the theory that perfectionism leads to distress in uncertain, unexpected situations, which leads to increased risk for internalizing disorders.

The need for further investigation of perfectionism and intolerance of uncertainty across development is clear. Further, information pertaining to maladaptive versus adaptive perfectionism and SPP or SOP domains is lacking. These remain important areas for future study. It is plausible that intolerance of uncertainty and perfectionism influence each other throughout development. Other key variables such as parenting and executive function likely influence and maintain this development as well. This may result in the two processes becoming more strongly linked across development. Indeed, research has found that intolerance of uncertainty in adolescents is highly correlated with parental rejection and alienation (Hale, Engels, \& Meeus, 2006; Zlomke \& Young, 2009), parental rearing behaviors that also influence perfectionism development. However, importantly, neither adult nor pediatric research has investigated any causal relation between intolerance of uncertainty and perfectionism. As such, the above represent hypothetical explanations. Because both constructs relate highly to internalizing disorders, grasping both the unique and shared aspects of these constructs is of vital clinical importance.

Perceived competence. Perceived competence has been defined as the belief in one's own mastery over challenges in their environment. This has been conceptualized as including separate but related domains of competence: cognitive, social, and physical (Harter, 1982). Yet, these skill-based domains relate to a global factor of self-competence 
(Granleese \& Joseph, 1994). Both the skill based domains and the global factor have shown linkages with perfectionism and internalizing disorders (Grills \& Ollendick, 2002; McVey, Pepler, Davis, Flett, \& Abdolell, 2002; Rice, Choi, Zhang, Moreno, \& Anderson, 2012). Theoretically, continued perceived failure at achieving high, rigid standards would lead to the development of poor self-competence. This poor self-competence would then lead to internalizing disorders by raising anxiety and lowering coping. Although no study has examined this theory across development, separate lines of research do provide some support.

Perfectionism has been linked with lower ratings of perceived competence. In a sample of 286 undergraduates, interpersonal competence was correlated with perfectionism (Jackson, Towson, \& Narduzzi, 1997). Similar results were reported in a sample of 363 females with an average age of approximately 13 years (McVey et al., 2002). In a sample of 187 females with a mean age of 14 , perfectionism was found to be associated with domain-specific competencies (McArdle, 2010). That is, perfectionism about cognitive tasks was associated with perceived competence about cognitive tasks, but not with perceived competence about physical tasks. Perfectionism about physical tasks was associated with perceived competence about physical tasks but not perceived competence about cognitive tasks. This may suggest that perfectionism leads to domainspecific competency deficits. That is, perfectionism may lead to lowered competence in a specific domain (e.g., academic). Yet, some research has shown that perfectionism leads to more global deficits of competence (DiBartolo, Frost, Chang, LaSota, \& Grills, 2004; Rice et al., 1998). 
Separately, there is a large body of research that has linked poor competence with internalizing disorders and symptoms (Kupersmidt \& Patterson, 1991; Masten, Burt, \& Coatsworth, 2006; Messer \& Beidel, 1994; Rutter, Kim-Cohen, \& Maughan, 2006). For example, in a longitudinal study following 87 children from grade 2 to grade 5 , perceptions of social incompetence were predictive for subsequent internalizing problems (Hymel, Rubin, Rowden, \& LeMare, 1990). Further, low levels of global selfcompetence have been shown to predict depression in children with a mean age of 11 years (Garber, Robinson, \& Valentiner, 1997). Similar results have been reported in a meta-analysis of longitudinal studies (Sowislo \& Orth, 2013). A longitudinal study following 205 children from age 8 years to 28 years found that social incompetence predicted for subsequent internalizing problems at all follow-up time points: 7, 10, and 20 years after the initial assessment (Burt, Obradović, Long, \& Masten, 2008).

No study has combined these two lines of research. Taken together, this may suggest that individuals high in perfectionism, either SOP or SPP, may develop low competence when faced with frequent perceived failure. SOP and SPP may play roles in the specific domain of lowered competence. That is, SPP may be related more specifically to social competence, whereas SOP may relate to global self-competence levels. Further, specific areas of perfectionistic concern (e.g., social relationships) may lead to lowered competence for this specific area. This lowered competence may increase the risk of developing internalizing disorders across development.

Importantly, research has not yet investigated the directionality of the relation between perfectionism and lowered self-competence. Competence, like perfectionism, is likely influenced by multiple developmental factors. For example, parental control and 
authoritarian parenting have shown to be predictive of competence deficits by restricting a child's ability to develop competence in challenging situations (de Minzi, 2006; Grolnick \& Ryan, 1989). Further, temperament may put a child at risk of developing lower competence by moderating their response to stress (Sallquist et al., 2009). As such, future research must better clarify the role of perfectionism in the development of competence.

"Not just right experiences". The clinical phenomenon of a "not just right experience" (NJRE) is when an individual reports uncomfortable sensations that compels $\mathrm{him} /$ her to perform an action until the uncomfortable sensation is resolved as being "just right" (Coles, Frost, Heimberg, \& Rhéaume, 2003). These behaviors are conceptualized as a striving for perfection, certainty, or control that needs to be achieved in order to reduce distress. That distress likely arises out of a mismatch between input and expectations (Coles, Heimberg, Frost, \& Steketee, 2005). NJREs are often observed in OCD, though it has also been observed in individuals with tic disorders as well (Ghisi, Chiri, Marchetti, Sanavio, \& Sica, 2010; Leckman, Walker, Goodman, Pauls, \& Cohen, 1994; Miguel et al., 2000; Neal \& Cavanna, 2013). There is also some research that NJREs are significantly related to generalized anxiety disorder symptoms and worry (Fergus, 2014). It is possible that heightened sensitivity to sensory stimuli is at the root of such experiences. However, perfectionism may lead to the sensation that certain experiences are imperfect, or not "just right", which leads to distress. Behaviors such as compulsions or worry result as a way to decrease this distress, leading to internalizing disorders such as OCD and generalized anxiety disorder. 
Few studies have investigated the association between perfectionism and NJREs. However, in the few studies that have examined this, perfectionism has been found to be strongly associated with NJREs. Coles et al. (2003) found that NJREs significantly correlated with all domains of perfectionism on two separate questionnaires of perfectionism in a sample of 119 undergraduates. Similar results were reported in a separate undergraduate sample of 188 students (Moretz \& McKay, 2009). Although these studies have provided preliminary evidence for the link between NJREs and perfectionism, they are limited by their use of undergraduates and cross-sectional data. More research is needed to confirm that perfectionism precedes the development of NJREs in the development of OCD or worry. Furthermore, given the internal nature of NJREs it is likely that SOP is more strongly related than SPP. Research examining SPP and SOP in NJREs may yield important results on their development.

Though NJREs are understudied in children, sensory intolerance may represent analogous experiences in children. Sensory intolerance is the phenomenon of marked intolerance or intrusive re-experiencing of sensory stimuli that drive compulsive behaviors (Hazen et al., 2008). Indeed, sensory intolerance may include NJREs as one possible subtype (Miguel et al., 2000) and is common in pediatric OCD and tic disorders (Ferrão et al., 2011; Hazen et al., 2008). Yet, the role of perfectionism within sensory intolerance experiences is not well understood. Though clinical case studies report cooccurrences between sensory intolerance and perfectionism (Hazen et al., 2008), no studies have empirically investigated this connection. As such, future research is needed to understand if perfectionism develops prior to or after sensory intolerance in the development of OCD. 
Both NJREs and sensory intolerance likely have multiple causal factors (e.g., temperament) that influence their development. Yet, no studies have investigated the role of temperament, parenting, executive function, or other such factors in the development of NJREs or sensory intolerance. Further, it is likely that intolerance of uncertainty, competence, and NJREs influence the expression of each other and perfectionism in internalizing disorders. Given the associations observed, perfectionism remains a salient risk factor for the development of NJREs, intolerance of uncertainty, and lower perceived self-competence in the development of internalizing disorders.

\section{Summary}

The construct of pediatric perfectionism is a complex one. Conceptualizations of perfectionism have focused on it being a multidimensional process, incorporating both socially demanded high standards (SPP) and high, inflexible standards held by the self (SOP; Hewitt \& Flett, 1991a; Tozzi et al., 2004). Further, studies have shown that certain aspects of perfectionism may be adaptive and not associated with internalizing disorders and other negative outcomes (Bieling, Israeli, Smith, \& Antony, 2003; Cox et al., 2002; Kempke et al., 2011; Herman et al., 2011). Given the complexity of perfectionism, a number of factors are involved in its development, including vulnerability and protective influences (Affrunti \& Woodruff-Borden, 2014; Flett et al., 2002). The development of perfectionism has also been implicated as a risk and maintenance factor for internalizing disorders through its effects on clinical processes (e.g., competence; Egan et al., 2011).

Importantly, these factors do not operate in isolation. They interact with each other in the context of a developing individual over time. Indeed, the developmental psychopathology approach contends that developmental processes interact in multiple, 
dynamic ways within a developing individual (Cicchetti \& Cohen, 1995). As such, consideration needs to be given to multifactorial models in which vulnerability and protective factors interact with each other across development to produce adaptive and maladaptive outcomes.

Although the proposed model of pediatric perfectionism is consistent with previous research, direct evaluation is needed. That is, examining predisposing factors, perfectionism, and internalizing disorders, within a single model, represents an important addition to previous research. Further, the model generates specific testable hypotheses presented in the section below. Although longitudinal studies are needed to confirm the model's accuracy across development, the current study, using a cross-sectional approach allows establishing of initial associations needed to inform subsequent investigations.

\section{The Current Study}

In order to provide preliminary evidence for a developmental psychopathology approach to perfectionism, the current study aimed to investigate the role of vulnerability and protective factors in child perfectionism. The integration of vulnerability and protective processes in a single model is a significant addition to extant models of perfectionism and can indicate a developmental psychopathology approach is warranted. As such, the current study represents a first step in the examination of perfectionism through a developmental psychopathology approach. Given that this is a preliminary investigation, the vulnerability and protective factors chosen are those previously hypothesized and shown to have an effect on perfectionism: negative affect temperament, anxious rearing parenting, and effortful control. Although subsequent examinations of the model utilizing other variables will be needed, the current study represents an important 
preliminary step in assessing the associations among factors in the development of perfectionism through a developmental psychopathology approach.

Based on extant research, the proposed model focuses on two vulnerability factors, negative affect temperament and anxious rearing parenting, and a protective factor, effortful control, in the development of child perfectionism. The empirical model (see Figure 2) represents hypothetical pathways that lead to perfectionism.

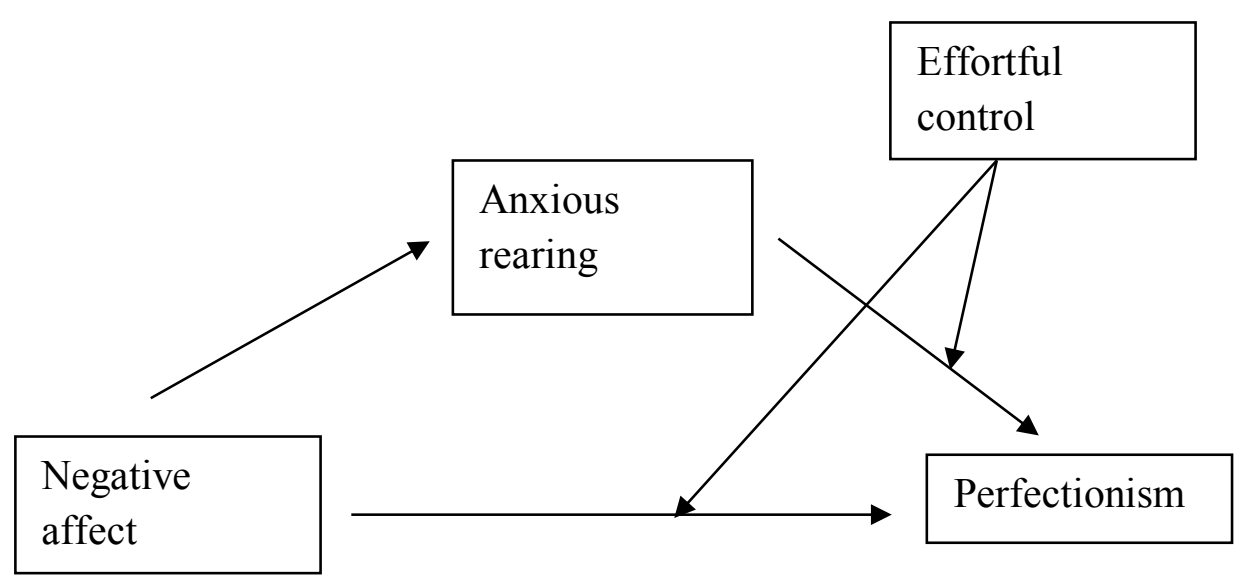

Figure 2. Proposed empirical model of the developmental psychopathology of perfectionism in anxiety disorders.

Figure 2 presents the empirical model tested in the current study. Briefly, the proposed model begins with negative affect, given its observed effect of perfectionism (Damian, Stoeber, Negru, \& Băban, 2014; DiBartolo \& Varner, 2012; Dunkley, Berg, \& Zuroff, 2012). Although negative affect represents a vulnerability factor, it is influenced by protective factors such as effortful control. Indeed, development of effortful control 
may represent an important influence against the development of perfectionism. Thus, it is posited to have a moderating effect. Negative affect, in the absence of protective factors, also influences parental behaviors (Mezulis, Hyde, \& Abramson, 2006). Additionally, anxious rearing parenting predicts for greater perfectionism (Kenny-Benson \& Pomerantz, 2005; Mitchell et al., 2013a; Soenens et al., 2008). That is, there may be a significant indirect effect of anxious rearing on the association between negative affect temperament and perfectionism. Further, effortful control may represent a protective factor by influencing the effect of anxious rearing parenting on perfectionism.

By analyzing the above associations in a single model, the current study addressed shortcomings in previous examinations of the role of vulnerability and protective factors in the development of perfectionism. This is a notable addition to previous research for a number of reasons. First, the current study represents the first attempt to address protective factors in the development of perfectionism. Previous studies have primarily examined factors that contribute to the development of perfectionism (Chang et al., 2007; Clark \& Coker, 2009; Mitchell et al., 2013; Tchanturia et al., 2004), but the current study may additionally inform methods to prevent dysfunction. Second, no previous study has examined the effect of effortful control on the development of perfectionism in children. Third, previous studies (DiBartolo \& Varner, 2012; Kenney-Benson \& Pomerantz, 2005; Mitchell et al., 2013a) have found parenting and temperament to be important factors in the development of perfectionism, yet no studies have examined these factors within a single model. The current study examined whether anxious rearing parenting predicts perfectionism beyond negative affect temperament. Fourth, examining the interaction between negative affect, anxious rearing 
parenting, and effortful control is consistent with the developmental psychopathology approach. That is, psychopathology is the result of dynamic and complex changes that occur as a function of other variables within a system. Negative affect and effortful control represent two such factors. Such information would be crucial for treatment and prevention programs aimed at addressing dysfunction associated with perfectionism.

\section{Hypotheses}

Based on the extant research reviewed, negative affect temperament and anxious rearing parenting were theorized to be risk factors for the development of perfectionism. Effortful control was theorized to be a protective factor against the development of perfectionism. As such, an empirical model (see Figure 2) was created to explain the development of perfectionism that incorporates both risk factors and a protective factor. The protective factor is represented by the interactions between effortful control and negative affect and parenting. Further, anxious rearing parenting is posed as a mediator between negative affect and perfectionism due to negative affect's genetic underpinnings (Goldsmith et al., 1997). Specific hypotheses are detailed as follows:

Hypothesis 1. The model using perfectionism task scores and child-report anxious rearing will provide the best fit of the models tested because child perception of anxious rearing would more strongly predict for perfectionism, compared to maternal perceptions of their rearing style. This will be examined based on the Akaike Information Criterion (AIC) and Bayesian Information Criterion (BIC) scores because models are not nested.

Hypothesis 2. The data will provide at least an adequate fit for the model based on the following model fit indices: root mean square error of approximation (RMSEA), 
standard root mean square residual (SRMR), comparative fit index (CFI), and chi-square $\left(\chi^{2}\right)$ test.

Hypothesis 3. Negative affect temperament, as measured by the Temperament in Middle Childhood Questionnaire (TMCQ) and anxious rearing parenting, as measured by the Egna Minnen Betraffande Uppfostran (EMBU) will each predict for higher levels of perfectionism, as measured by the figure copy task or the Child and Adolescent Perfectionism Scale (CAPS).

Hypothesis 4. There will be a significant indirect effect of anxious rearing on the association between negative affect and perfectionism.

Hypothesis 5. Effortful control, as measured by the Temperament in Middle Childhood Questionnaire (TMCQ) will significantly moderate the association between negative affect and perfectionism, controlling for anxious rearing.

Hypothesis 6. Effortful control will significantly moderate the association between anxious rearing and perfectionism, controlling for negative affect. 


\section{METHOD}

\section{Recruitment}

This study was reviewed and approved the by the University of Louisville's Internal Review Board (Approval \#13.2140). Participants were recruited through the distribution of Institutional Review Board approved brochures and flyers to multiple familial community resources, such as Jefferson County Public Schools, local pediatricians, social media websites (e.g., Facebook) and community health fairs. Additionally, study information was presented at talks to school counselors, at libraries, and for parents at community centers.

The required sample size was calculated a priori using two separate indicators of power. First, the sample size needed to determine a lack of model fit in a path model was calculated. Second, the sample sized needed to determine if an effect within the path model is significantly different from zero. This includes both indirect and moderation effects. The necessary sample size needed to observe goodness of fit for a path model has been estimated to be at least 5 people per parameter (Kline, 2011). A parameter is considered any aspect of the model (e.g., regression weight, variance explained, disturbance term) that is estimated from the data. The current study's path model includes 12 focal parameters. As such, to observe at least good model fit a sample size of 60 would be required. Measures of model fit used in the current study, specifically RMSEA and CFI are less dependent on sample size when assessing for model fit (Fan, Thompson, \& Wang, 1999). In order to calculate the sample size necessary to examine effects within 
the path model, G*Power 3.1.3 (Erdfelder, Faul, \& Buchner, 1996) was used to calculate the power for a regression model. Given effect sizes in previous studies investigating perfectionism, parenting, and temperament in models of child anxiety (e.g., Becker, Ginsburg, Domingues, \& Tein, 2010; Flett et al., 2011; Muris, van Brakel, Arntz, \& Schouten, 2011), a medium effect size of .30 was predicted. To detect a moderate effect size (.30) with a power of .80 and for regression analyses examining 5 potential predictors a sample size of 42 was needed. However, Fritz and MacKinnon (2007) suggest a sample size of at least 54 to determine the significant of an indirect effect using bootstrapping. Thus, a total of 60 parent-child dyads was estimated as the sample size for the current study.

\section{Procedure}

Participants who expressed interest in the study were contacted via e-mail and/or phone to screen for exclusion and inclusion criteria. Families that met inclusion criteria were enrolled in the study. Prior to the collection of any data, parental consent and child assent was obtained and explained. Parent-child dyads were required to complete questionnaires and attend a single session at the Developmental Psychopathology Lab at the University of Louisville to complete the figure copy task. Some participants wished to have the consent, assent, and questionnaires sent home for their review prior to attending the lab visit in order to lessen the burden of time during the lab visit. Any questionnaires not completed at home were completed during the lab visit. All questionnaires were reviewed by study staff to ensure their completion during the lab visit. Questionnaires were presented in a randomized packet in order to control for order effects. 
When enrolled families arrived, consent and assent was reviewed with parents and children. Any questions regarding the study were answered by research assistants. During the lab visit the child completed various tasks including the figure copy task, and completed any questionnaires not completed prior to the lab visit. All tasks were counterbalanced to address order effects. Throughout the completion of tasks and, if necessary, questionnaires, trained study staff were available to answer participant questions or address concerns.

Overall, the lab visit took between 15 and 30 minutes for families to complete, if measures were completed at home. If measures were completed at the lab, the current study took between 45 minutes and 1 hour to complete. Of the 60 families who participated in the study, 56 completed measures at home prior to the lab visit $(93.3 \%)$ and 4 completed them at the lab. Based on the information collected as part of the larger study on developmental factors within child worry and anxiety, all families were provided a report regarding their child's anxiety status, as well as any other pertinent information found based on the diagnostic interviews conducted as part of the larger study. In addition, referrals were provided as needed and upon parents' request. Participants were compensated 20 dollars for their time for participation in the larger study.

\section{Participants}

In order to be eligible for the current study dyads needed to meet the following inclusion criteria: parents and children must be biologically related, children must be between the ages of 7.5 and 13 years, and children cannot have any known developmental disability. The age range of 7.5 to 13 years was chosen to ensure that all 
variables could be validly and reliably measured. That is, the temperament measure and the questionnaire-based measure of perfectionism were designed for and have been used in samples of children 7 to 17 (Essau et al., 2008; Kenney-Benson \& Pomerantz, 2005; Simonds \& Rothbart, 2004). Further, the age range for children allowed appropriate measure of the variables of interest in a school-aged sample prior to the changes observed in parenting effects during adolescence. Only one child per family was eligible to participate in the study.

Participants in the current study consisted of 60 parent-child dyads from the Louisville community. Parents ranged in age from 30 to 49 years old $(M=39.42, S D=$ $5.51)$, were primarily mothers $(95 \%)$, had a college degree or higher education $(64.3 \%)$, were employed full time $(68.3 \% ; 16.7 \%$ part-time $)$ and were mostly married $(78.3 \%$; $11 \%$ divorced). Most families had an annual income of greater than 60,000 per year (72.9\%). Children were between the ages of 7.5 and 13 years $(M=9.73, S D=1.67)$, primarily Caucasian (75\%; 16.7\% African American), and there were slightly more females than males ( $55 \%$ female).

\section{Measures}

\section{Child perfectionism.}

Figure copy task (Mitchell et al., 2013a). The figure copy task is a behavioral assessment completed by the child and designed to assess perfectionistic behaviors in children. Given limitations of the use of self-report in investigating child perfectionism, a behavioral task was used to assess child perfectionism. The task involves asking children to copy sets of figures from stimulus booklets as accurately as possible over three separate 3-min periods. The task is videotaped and subsequently coded for children's 
perfectionistic behavior based on the coding manual developed by Mitchell and colleagues (2013a). To activate evaluative threat, children are informed that (a) their results will be scored based on how similar their copy is to the original, (b) their results will be compared with those of their peers, and (c) the test will be timed using a stopwatch. Further, it is emphasized to children that they should attempt to copy the designs exactly as they appear. Children are provided four sharpened pencils, an eraser, a ruler, and a protractor to use as they desired to copy the pictures in a separate booklet. Importantly, the figure copy task only has been used in a single study of perfectionism. Although a previous study (Mitchell et al., 2013) found significant associations between the figure copy task scores and the Child and Adolescent Perfectionism Scale, these results have yet to be replicated. As such, the figure copy task requires further investigation to assure that valid inferences may be drawn. Due to this, the current study examined model fit using both figure copy task scores and the Child and Adolescent Perfectionism Scale scores (see below).

The Figure Copy Task was designed by Mitchell et al (2013a) as a measure of perfectionism in both anxious and nonanxious children of the target age range. Stimuli for the Figure Copy Task were developed by generating a large number of shapes and figures, with a subset selected for use. Selection was determined by consideration of previous copy or memory tasks such as the Memory for Designs Test (Graham \& Kendall, 1960) and the Rey Complex Figure Test (Meyers \& Meyers, 1995). Within each set, figures were of roughly equal difficulty, but difficulty increased from Set 1 to Set 3 to cater for practice effects. 
Video recordings of children completing the copying task were coded for observable perfectionistic behavior. A coding manual was developed by Mitchell and colleagues (2013) following consultation of existing anxiety behavior coding manuals (e.g., Kendall, 1994) and consideration of behaviors previously associated with elevated perfectionism in the literature such as repeated and/or excessive checking (Glover et al., 2007; Shafran et al., 2004) and a slower style of task completion to minimize mistakes (Antony et al., 1998). More specifically, children's use of rulers, protractors, erasers, and focus on the figure booklet were observed. This yields a frequency count of the number of times each behavior occurs and the length of time each is performed. Specific behaviors rated included measuring the figures, measuring angles, copying the figures, copying the angles, erasing marks, and studying figures on either the figure booklet or the child's own sheet. Based on these observations the child is given a rating on a 5-point scale, with higher scores indicating more extreme perfectionism. Coders were instructed to use both frequency and duration of all behaviors to arrive at their score. Each child received separate scores for each trial as well as a total score that encompasses all trials. Additionally, the time to complete each set of figures is recorded. Each coder was given the relevant coding manual and trained to meet a reliability criterion of three successive matches on perfectionism scores, within an error of $+/-1$, on the coding system using recorded samples. A total of 4 separate coders trained and scored videos. Training included discussing various perfectionistic behaviors, reading the scoring manual, watching sample videos, scoring sample videos as a team, and discussing those scores. All raters met reliability criteria in fewer than 5 videos watched, not including three successive matches. 
All recorded segments used for coding purposes were de-identified using an ID number prior to being coded by a research assistant. The assistant was unaware of children's diagnostic status and the study hypotheses. A random sample of these video segments $(25 \%)$ was coded by a second research assistant who was also unaware of the diagnostic status and hypotheses for reliability purposes. A standard of $\kappa=.80$ was required for the task to be considered reliable and included in the final analysis. Interrater reliability analysis was performed on total perfectionism scores, not individual trials, to determine consistency among raters using exact matches as the criterion, producing a $\kappa=.82$ for total perfectionism scores.

Child and Adolescent Perfectionism Scale (CAPS; Flett \& Hewitt, 1990; Hewitt, Caelian, Flett, Sherry, Collins \& Flynn, 2002). The CAPS was used to assess self-report child perfectionism. The CAPS is a self-report questionnaire consisting of 22 items. Children denote how true certain statements are using a 5-point Likert scale from 1 (false) to 5 (true). It has been utilized with children 7 to 17 years of age (Essau et al., 2008; Kenney-Benson \& Pomerantz, 2005). The CAPS is comprised of two subscales: self-oriented perfectionism (SOP), or standards imposed by the child on him/herself to be perfect and socially-prescribed perfectionism (SPP), or the belief that others require the child to be perfect. Scores are obtained by taking the average of completed items and multiplying the sum by the number of items for the scale. Seventy percent of items for each scale must be completed or the data was excluded from the analysis. The SOP subscale yields possible scores ranging from 12 to 60 . The SPP subscale yields possible scores ranging from 10 to 50 . High scores on the subscales indicate a greater amount of perfectionism. The CAPS has shown to have acceptable intraclass correlations $(I C C=.61$ 
to .65) over 6 months (O'Connor, Dixon, \& Rasmussen, 2005). Further, previous samples have shown it to have acceptable to high internal consistencies, ranging from $\alpha=0.76$ to 0.90 (Affrunti \& Woodruff-Borden, 2015; Enns et al., 2003; Essau et al., 2008). In the current sample the two subscales demonstrated acceptable to high internal consistencies: SOP $\alpha=.88$ and SPP $\alpha=.87$.

\section{Anxious rearing.}

The Egna Minnen Betraffande Uppfostran-parent and child versions (EMBU-P/C; Muris et al., 2003), Swedish for "My memories of upbringing", are derived from the 81item EMBU (Ferris, Jacobsson, Lindström, Von Knorring, \& Perris, 1980), a measure for adults' recollections of their parents' rearing behaviors. The EMBU-P/C are complimentary parent self-report and child report measures assessing perceptions of parental rearing behaviors. It was developed to be used with children as young as 7 years old. Each measure consists of 40 items that load on four subscales:

overprotection/control, emotional warmth, rejection, and anxious rearing. This four factor solution was found using factor analytic methods (Gruner, Muris, Merckelbach, 1999). Each subscale contains 10 items. For the purposes of this study only the 10 item anxious rearing subscale will be used. The respective reporter (child or parent) is asked to denote how often each behavior occurs (e.g., "Your parents are scared when you do something on your own") on a 4 point Likert scale from 1 (no, never) to 4 (yes, most of the time). Possible scores range from 10 to 40, where higher scores indicate greater anxious rearing behaviors. Scores are calculated by taking the average of all individual questions answered, then multiplying that sum by 10 . Seventy percent of items must be completed or the data was excluded from the analysis. Previous studies have shown that both the 
EMBU parent and child versions separately are correlated with anxiety symptoms in children and adolescents (Castro et al., 1997; Muris et al., 2003). Furthermore, internal consistencies and test-retest reliabilities (over a two-month period; $r=.80$ ) were found to range from acceptable to good $\alpha=.66$ to .81 (Muris et al., 2003). For the purposes of the current study, separate models were examined using different reporter scores. That is, a separate model was analyzed using each the EMBU-P and the EMBU-C. In the current sample the EMBU-C had an internal consistency of $\alpha=.72$ and the EMBU-P had an internal consistency of $\alpha=.82$.

\section{Child temperament.}

The Temperament in Middle Childhood Questionnaire (TMCQ; Simonds \& Rothbart, 2004) was used to assess negative affect and effortful control in children. The TMCQ is based on the child behavior questionnaire (CBQ; Rothbart et al., 2001), a wellestablished caregiver-report measure of temperament in children 3 to 7 years old. Although originally created for children 7 to 10 years of age, it has been used with children as old as 13 years (Kotelnikova, Mackrell, Jordan, \& Hayden, 2014; Simonds \& Rothbart, 2004). The TMCQ is a parent-report measure consisting of 157 items that measure 17 different facets of temperament. Parents are asked to denote how true a description of the child's reaction (e.g. "Remains upset for hours when someone hurts his/her feelings") has been within the past six months on a 5-point Likert scale from 1 (almost always untrue) to 5 (almost always true). The current study utilized two broad factors from this scale that do not overlap on specific questions: negative affect and effortful control. 
The negative affect factor measures the amount of emotional reactivity, distress, and difficulty being soothed a child experiences (Simonds \& Rothbart, 2004). This factor is comprised of the anger/frustration, discomfort, fear, sadness, and soothability subscales. Each subscale consists of separate questions and varies in length: the anger/frustration subscale is 7 items, the discomfort subscale is 10 items, the fear subscale is 9 items, the sadness subscale is 10 items, and the soothability subscale is 8 items. Additional evidence for this factor comes from factor analytic methods (Simonds $\&$ Rothbart, 2004). The negative affect factor is obtained by taking the average score across all subscale items, with a possible range of 1 to 5 . Higher scores indicate a greater negative affect. In the current sample, the negative affect factor had high internal consistency at $\alpha=0.95$.

The effortful control factor measures the amount of perceptual sensitivity, attentional and inhibitory control a child has (Simonds \& Rothbart, 2004). The factor is comprised of the activation control, attention focusing, inhibitory control, low intensity pleasure, and perceptual sensitivity subscales. Each subscale consists of separate questions and varies in length: the activation control subscale is 15 items, the attention focusing subscale is 7 items, the inhibitory control subscale is 8 items, the low intensity pleasure subscale is 8 items, and the perceptual sensitivity subscale is 10 items. Additional evidence for this factor comes from factor analytic methods (Simonds \& Rothbart, 2004). The effortful control factor is obtained by taking the average score across all subscale items, with a possible range of 1 to 5 . Higher scores indicate greater effortful control. In the current sample, the effortful control factor had high internal consistency at $\alpha=0.89$. 


\section{Data Analysis Plan}

Data were analyzed using the Statistical Package for Social Sciences (SPSS) version 21 and AMOS version 21. Descriptive statistics, correlations, and internal consistencies were calculated prior to conducting analyses related to study hypotheses. Additionally, correlations and t-tests were run to analyze any significant differences in the variables by child age and gender. If significant, child age and gender would be controlled for in the final analyses.

In order to test the hypotheses of the proposed study, path analysis was used. Path analysis is a type of structural equation modeling that uses all observed variables (i.e., those variables which are directly measured) rather than latent variables. Structural equation modeling is a set of statistical techniques that rely on covariances between variables to explore relations.

Given that all variables in the current study are directly measured, or observed, path analysis is an appropriate statistical technique for the current study. Path analysis holds specific advantages given the model proposed in the current study includes both indirect and moderation effects. First, path analysis allows for testing of the complete model at one time, rather than using a piecemeal approach seen in multiple regressions (Edwards \& Lambert, 2007). This allows for continuous moderation terms to be used without utilizing arbitrary subgroups or split points within the data (Frazier, Tix, \& Barron, 2004). Second, in addition to assessment of the full model to the data, path analysis is able to examine specific indirect or interaction effects (Edwards \& Lambert, 2007). It uses maximum likelihood (ML) to estimate the parameters that best fit the available raw data. Lastly, path analysis allows testing of indirect effects using 
bootstrapping. Although structural equation modeling techniques typically require large samples, path analysis can be specified with lower sample sizes. Given their relative simplicity compared with latent variable models and that all variables are observed, path analytic models do not need larger samples. Further, the use of bootstrapping within the path analysis approach allows for effects to be observed with lower sample sizes (Edwards \& Lambert, 2007; Efron \& Tibshirani, 1993).

Indeed, the present study employed a bootstrapping approach to assess effects ( $n$ $=5000$ bootstrap samples; Preacher $\&$ Hayes, 2008). This approach produces estimates of the standard errors of parameter estimates and a bias-corrected confidence interval of the indirect effect. All confidence intervals used were $95 \%$ bias-corrected confidence intervals. Bias-corrected confidence intervals account for the skewness of the distribution due to resampling, producing more accurate confidence intervals, especially in small samples (Efron \& Tibshirani, 1993). Bootstrapping is considered a superior technique for evaluating an indirect effect in small samples (MacKinnon, Lockwood, Hoffman, West, \& Sheets, 2002; Preacher \& Hayes, 2008). Although other tests of the significance of indirect effects exist (e.g., Sobel test or Aorian test; Baron \& Kenny, 1986; Sobel, 1982), they require larger samples in order to present valid and reliable results. The significance of the indirect effects will be based on criteria found in Zhao, Lynch, and Chen (2010) who demonstrated the only requirement necessary is the significance of the indirect effect.

To examine moderation, the effects of interaction term were analyzed within the path analysis. The path analysis included appropriate covariates and interaction terms as possible paths predicting perfectionism. According to Frazier, Tix, and Barron (2004), in 
order for moderation to be determined, the method of analysis must measure and test the differential effect of the independent variable on the dependent variable as a function of the moderator. For continuous variables, it is recommended that variables be standardized to account for multicollinearity (Frazier et al., 2004). As such, all variables were standardized by obtaining the mean and standard deviation. The mean was then subtracted from each individual score, with the resulting term divided by the standard deviation (Aiken \& West, 1991). Although standardized variables were used to determine the interaction term, as described here, they were also used for main effects. Once the variables were standardized, they were multiplied together to create the interaction term used to test moderation. The significance of this path determined whether the moderation was statistically significant or not. In cases of a significant interaction term, simple slopes analyses were conducted in order to determine the interaction effect of the continuous predictor and moderator variable (Aiken \& West, 1991). Specifically, separate regression lines were computed, plotted, and tested for participants one standard deviation below the mean, at the mean, and one standard deviation above the mean on the predictor variable (Aiken \& West, 1991; Frazier et al., 2004).

Prior to examining study hypotheses, six models were run to determine the best fitting model across different reporters of anxious rearing and for different perfectionism measures. The models are summarized below: Model 1: Child-report anxious rearing, Figure copy task perfectionism Model 2: Child-report anxious rearing, Socially-prescribed perfectionism Model 3: Child-report anxious rearing, Self-oriented perfectionism Model 4: Parent-report anxious rearing, Figure copy task perfectionism 
Model 5: Parent-report anxious rearing, Socially-prescribed perfectionism

Model 6: Parent-report anxious rearing, Self-oriented perfectionism

In order to determine the best fitting model, the models were compared using the Akaike Information Criterion (AIC) and Bayesian Information Criterion (BIC) since the models were not nested. Differences in AIC values represent evidence for sameness in models, while differences in BIC values represent evidence for difference between models. That is, higher discrepancies in AIC provide less evidence for sameness, while higher discrepancies for BIC provide more evidence for differences. AIC differences greater than 4 and BIC differences greater than 6 are considered significant differences in model fit, with the smallest AIC and BIC values considered the best fitting model (Burnham \& Anderson, 2002; Raftery, 1995). Additionally, if models are not significantly different, based on the above criteria, the best fitting model would be determined using the model fit indices: root mean square error of approximation (RMSEA), standard root mean square residual (SRMR), comparative fit index (CFI), and chi-square $\left(\chi^{2}\right)$ test. Using different fit indices allowed for estimation of goodness of fit for the model, while not relying on any single indicator. Goodness of fit was indicated by a nonsignificant $\chi 2$, RMSEA $<0.06$, SRMR $<0.08$, and CFI $>0.90$ (Hu \& Bentler, 1999). Finally, $R^{2}$ values were examined to determine how much variance predictors explain for their respective dependent variable. Higher $R^{2}$ values indicate greater variance explained in the dependent variable. 


\section{RESULTS}

\section{Preliminary Examination of Measures}

The final sample included 60 parent-child dyads. Of this 60,1 child did not complete the perfectionism task yet did still complete self-report measures. To increase power and to examine model fit due to variable differences, all attempts were made to include data in all the models. As such, if $70 \%$ of any self-report measure was completed, it was included in the final sample. There were no parents or children who completed less than $70 \%$ on any self-report measure. As all self-report measures used an average score, missing data was accounted for by including the number of completed items for the measure as the denominator when taking the average. Of the total 60 completed selfreport packets, there were a total of 73 missing items (60 participants * 256 items per packet $=15360$ total items), or less than $1 \%$ of the total items.

Psychometrics for self- and parent-report study measures were assessed by examining internal consistency with Cronbach coefficient alphas $(\alpha)$. Task-based measures were assessed by examining Cohen's kappa ( $\kappa)$ values of interrater reliability. Alpha and Kappa values of .70 or greater were considered acceptable (McHugh, 2012). All study variables met criteria for acceptable internal consistency and were included in relevant analyses.

Normality of the data distribution for study variables was examined using histogram and Q-Q plots. Skewness and kurtosis z-scores were used to determine normality. The absolute value of z-score values greater than 2.58 were considered 
significant and would require transformation (Field, 2005). Visual inspect of histograms and Q-Q plots indicated that all distributions were approximately normally distributed with no outliers of greater than $+/-3$ standard deviations from the mean. Skewness zscores ranged from -0.10 to 0.36 and kurtosis $\mathrm{z}$-scores ranged from -0.95 to -0.14 , suggesting that distributions across measures were approximately normal. As such, all variables were approximately normally distributed, with appropriate skewness and kurtosis values (West, Finch, \& Curran, 1995). Additionally, a curve estimation was conducted for all relationships hypothesized in the all models, and determined that all relationships were sufficiently linear to be tested using a covariance-based structural equation modeling algorithm such as the one in Amos version 21.

\section{Descriptive Statistics and Correlations}

Descriptive statistics and first-order Pearson correlation coefficients for all study variables are presented in Table 2. As expected, there was significant inter-correlation among the variables. Mullticollinearity of each model was evaluated by examining the variance inflation factor (VIF; values greater than 10 are considered problematic) and tolerance statistic (values less than .1 are considered problematic). All VIFs and tolerance values were within acceptable limits.

Table 2.

Descriptive statistics and Pearson correlation coefficients for all variables

\begin{tabular}{lccccccc}
\hline & 1 & 2 & 3 & 4 & 5 & 6 & 7 \\
\hline $\begin{array}{l}1 . \text { Perfectionism } \\
\text { task score }\end{array}$ & - & $.45^{* *}$ & .14 & .25 & $-.39^{* *}$ & $.38^{* *}$ & $.26^{*}$
\end{tabular}


2. Self-oriented

perfectionism

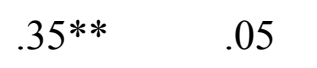

$-.31 * * \quad .10$

.22

3. Socially-

prescribed

.08

$-.32$

$.33 * * \quad .37 * *$

perfectionism

4. Negative

affect

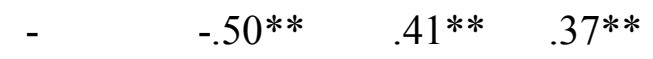

5. Effortful

control

6. Anxious

rearing-child

- $.41 * *$

report

7. Anxious

rearing-parent

report

\begin{tabular}{lrrrcccc} 
Mean & 3.24 & 36.67 & 23.88 & 2.87 & 3.36 & 25.78 & 23.57 \\
SD & 1.19 & 9.85 & 8.46 & 0.65 & 0.44 & 5.14 & 5.23 \\
Range & $1-5$ & $14-57$ & $10-42$ & $1.62-4.36$ & $2.57-4.59$ & $14-37$ & $13-37$ \\
\hline$* p<.05, * * p<.01$ & & & & & & &
\end{tabular}

Analyses revealed that perfectionism task scores were significantly and positively related SOP but was not significantly correlated with SPP. Additionally, perfectionism 
task scores were not significantly correlated with negative affect temperament. However, perfectionism task scores were significantly and positively correlated with and anxious rearing-child report anxious rearing-parent report and significantly and negatively related to effortful control. SOP was significantly and positively correlated with SPP and significantly and negatively associated with effortful control. SOP was not significantly correlated with anxious rearing-child report, anxious rearing-parent report, and negative affect. SPP was significantly and positively correlated with anxious rearing-child report and anxious rearing-parent report but was not correlated with negative affect. SPP was significantly and negatively associated with effortful control. Effortful control was significantly and negatively associated with negative affect, anxious rearing-child report, and anxious rearing-parent report. Negative affect temperament was positively and significantly correlated with anxious rearing-parent report and anxious rearing-child report. Lastly, anxious rearing parenting-child report and anxious rearing parentingparent report were significantly and positively correlated.

\section{Sample Characteristics}

Because not all dyads had complete data sets, differences between the three groups (complete, missing task, missing self- or parent-report questionnaires) were examined. ANOVAs for perfectionism scores were nonsignificant, suggesting that data are missing at random and that failure to complete the task or self- or parent-report questionnaires was not related to perfectionism. Additionally, no differences were observed on any study variable by parent gender. Table 3 displays the associations between all study variables and child age and gender. Child age not significantly related to any study variables. Additionally, there were no differences among study variables 
between male and female children. As such, neither were included as covariates in subsequent analyses.

Table 3.

Associations between study variables and child age and means and standard deviations for study variables by child gender

\begin{tabular}{|c|c|c|c|c|}
\hline & $\begin{array}{l}\text { Correlations } \\
\text { with child age }\end{array}$ & $\begin{array}{l}\text { Male } \\
(n=27)\end{array}$ & $\begin{array}{l}\text { Female } \\
(n=33)\end{array}$ & $\mathrm{t}$ \\
\hline 1. Perfectionism task score & .15 & $\begin{array}{l}3.08 \\
(1.13)\end{array}$ & $\begin{array}{l}3.36 \\
(1.25)\end{array}$ & -0.91 \\
\hline 2. Self-oriented perfectionism & .23 & $\begin{array}{l}35.37 \\
(11.72)\end{array}$ & $\begin{array}{l}37.73 \\
(8.06)\end{array}$ & -0.89 \\
\hline 3. Socially-prescribed perfectionism & -.02 & $\begin{array}{l}23.89 \\
(7.08)\end{array}$ & $\begin{array}{l}23.88 \\
(9.55)\end{array}$ & 0.01 \\
\hline 4. Negative affect & -.03 & $\begin{array}{l}2.76 \\
(0.71)\end{array}$ & $\begin{array}{l}2.97 \\
(0.59)\end{array}$ & -1.28 \\
\hline 5. Effortful control & .05 & $\begin{array}{l}3.28 \\
(0.36)\end{array}$ & $\begin{array}{l}3.42 \\
(0.50)\end{array}$ & -1.26 \\
\hline 6. Anxious rearing-child report & .01 & $\begin{array}{l}24.44 \\
(5.15)\end{array}$ & $\begin{array}{l}26.88 \\
(4.95)\end{array}$ & -1.86 \\
\hline 7. Anxious rearing-parent report & -.05 & $\begin{array}{l}23.00 \\
(5.47)\end{array}$ & $\begin{array}{l}24.03 \\
(5.07)\end{array}$ & -0.76 \\
\hline
\end{tabular}




\section{Hypothesis Testing}

\section{Hypothesis One: Examination of various models}

It was hypothesized that the model using perfectionism task scores and childreport anxious rearing (Model \#1) would provide the best fit of the models tested based on the Akaike Information Criterion (AIC) and Bayesian Information Criterion (BIC). The standard for significant discrepant models was an AIC value greater than 4 or a BIC value greater than 6 , where the smallest AIC and BIC values indicated better fitting models (Burnham \& Anderson, 2002; Raftery, 1995). Model fit statistics (e.g., AIC, BIC, RMSEA, SRMR, CFI, and $\chi^{2}$ ) for all models are in Table 4.

Table 4.

Model fit statistics for all models

\begin{tabular}{llllllll}
\hline & AIC & BIC & Chi-square $\left(\chi^{2}\right) ; \mathrm{p}$ & RMSEA & SRMR & CFI & $R^{2}$ \\
\hline Model 1 & 39.672 & 77.068 & $3.67, p=.299$ & .062 & .046 & .984 & .22 \\
Model 2 & 39.759 & 77.458 & $3.76, p=.289$ & .065 & .048 & .982 & .21 \\
Model 3 & 39.759 & 77.458 & $3.76, p=.289$ & .065 & .045 & .978 & .12 \\
Model 4 & 48.166 & 85.562 & $12.17, p=.007$ & .230 & .079 & .787 & .04 \\
Model 5 & 47.773 & 85.471 & $11.77, p=.008$ & .223 & .083 & .814 & .17 \\
Model 6 & 47.773 & 85.471 & $11.77, p=.008$ & .223 & .079 & .785 & .11
\end{tabular}

Note: Model 1 = Child-report anxious rearing, Figure copy task perfectionism; Model $2=$ Child-report anxious rearing, Socially-prescribed perfectionism; Model 3 = Child-report anxious rearing, Self-oriented perfectionism; Model $4=$ Parent-report anxious rearing, 
Figure copy task perfectionism; Model 5 = Parent-report anxious rearing, Sociallyprescribed perfectionism; Model $6=$ Parent-report anxious rearing, Self-oriented perfectionism

The hypothesis that the model using perfectionism task scores and child report anxious rearing (Model \#1) was supported. Differences between models were observed. Significant differences were observed between Models \#1, \#2, \#3 and Models \#4, \#5, \#6. Models \#1, \#2, \#3 were all significantly better fitting models evidenced by AIC and BIC values ranging from 8.01 to 8.49 . However, no significant differences in models were observed between Models \#1, \#2, and \#3. Model \#1 was observed to be the best fitting model using model fit statistics RMSEA, SRMR, CFI, and $\chi^{2}$ and its predictors explained the highest amount of variance $\left(R^{2}\right)$ in the dependent variable. As such, Model \#1 represents the best fitting model. The following hypotheses were then examined using Model \#1. However, differences between Model \#1 and Models \#2, \#3 will be noted were relevant.

\section{Hypothesis Two: Model fit}

It was hypothesized that the data would provide at least an adequate fit for the model based on the following model fit indices: root mean square error of approximation (RMSEA), standard root mean square residual (SRMR), comparative fit index (CFI), and chi-square $\left(\chi^{2}\right)$ test. As noted in hypothesis one, Model \#1 provided the best fit using model fit criteria outlined above. In examining the model fit of Model \#1 against the standard of a nonsignificant $\chi^{2}$, RMSEA $<0.06$, SRMR $<0.08$, and CFI $>0.90$ (Hu \& Bentler, 1999), it was shown to range from an adequate to good fitting model. Figure 3 presents the path model with results of the test for the full model. That is, the results 
presented in the figure examined the associations between negative affect, anxious rearing-child report, effortful control, their interactions, and perfectionism figure task scores. The hypothesized model resulted in a nonsignificant $\chi^{2}(3)=3.67, p=.30$, RMSEA $=.062,90 \%$ CI $[.00, .24]$, SRMR $=.046, \mathrm{CFI}=.984$, and $R^{2}=.22$. However, as can be observed from the model, not all paths were significant. The results, as they pertain to specific effects (i.e., direct effects, indirect effects, interactions) are presented below.

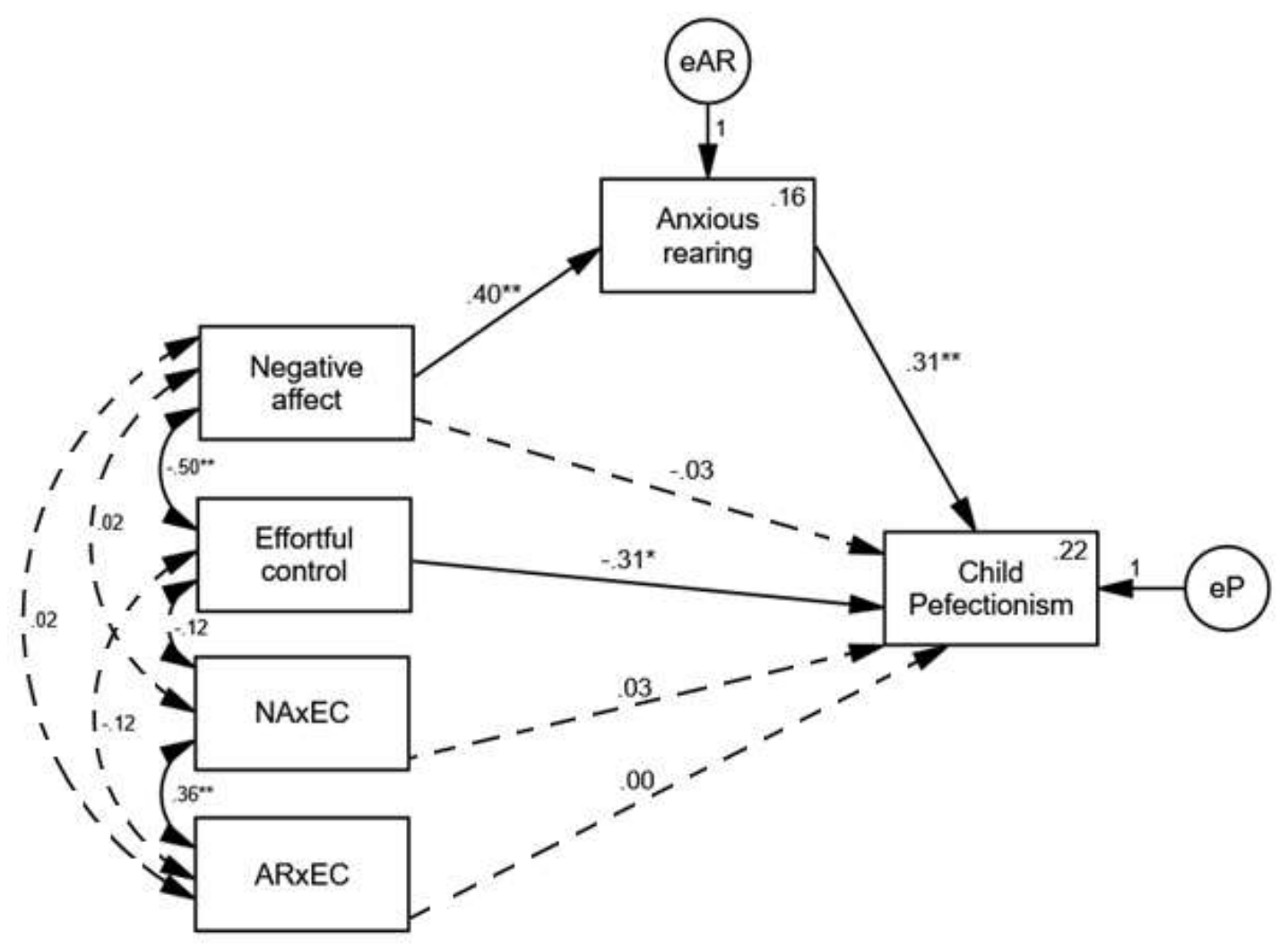

Figure 3. Path model of child perfectionism predicted by negative affect, anxious rearing, effortful control, and their interactions. Note. Significant paths are indicated by a solid lie. Non-significant paths are indicated by a broken line. NAxEC is the interaction term for negative affect by effortful control. ARxEC is the interaction term for anxious rearing by effortful control. eP and eAR are error terms. ${ }^{*} p<.05,{ }^{* *} p<.01$. 


\section{Hypothesis Three: Effects of negative affect and anxious rearing on}

\section{perfectionism}

It was hypothesized that negative affect temperament and anxious rearing would each predict for higher levels of perfectionism. In order to explore this hypothesis, Model \#1 was used, as it provided the best fit for the data. As such, anxious rearing subscales from the EMBU-C are child-reported and the measure of perfectionism is figure copy task. Path analysis was used to provide a test of each the effect of negative affect and the effect anxious rearing on perfectionism, controlling for the effect of the other. Path analysis showed that negative affect did not significantly predict perfectionism, $\beta=-0.29$, $p=.84,95 \% \mathrm{CI}[-0.29,0.23]$, when controlling for anxious rearing. The same findings held across Models \#2 and \#3. However, path analysis showed a statistically significant positive effect of anxious rearing on perfectionism, $\beta=0.31, p=.01,95 \% \mathrm{CI}[0.03$, 0.59 ], with anxious rearing uniquely explaining $7.4 \%\left(R^{2}=.07\right)$ of the variance in perfectionism. Model \#3 also showed a significant effect, $\beta=0.38, p=.02,95 \% \mathrm{CI}$ $[0.08,0.62], R^{2}=.06$; whereas Model \#2 did not show a significant effect. Additionally, though it was not hypothesized, the path between effortful control and anxious rearing was tested to determine if it would be significant and improve model fit. The path between effortful control and anxious rearing was found to be nonsignificant, $p=.45$ and did not improve model fit. As such, the path was dropped from all models. See Table 5 for a list of effects for all paths.

Table 5 . 
Direct effects for all paths

\begin{tabular}{lllll}
\hline IV & DV & $\beta$ & $\mathrm{p}$ & $95 \% \mathrm{CI}$ \\
\hline Negative affect & Anxious rearing & .404 & $<.001$ & $.206-.582$ \\
Negative affect & Perfectionism & -.029 & .84 & $-.289-.231$ \\
Anxious rearing & Perfectionism & .311 & .01 & $.025-.594$ \\
Effortful control & Anxious rearing & -.103 & .43 & $-.314-.168$ \\
Effortful control & Perfectionism & -.313 & .02 & $-.560--.029$ \\
NAxEC & Perfectionism & .031 & .81 & $-.180-.261$ \\
ARxEC & Perfectionism & -.002 & .99 & $-.239-.231$ \\
& & & &
\end{tabular}

Note: NAxEC is the interaction between negative affect and effortful control. ARxEC is the interaction between anxious rearing and effortful control. Anxious rearing is based on child-report only.

\section{Hypothesis Four: Indirect effect of anxious rearing}

It was hypothesized that there would be a significant indirect effect of anxious rearing on the association between negative affect and perfectionism. The significance of the indirect effect was assessed utilizing a bootstrapping approach $(\mathrm{n}=5000$ bootstrap samples; Preacher \& Hayes, 2008). An indirect effect is considered significant if it meets the standards for significance testing, regardless of the significance of the direct effect (Zhao et al., 2010). For the current model, anxious rearing was the mediating variable, between the independent variable negative affect and the dependent variable perfectionism. Negative affect was significantly and positively associated with anxious rearing, $\beta=0.40, p<.001,95 \% \mathrm{CI}[0.21,0.58]$, and anxious rearing was significantly 
and positively associated with perfectionism, $\beta=0.31, p=.01,95 \%$ CI $[0.03,0.59]$, controlling for the effects of negative affect. As such, the indirect effect of anxious rearing on the relation between negative affect and perfectionism was significant $\beta=$ $0.13, p=.02,95 \% \mathrm{CI}[0.02,0.32]$. As noted above, the association between negative affect and perfectionism was not significant, $\beta=-0.29, p=.84,95 \%$ CI $[-0.29,0.23]$, and remained so when accounting for the indirect effect, suggesting that this is an indirect only effect by Zhao and colleagues (2010) criteria. Model \#3 showed a significant indirect effect, $\beta=0.15, p=.01,95 \%$ CI [0.04, 0.32]; whereas, Model \#2 did not show such an effect.

\section{Hypothesis Five: Interaction of effortful control and negative affect}

It was hypothesized that effortful control would significantly moderate the association between negative affect and perfectionism, controlling for anxious rearing. In order to test the significance of the interaction between negative affect and effortful control, both variables were standardized prior to inclusion in the path model. Using the standardized variables, paths predicting perfectionism from negative affect, effortful control, and their product were included in the model. Anxious rearing was included in the model as well, and therefore, its effect was controlled for. The interaction between negative affect and effortful control did not significantly predict for perfectionism, $\beta=$ $0.03, p=.81,95 \%$ CI $[-0.18,0.26]$. Since the interaction was not significant, a simple slopes analysis was not performed. Models \#2 and \#3 also showed no significant interaction.

\section{Hypothesis Six: Interaction of effortful control and anxious rearing}


It was hypothesized that effortful control would significantly moderate the association between anxious rearing and perfectionism, controlling for negative affect. In order to test the significance of the interaction between anxious rearing and effortful control, both variables were standardized prior to inclusion in the path model. Using the standardized variables, paths predicting perfectionism from anxious rearing, effortful control, and their product were included in the model. Negative affect was included in the model as well, and therefore, its effect was controlled for. The interaction between negative affect and effortful control did not significantly predict for perfectionism, $\beta=$ $0.001, p=.99,95 \% \mathrm{CI}[-0.02,0.23]$. Since the interaction was not significant, a simple slopes analysis was not performed. Models \#2 and \#3 showed no significant interaction. 


\section{DISCUSSION}

The current study examined a potential model of risk for the development of perfectionism in a community sample of school-aged children. The goal of the current study was to examine the effects of negative affect, effortful control, and anxious rearing on child perfectionism. Additionally, the current study sought to determine whether there would be a significant indirect effect of anxious rearing on the association between negative affect and perfectionism and whether effortful control would moderate the relations between negative affect and anxious rearing and perfectionism. Because data on anxious rearing was completed by parents and children, and perfectionism was selfreported and measured through a behavioral task, separate models were run to determine the best fit of the model to the data. Several hypotheses were examined: 1) the model using perfectionism task scores and child-report anxious rearing would provide the best fit of the models tested; 2) the data would provide at least an adequate fit for the model based on the model fit indices; 3 ) negative affect and anxious rearing would each predict for higher levels of perfectionism; 4) there would be a significant indirect effect of anxious rearing on the association between negative affect and perfectionism; 5) effortful control would significantly moderate the association between negative affect and perfectionism, controlling for anxious rearing; 6) effortful control would significantly moderate the association between anxious rearing and perfectionism, controlling for negative affect. 
Overall, results from the current study supported the inclusion of multiple areas of effects (e.g., parenting, child factors) in a single model predicting perfectionism. This suggests that multivariate models, like the larger model proposed earlier, are needed to best understand the development of child perfectionism. Indeed, including both risk and protective factors in models of child perfectionism allows a greater appreciation for how perfectionism develops, but also how its development may be altered. Such information would be vital in advancing knowledge, not only of perfectionism, but of pediatric internalizing disorders. Results as they pertain to individual hypotheses are presented below.

\section{Preliminary analyses.}

All variables were examined and determined to be approximately normally distributed and models determined to be valid based on their covariance matrix. As such, hypothesis testing of models and individual effects was conducted on valid data.

Additionally, significant intercorrelations were observed between measures. As expected, there were significant correlations between SOP, SPP, and the figure copy task. However, importantly, SPP and the figure copy task were not significantly correlated. This may indicate that the figure copy task better measures SOP than SPP. This may be because the figure copy task does not account well for hopelessness, or a decrease in effort, across the task. Indeed, SPP has been associated with depressive symptoms and hopelessness (Blankstein, Lumley, \& Crawford, 2007; Donaldson et al., 2000; Hewitt et al., 1997), which were not well captured by the figure copy task. The figure copy task focuses primarily on checking and behaviors that slow completion speed, but for those individuals with the tendency to engage in hopelessness, or negative self-blame, they may 
engage in faster completion, putting forth little effort. Differentiating this hopeless style from those who complete the task quickly due to lower levels of perfectionism will be important for the figure copy task to account for. Combining this style of completion with those who perseverate may lead to a more complete behavioral task for measuring perfectionism.

As expected, parent and child reports of anxious rearing were significantly correlated. Yet, the correlations were in the moderate range suggesting that despite significant agreement, parents and children do show some variability in rating anxious rearing. This is consistent with studies finding that parents and children have low to moderate agreement of parenting behaviors (Bögels \& van Melick, 2004). However, current findings show a higher correlation than previous studies. This may be due to the community sample used in the current study. Studies using clinical samples show greater levels of disagreement between parents and children (De Los Reyes \& Kazdin, 2004).

Additionally, perfectionism dimensions showed separate associations with anxious rearing reporters. Whereas SPP and the figure copy task were significantly correlated with child and parent-report of anxious rearing, SOP showed no significant correlation with either child or parent-report anxious rearing. This suggests different dimensions of perfectionism associate with different parental and environmental factors. For example, SPP is partially socially derived; thus, parenting likely plays a strong role in why a child may feel standards are set highly for them by those in the child's life. However, because SOP focuses on standards set by children themselves, parental rearing may not correlate strongly with SOP. Anxious rearing may have correlated with the figure copy task, a behavioral measurement of perfectionism for two reasons. First, 
children who are perfectionistic may seek higher levels of control from their parents, characteristic of anxious rearing, in order to solve difficult problems or complete challenging tasks. This may not only serve to help the child meet the high standard set, but also reduce distress about whether or not they are achieving that standard. Secondly, parents who engage in higher levels of anxious rearing may point out mistakes the child has made or remind them of consequences of mistakes, making the child more vigilant of errors and engaging in perfectionistic behaviors, such as checking, to avoid them.

Temperament domains effortful control and negative affect also were significantly associated with each other and other variables. This is consistent with literature showing that negative affect and effortful control are negatively linked, such that those children with higher levels of negative affect show lower levels of effortful control (Eisenberg et al., 2005; Eisenberg et al., 2009). Both negative affect and effortful control showed significant correlations with both parent and child reported anxious rearing. Correlations with effortful control were negative, whereas those with negative affect were positive. This is consistent with research showing that temperament and parenting are related (Karreman, de Haas, van Tuijl, van Aken, \& Deković, 2010; Mezulis, Hyde, \& Abramson, 2006). Additionally, it suggests that this relation hold regardless of reporter of anxious rearing and across negative affect and effortful control domains of temperament.

Lastly, temperament domains showed significant correlations with dimensions of perfectionism. Specifically, effortful control was significantly correlated with the perfectionism task, SOP, and SPP. Negative affect was not significantly correlated with any dimension of perfectionism, though did approach significance $(p=.06)$ with the 
perfectionism task. The finding that negative affect was not correlated with dimensions of perfectionism differs from research showing that negative affect does correlate with perfectionism (DiBartolo \& Varner, 2012; Flett et al., 2012). However, it is possible that the correlation observed in the current sample was smaller than other studies. This may be due to the community nature of the sample. It is possible that clinical samples would show a stronger association between negative affect and perfectionism. The association between effortful control and perfectionism domains is the first time such as association has been reported in children. However, it is partially consistent with Tangney et al. (2004)'s study of undergraduates. The authors found a correlation between effortful control and SPP but not SOP. The correlation observed between effortful control and SOP in the current sample may be due to the age of participants. Effortful control continues to develop throughout adolescence (Brocki \& Bohlin, 2004) and as such may not be cemented in the current sample. As such, it may be more diffusely related to perfectionism dimensions at an earlier age. Also, it is possible that SOP in undergraduates reflected higher levels of adaptive perfectionism compared with children in the current study. However, effortful control's association with the perfectionism task scores suggests that behavioral manifestations of perfectionism are linked to effortful control deficits.

\section{Hypothesis testing.}

First, prior to examining individual effects, separate models were examined in order to determine the model which best fit the data. Models differed based on reporter for anxious rearing (i.e., parent or child) and perfectionism domain and report (i.e., self- 
SOP, self-SPP, or independent evaluator based on task performance). A total of six models were examined. The models are:

Model 1: Child-report anxious rearing, Figure copy task perfectionism

Model 2: Child-report anxious rearing, Socially-prescribed perfectionism

Model 3: Child-report anxious rearing, Self-oriented perfectionism

Model 4: Parent-report anxious rearing, Figure copy task perfectionism

Model 5: Parent-report anxious rearing, Socially-prescribed perfectionism

Model 6: Parent-report anxious rearing, Self-oriented perfectionism

In reviewing model fit statistics, Models $\# 4, \# 5$, \#6 were found to provide poor fit for the data. These models differed in their use of parent-reported anxious rearing, rather than child-reported anxious rearing. Although parent report of parenting behaviors have been shown to be valid in previous studies (e.g., Shelton, Frick, \& Wootton, 1996), in the current sample child-report appeared to provide a better fit for the model. As such, it is possible that child perceptions of parenting are quite important, even if those perceptions differ from parent-report. This may be especially true for the anxious rearing domain of parenting, as children may feel competent to become autonomous in some areas where parents disagree. If children perceive their parents as withdrawing chances to gain autonomy in areas they feel competent, they may be more likely to report anxious rearing than parents. Separately, parents may perceive their child as needing their intervention to assist with a task or activity, and thus report lower levels of anxious rearing. Importantly, as noted above, scores on the parent- and child-report measure of anxious rearing correlated, indicating that there is some level of agreement between parent and child on parenting behaviors. However, child perceptions of anxious rearing may be more salient a 
predictor of outcomes such as perfectionism. In the future it will be important to determine how to reconcile reports of parenting made by multiple informants, and their relevance to child outcomes.

Contrary to Models, $\# 4$, \#5, and \#6, Models $\# 1, \# 2$, and \#3 showed good fit with the data. Further, though no significant differences were observed between Models \#1, $\# 2$, and \#3, Model \#1 provided the best fit based on model fit statistics. This was consistent with expectations. Because models using the same predictors, predicting a dependent variable through the same paths, will provide essentially the same model fit statistics, $R^{2}$ was used to determine which predictors explained the most variance in their respective dependent variable. Model \#1 also explained the highest amount of variance in its dependent variable. As such, Model \#1 was used to examine further hypotheses. Importantly, Models \#2 and \#3 also displayed good model fit and suggest that the current predictors explain well individual dimensions of perfectionism (e.g., SPP and SOP). However, Model \#1 may have provided the best fit because it directly measured behaviors in the perfectionism task, rather than cognitions and traits in the self-report questionnaire of perfectionism. Because the questionnaires used for temperament and parenting also focused on behaviors, they may have more strongly predicted a measure of behavior, the perfectionism task, rather than a cognitive measure. Future research may do well to explore whether measures focusing on parent and child cognitions better predict for the self-report measure of perfectionism, rather than the behavioral task-based measure.

The use of such a behavioral task-based measure represents a strength of the current study. Previous studies have nearly exclusively used self-report measures of 
perfectionism in children (see Mitchell et al., 2013a for an exception). Although selfreport measures provide important information about internal processes (Kazdin \& Peiti, 1982), they may be limited and subject to biases (Van de Mortel, 2008). For example, perfectionistic children may attempt to present themselves in more a social desirable light. By using a behavioral task to measure perfectionism, the current study was able to minimize the effect of these biases without requiring introspection on the part of the child. Indeed, for children who may have difficulty with insight into their own thoughts and actions, task-based measures can provide valid data on levels of perfectionism. This is especially true for young children, who may not be able to accurately differentiate between perfectionism and positive goal striving. However, the perfectionism task as coded in the current study does have limitations. It may not account for all perfectionistic behaviors or responses to the instructions. As noted above, perfectionistic children who tend to respond to perceived challenges or failure with hopelessness and decreased effort are not well captured with the current coding scheme. The coding scheme seems more sensitive to anxious perfectionistic behaviors such as perseveration and checking, rather than depressive perfectionistic behaviors. Future research will be required to determine how to best measure perfectionism in these children using behavioral methods. In spite of its limitations, the use of a valid and reliable behavioral task to measure perfectionism is an important step towards better understanding and measuring perfectionism in children.

Overall, Model \#1 fit the data well. The model explained $22 \%$ of the variance in child perfectionism. Although in the moderate range, the current model explains a higher proportion of variance than other similar models of child perfectionism (Affrunti, Gramszlo, \& Woodruff-Borden, 2016). Additionally, this suggests that other factors are 
likely implicated in higher levels of perfectionism (Clark \& Coker, 2009; Cook \& Kearney, 2014). Indeed, the current model represented only a partial test of a larger conceptual model of perfectionism development. The results are thus consistent with the larger model suggesting multiple disparate areas of effects contribute to the development of child perfectionism and with previous reviews on child perfectionism (Affrunti \& Woodruff-Borden, 2014; Flett et al., 2002). Despite this, not all effects in the current model were significant. Individual effects are explained below.

Negative affect and anxious rearing were each hypothesized to predict increased levels of child perfectionism. Results were partially consistent with this hypothesis. That is, negative affect did not significantly predict higher levels of perfectionism when controlling for anxious rearing; however, anxious rearing did significantly predict for higher levels of perfectionism. It was surprising that negative affect did not predict for higher levels of perfectionism, as previous research has demonstrated such a link (e.g., DiBartolo \& Varner, 2012). It is possible that levels of negative affect in the current sample were lower than those observed in other studies. Direct comparisons are difficult due to differences in measurement methods but the current sample had mild levels of negative affect. In samples with higher levels of negative affect, stronger effects may be observed. Another possible explanation for the divergence in findings is that the current study accounted for other temperamental traits (e.g., effortful control) and environmental factors (e.g., anxious rearing) that are not present in previous work. Negative affect may appear connected to perfectionism when examined in isolation of other factors. Indeed, previous studies have shown that effortful control and negative affect are highly linked (Eisenberg et al., 2005; Oldehinkel et al., 2007), and therefore may explain similar areas 
of variance in perfectionism. When accounting for factors such as effortful control and parenting, negative affect may not display strong effects on perfectionism, which underlies the need for multivariate models. Additionally, it is possible that effect sizes for negative affect in multivariate models are smaller than previously reported and did not reach significance in the current sample.

The finding that anxious rearing predicted higher levels of perfectionism is consistent with previous research and theory (Affrunti \& Woodruff-Borden, 2014; Kenney-Benson \& Pomerantz, 2005; Mitchell et al., 2103a). Anxious rearing accounted for approximately $7.4 \%\left(R^{2}=.074\right)$ Anxious rearing likely contributes to increased levels of perfectionism by a parents' focus on mistakes, failure, and negative judgements. This focus suggests to the child that these threats result in negative consequences and that the child cannot cope with these threats and consequences. This in comparison to parents who focus on the goal attainment process and reward effort rather than results, which may relate to more adaptive goal striving. Further, parents who engage in anxious rearing may signal to their child that she/he is not competent in specific areas. For example, a parent who worries about their child completing a task may attempt to intervene and complete the task for the child, subverting the child's attempt at autonomy and reducing her/his perceived competence in that area. This reduced competency, when paired with a focus on the negative consequences of mistakes and failure, may make children more distressed in specific situations. Theoretically, children exposed to this parenting may experience greater distress and become more self-critical in situations of perceived failure, leading to greater perfectionistic behaviors. Although current findings are 
consistent with this hypothesis, further research is needed to examine this hypothesis more directly.

The hypothesis that there would be a significant indirect effect of anxious rearing on the association between negative affect and perfectionism was supported by the data. This suggests that anxious rearing is one mechanism through which negative affect may exert its effect on perfectionism. In other words, anxious rearing explains why children who have negative affect have higher levels of perfectionism. Hypothetically, negative affect predicts for greater use of anxious rearing, which in turn puts children at risk of developing perfectionism. Although this theory has not been previously examined, the findings are consistent with previous research that has shown parenting behaviors to mediate the relation between temperament and internalizing disorders (Mezulis et al., 2006; Paulussen-Hoogeboom et al., 2008). Negative affect may predict anxious rearing because parents may worry about the functioning of children who are emotionally reactive and have difficulty being soothed. Parents may worry that children with high levels of negative affect may respond negatively to specific situations, and thus try to minimize a negative response by pointing out mistakes or controlling situations. However, this anxious rearing may have a destructive effect, predicting for greater levels of perfectionism. Indeed, theory would suggest that anxious rearing ultimately promotes a focus on the negative consequences of mistakes and failure and that these are threats with which the child cannot cope (Flett et al., 2002). Importantly, the current results are consistent with, though do not provide conclusive evidence for Flett et al.'s theory. Because data was cross-sectional, no claims to causality can be made. Further research will be required in order to confirm causal relations among the variables. Importantly, 
effortful control was not a significant predictor of anxious rearing and did not improve model fit. This suggests that negative affect may be a stronger predictor of parenting than effortful control. Because effortful control did not significantly predict anxious rearing and did not improve model fit, the path was dropped from all models.

The significance of the indirect effect between negative affect and perfectionism also suggests that parenting plays an important role alongside temperament. That is, anxious rearing remained a significant predictor of perfectionism even when controlling for the effects of negative affect. This may hold vital information for possible treatment targets aimed at ameliorating the negative effects of perfectionism. That is, treatment may be successful if it focuses on reducing levels of anxious rearing directly. However, it may also be successful if treatment focuses on reducing emotional reactivity on the part of the child. The child's lower emotional reactivity may result in lower levels of anxious rearing on the part of the parent, and ultimately lower perfectionism levels in the child. This may be why treatments that are successful in reducing emotion dysregulation also reduce levels of perfectionism (Sullivan, Keller, Paternostro \& Friedberg, 2015).

Results did not support the hypotheses that effortful control would moderate the relation between negative affect and perfectionism and, separately, between anxious rearing and perfectionism. This was unexpected as previous research has found that effortful control does moderate the effect of other temperamental factors (Murray \& Kochanska, 2002; Oldehinkel et al., 2007; Verstraeten et al., 2009) and parenting behaviors (Lengua, 2008) in children. However, research is sparse investigating the effect of effortful control on perfectionism in children. As such, it is possible that effortful control exerts different effects on temperament and parenting in predicting perfectionism. 
Indeed, the current study found that effortful control directly predicted for decreases in perfectionism, which is consistent with previous work in undergraduates (Tangney, Baumeister, \& Boone, 2004). It is possible that because effortful control exerts strong effects on perfectionism directly, it does not interact with negative affect and anxious rearing in the current sample. Indeed, the effect size of the direct effect of effortful control was in the medium range at $\beta=-0.31$ and it explained approximately $6.8 \%$ of the variance in perfectionism $\left(R^{2}=.068\right)$.

Children with higher levels of effortful control have lower levels of perfectionism regardless of levels of negative affect or anxious rearing. This may be because children with high levels of effortful control can prevent themselves from engaging in perseveration that may otherwise lead to increased repetitive behaviors due to perfectionism. For example, a child with high levels of effortful control may complete a portion of a task, notice it is not perfect, but move on to another portion without engaging in repetitive behaviors to correct it. Even if parent engages in anxious rearing, or the child experiences strong emotions, she/he may be able to prevent her/himself from repeatedly engaging with the task. When the child does this she/he is exposed to anxious rearing or those strong emotions but learns that no negative outcome occurs, suggesting that the basis for the anxious rearing or strong emotions was faulty. Over time, the child may perceive her/himself as more competent in coping with expectations, ultimately decreasing levels of perfectionism over time. Theoretically, this may explain why effortful control acts as a protective factor for perfectionism in children (Affrunti \& Woodruff-Borden, 2014). 
It is also possible that the moderating effect of effortful control on anxious rearing and negative affect may be small and require larger samples to meet significance criteria. Additionally, unique effects may be observed in clinical samples. As such, future research should replicate these findings with a larger and clinical sample to determine whether effortful control moderates the associations between perfectionism and negative affect and anxious rearing.

\section{Implications for a conceptual model.}

The current results provide important implications for the conceptual model proposed earlier. The results support a developmental psychopathology framework for the development of child perfectionism. That is, child perfectionism appears to be the result of multiple causal influences that provide both risk of and protection from negative outcomes that occur within a developmental context. The results support the use of a complex model to predict perfectionism in which risk and protective factors combine in dynamic ways. For example, effortful control may protect against maladaptive manifestations of perfectionism, whereas anxious rearing may put children at risk of those maladaptive presentations. Subsequent models of child perfectionism may examine executive functioning and peer relations as other possible factors in the development of perfectionism (Flett et al., 2002). Although the current study was not able to provide conclusions about the nature of these associations across time, or causality, it is consistent with the developmental psychopathology framework. Indeed, the finding that not all paths were significant in the current model provides more support for the use of multifactorial models in child perfectionism. For example, previous research has shown that negative affect is associated with increased child perfectionism (DiBartolo \& Varner, 
2012), though when accounting for effortful control and anxious rearing parenting in the current study, its effect was smaller and not significant. This suggests the importance of examining risk and protective factors in the context of other key variables, rather than in isolation.

More specifically, the current results suggest that temperament and parenting are each are influential in predicting higher levels of child perfectionism. Anxious rearing and effortful control were the strongest predictors of child perfectionism within the current model. Further, the results are consistent with anxious rearing as a mediator of the links between negative affect and perfectionism. That is, anxious rearing may be one mechanism through which negative affect exerts effects on perfectionism. However, effortful control was not shown to interact with either negative affect or anxious rearing in the prediction of child perfectionism. The effect of effortful control on perfectionism appears as a main effect, rather than a moderating one. Future studies should examine further the effect effortful control has on perfectionism, and other key developmental variables, in order to determine whether it buffers the effect of other risk factors.

\section{Limitations of the currents study.}

The current study was subject to certain limitations. The first limitation is the cross-sectional design of the study. Cross-sectional data prevent an examination of the dynamic and transactional links and limit assumptions about directionality between study variables. Although cross-sectional data provide important preliminary information on the nature of certain associations, they cannot make any conclusions about causality. This includes studying indirect effects through cross-sectional data. Indirect effects examined with cross-sectional data can show biased estimates (Maxwell \& Cole, 2007). Whereas 
cross-sectional data do provide a glimpse of the predicted associations specified in the hypothetical model, such associations can vary over time. Additionally, the use of crosssectional data does not allow for an examination of the influence of child development on the associations in the current study. Although study variables were not associated with child age, it is possible that associations between variables differ across stages of development. Consistent with the developmental psychopathology perspective, the effect of child development on temperament, parenting, and perfectionism should be investigated.

Although the current study represents the test of a specific theoretical model, grounded in previous research, it is simply one possible model of these associations. That is, although the path diagram represents a uni-directional theoretical model, there are likely others that would similarly fit the data. As noted above, the model is one of associations and not causal links. As such, caution should be used when interpreting the results. Indeed, it is likely that there exists reciprocity among the variables tested.

Additionally, methodological issues can impact findings. In the current study, the use of parent-, child-, and self-report for different variables can lead to method effects and/or reporter bias, which may bias results. Although the use of a behavioral task can strengthen the validity of the data, the perfectionism task may not have accounted for all behavioral presentations of perfectionism. For example, as noted above, the perfectionism task did not rate lack of effort or hopeless behaviors, which may have been exhibited by some perfectionistic children. Future studies will need to incorporate this into the scoring system, perhaps by coding for affect, for the perfectionism task. 
Lastly, the nature of the current sample limits the generalizability of the results. Given that the sample was recruited from the community and was not drawn at random, results may be biased. First, children and families who experience higher levels of perfectionism, or more negative outcomes as a result, may have participated because the study was more relevant to them. Although no specific criteria pertaining to perfectionism needed to be met, the sample may have reflected as bias towards higher levels of perfectionism. Results may be best understood as coming from a population of highly perfectionistic children, rather than from the larger population as a whole. Second, the study used a relatively wide age range, including children between 7.5 and 13 years of age, which may have contributed to results. As noted above, factors included in the current study likely depend on developmental stage, which may have differed across participants at the lower and higher range of the included ages. For example, anxious rearing may be perceived differently by children of different age groups or developmental stages. Future studies will be required to determine if relations hold across age groups. Third, the sample was predominantly Caucasian and consisted primarily of middle to upper class families. Replication with a more diverse sample, including both parents, may expose unique relations between anxious rearing, temperament, and child perfectionism.

\section{Summary and future directions.}

In summary, despite the limitations listed above, the current study provides support for a developmental psychopathology model in explaining the development of child perfectionism. Effortful control and anxious rearing appear to be closely linked with child perfectionism in the current sample, while negative affect was not. Further, anxious rearing demonstrated a significant indirect effect between the association of negative 
affect and child perfectionism, suggesting that parenting may be one reason for the link between temperament and perfectionism. Indeed, differences in anxious rearing may explain previous findings that have linked negative affect and child perfectionism (Affrunti \& Woodruff-Borden, 2016; DiBartolo \& Varner, 2005). However, more research is needed to determine the respective effects of anxious rearing and negative affect on child perfectionism. Further, future studies should include other parenting styles (e.g., harshness) may be important in understanding how parenting as a whole impacts the associations between temperament and child perfectionism. Although effortful control was not found to interact with negative affect or anxious rearing, it did show a direct effect on child perfectionism. As such, further studies are needed to understand why, and under what circumstances, effortful control reduces levels of child perfectionism. If, as results point to here, that effortful control exerts effects on perfectionism regardless of parenting and temperament, effortful control may represent an important target in reducing perfectionism in children. Overall, the current study provides important information on factors that predict for increased perfectionism in children. Given the relative lack of research examining factors that predict for increased perfectionism, the current study helps fill a gap in the current literature.

There remain many understudied areas in the development of perfectionism and its role in the development and maintenance of child psychopathology. For example, the nature of perfectionism in children is still poorly defined. Adult models have been downwardly applied to children with little research into whether such models are appropriate (Affrunti \& Woodruff-Borden, 2014). Additionally, previous research has used a wide range of different definitions and dimensions to explain perfectionism. Even 
within studies using a singular approach (i.e., multidimensional or uni-dimensional), differences exist as to what those dimensions are and their relevance to psychopathology (McCreary et al., 2004). Better understanding of the nature of perfectionism in children will undoubtedly lead to a more exacting definition, including appropriate dimensions, and more informative results from its study. Further, it will allow better measurement of the construct. This should include multi-informant methods, commonly found to be the most informative method for research on children (De Los Reyes \& Kazdin, 2004), including parent, teacher, and independent evaluation. Multi-informant measures are either not well validated or do not yet exist. Creating and validating such measures represents an important step in the study of child perfectionism. For example, as noted above, future research using the figure copy task would likely benefit from including defeatist and hopeless behaviors in the scoring system. The creation and validation of multi-informant measures may also create a more cohesive body of research.

Additionally, future research is needed to explore child perfectionism across a wide range of sample characteristics. Currently, many studies combine findings across genders, ethnicities and race and a broad range of ages. However, there is evidence that perfectionism may show unique associations within these groups (Frost et al., 1991; Hankin, 2005;). Using longitudinal methods, with specific age ranges, and cross-cultural samples likely holds promising information for the differential effects observed. Longitudinal studies will also help elucidate those factors which maintain perfectionism and those that act as risk factors. That is, examining the factors are instrumental in the etiology of perfectionism may guide prevention treatments to avert the development of perfectionism. Further, these studies would allow a better representation of when specific 
cognitive and affective factors influence the development of perfectionism most saliently. Currently, we lack knowledge on when certain cognitive factors become relevant. Similarly, research involving younger children under 7 years of age is vital to understand how perfectionism develops. Few studies have examined perfectionism in this age group. It is plausible that perfectionism manifests itself differently among this group than it does in adolescence and adulthood. This may also help clarify research showing that perfectionism changes for individuals within genders and ages (Hankin, 2005). Accurate conceptualizations of perfectionism in young children may provide insight as to when perfectionism begins to develop and the effects it has on cognitive and affect development.

Lastly, understanding the course and nature of perfectionism and its influence on related constructs will provide critical information to inform prevention and treatment of pediatric internalizing disorders. More specifically, few studies have differentiated between the effects of perfectionism in multiple disorders. For example, it is currently unknown whether different risk factors influence the effects of perfectionism on anxiety, worry, and depression. A child who has high levels of perfectionism and low levels of self-competence may show depression, hopelessness or suicidality. Whereas a child with high perfectionism and high intolerance of uncertainty may be more likely to pathologically worry. Further, the predictive power of perfectionism within each of these disorders, or clusters of symptoms, is currently unknown. Although research has shown that perfectionism negatively impacts child depression and anxiety treatment (Essau et al., 2008; Rogers et al., 2009), studies need to assess whether treatment targeted to pediatric perfectionism is efficacious (Flett \& Hewitt, 2014). Adult studies have begun to 
show this (Egan et al., 2014; Steele et al., 2013). Novel treatments, such as cognitive bias modification and mindfulness may also be successful at resolving perfectionism symptoms (Bar-Haim, 2010; Handorf, 2012; MacLeod \& Matthews, 2012). Given the nature of perfectionism, effective treatments and prevention may not only reduce the dysfunctional effects of perfectionism in children, but also may help treat pediatric internalizing disorders. 


\section{REFERENCES}

Affrunti, N. W., Geronimi, E. M. C., \& Woodruff-Borden J. (2015). Language of perfectionistic parents predicting child anxiety diagnostic status. Journal of Anxiety Disorders, 30, 94-102. doi: 10.1016/j.janxdis.2015.01.001

Affrunti, N. W., Gramszlo, C., \& Woodruff-Borden, J. (2016). Executive function moderates the association between fearful temperament and dimensions of perfectionism. Personality and Individual Differences, 89, 117-122. doi:

10.1016/j.paid.2015.10.012

Affrunti, N. W., \& Woodruff-Borden, J. (2014). Perfectionism in pediatric anxiety and depressive disorders. Clinical Child and Family Psychology Review, 17, 299-317. doi: 10.1007/s10567-014-0164-4

Affrunti, N. W., \& Woodruff-Borden, J. (2015). Parental Perfectionism and overcontrol: Examining mechanisms in the development of child anxiety. Journal of Abnormal Child Psychology, 43, 517-529. doi: 10.1007/s10802-014-9914-5

Affrunti, N. W. \& Woodruff-Borden, J. (2016). Negative affect and child internalizing symptoms: The mediating role of perfectionism. Child Psychiatry and Human Development, 47, 358-368. doi: 10.1007/s10578-015-0571-x

Aiken, L. S., \& West, S. G. (1991). Multiple regression: Testing and interpreting interactions. Newbury Park, CA: Sage. 
Albert, P., Rice, K. G., \& Caffee, L. (2014). Perfectionism affects blood pressure in response to repeated exposure to stress. Stress and Health, Advance online publication doi: 10.1002/smi.2591

Aldea, M. A., \& Rice, K. G. (2006). The role of emotional dysregulation in perfectionism and psychological distress. Journal of Counseling Psychology, 53, 498-510. doi: $10.1037 / 0022-0167.53 .4 .498$

Anthony, J. L., Lonigan, C. J., Hooe, E. S., \& Phillips, B. M. (2002). An affect-based, hierarchical model of temperament and its relations with internalizing symptomatology. Journal of Clinical Child and Adolescent Psychology, 31, 480490.

Antony, M. M., Purdon, C. L., Huta, V., \& Swinson, R. P. (1998). Dimensions of perfectionism across the anxiety disorders. Behaviour Research and Therapy, 36, 1143-1154. doi:10.1016/S0005-7967(98)00083-7

Asseraf, M., \& Vaillancourt, T. (2014). Longitudinal links between perfectionism and depression in children. Journal of Abnormal Child Psychology, Advance online publication doi: 10.1007/s10802-014-9947-9

Aycicegi-Dinn, A., Dinn, W. M., \& Caldwell-Harris, C. L. (2009). Obsessive-compulsive personality traits: compensatory response to executive function deficit?. International Journal of Neuroscience, 119, 600-608.

Bachner-Melman, R., Lerer, E., Zohar, A. H., Kremer, I., Elizur, Y., Nemanov, L., ... \& Ebstein, R. P. (2007). Anorexia nervosa, perfectionism, and dopamine D4 receptor (DRD4). American Journal of Medical Genetics Part B: Neuropsychiatric Genetics, 144, 748-756. 
Baddeley, A. D., \& Hitch, G. J. (1994). Developments in the concept of working memory. Neuropsychology, 8, 485-493. doi: 10.1037/0894-4105.8.4.485

Bandura, A., Grusec, J. E., \& Menlove, F. L. (1967). Some social determinants of selfmonitoring reinforcement systems. Journal of Personality and Social Psychology, 5, 449-455.

Bar-Haim, Y. (2010). Research review: Attention bias modification (ABM): A novel treatment for anxiety disorders. Journal of Child Psychology and Psychiatry, 51, 859-870.

Baron, R. M., \& Kenny, D. A. (1986). The moderator-mediator variable distinction in social psychological research: Conceptual, strategic, and statistical considerations. Journal of Personality and Social Psychology, 51, 1173-1182.

Beck, A. T. (1976). Cognitive therapy and the emotional disorders. New York: International Universitites Press.

Becker, K. D., Ginsburg, G. S., Domingues, J., \& Tein, J. Y. (2010). Maternal control behavior and locus of control: Examining mechanisms in the relation between maternal anxiety disorders and anxiety symptomatology in children. Journal of Abnormal Child Psychology, 38, 533-543.

Bell, M. A. (2012). A psychobiological perspective on working memory performance at 8 months of age. Child Development, 83, 251-265.

Bennett, J. (2000). Mediator and moderator variables in nursing research: Conceptual and statistical differences. Research in Nursing \& Health, 23, 415-420. 
Bernier, A., Carlson, S. M., \& Whipple, N. (2010). From external regulation to selfregulation: Early parenting precursors of young children's executive functioning. Child Development, 81, 326-339.

Besser, A., Flett, G. L., Hewitt, P. L., \& Guez, J. (2008). Perfectionism, and cognitions, affect, self-esteem, and physiological reactions in a performance situation. Journal of Rational-Emotive \& Cognitive-Behavior Therapy, 26, 206228.

Best, J. R., \& Miller, P. H. (2010). A developmental perspective on executive function. Child Development, 81, 1641-1660.

Bieling, P. J., Israeli, A. L., \& Antony, M. M. (2004). Is perfectionism good, bad, or both? Examining models of the perfectionism construct. Personality and Individual Differences, 36, 1373-1385.

Bieling, P. J., Israeli, A., Smith, J., \& Antony, M. M. (2003). Making the grade: The behavioural consequences of perfectionism in the classroom. Personality and Individual Differences, 35, 163-178.

Bieling, P. J., Summerfeldt, L. J., Israeli, A. L., \& Antony, M. M. (2004). Perfectionism as an explanatory construct in comorbidity of axis I disorders. Journal of Psychopathology and Behavioral Assessment, 26, 193-201.

Biran, M. W., \& Reese, C. (2007). Parental influences on social anxiety: The sources of perfectionism. Journal of the American Psychoanalytic Association, 55, 282-285.

Blair, C., Granger, D., \& Peters Razza, R. (2005). Cortisol reactivity is positively related to executive function in preschool children attending Head Start. Child Development, 76, 554-567. 
Blankstein, K. R., Lumley, C. H., \& Crawford, A. (2007). Perfectionism, hopelessness, and suicide ideation: Revisions to diathesis-stress and specific vulnerability models. Journal of Rational-Emotive \& Cognitive-Behavior Therapy, 25, 279319.

Blatt, S. J., Quinlan, D. M., Chevron, E. S., McDonald, C., \& Zuroff, D. (1982). Dependency and self-criticism: Psychological dimensions of depression. Journal of Consulting and Clinical Psychology, 50, 113-124.

Blatt, S. J., Quinlan, D. M., Pilkonis, P. A., \& Shea, M. T. (1995). Impact of perfectionism and need for approval on the brief treatment of depression: The National Institute of Mental Health treatment of depression collaborative research program revisited. Journal of Consulting and Clinical Psychology, 63, 125-132. doi:10.1037/0022-006X.63.1.125

Boelen, P. A., Vrinssen, I., \& van Tulder, F. (2010). Intolerance of uncertainty in adolescents: Correlations with worry, social anxiety, and depression. The Journal of Nervous and Mental Disease, 198, 194-200.

Boergers, J., Spirito, A., \& Donaldson, D. (1998). Reasons for adolescent suicide attempts: Associations with psychological functioning. Journal of the American Academy of Child \& Adolescent Psychiatry, 37, 1287-1293. doi:10.1097/00004583-199812000-00012

Bögels, S. M., \& van Melick, M. (2004). The relationship between child-report, parent self-report, and partner report of perceived parental rearing behaviors and anxiety in children and parents. Personality and Individual Differences, 37, 1583-1596. 
Boisseau, C. L., Thompson-Brenner, H., Pratt, E. M., Farchione, T. J., \& Barlow, D. H. (2013). The relationship between decision-making and perfectionism in obsessive-compulsive disorder and eating disorders. Journal of Behavior Therapy and Experimental Psychiatry, 44, 316-321.

Bouffard, T., Roy, M., \& Vezeau, C. (2005). Self-perceptions, temperament, socioemotional adjustment and the perceptions of parental support of chronically underachieving children. International Journal of Educational Research, 43, 215 235.

Brand, M., \& Altstötter-Gleich, C. (2008). Personality and decision-making in laboratory gambling tasks-Evidence for a relationship between deciding advantageously under risk conditions and perfectionism. Personality and Individual Differences, 45, 226-231.

Brocki, K. C., \& Bohlin, G. (2004). Executive functions in children aged 6 to 13: A dimensional and developmental study. Developmental Neuropsychology, 26, 571593.

Buhr, K., \& Dugas, M. J. (2006). Investigating the construct validity of intolerance of uncertainty and its unique relationship with worry. Journal of Anxiety Disorders, $20,222-236$.

Burt, K. B., Obradović, J., Long, J. D., \& Masten, A. S. (2008). The interplay of social competence and psychopathology over 20 years: Testing transactional and cascade models. Child Development, 79, 359-374. 
Calkins, S. D., \& Fox, N. A. (1992). The relations among infant temperament, security of attachment, and behavioral inhibition at 24 months. Child Development, 63, 14561472.

Calkins, S. D., \& Keane, S. P. (2004). Cardiac vagal regulation across the preschool period: Stability, continuity, and implications for childhood adjustment. Developmental Psychobiology, 45, 101-112.

Carlson, S. M. (2005). Developmentally sensitive measures of executive function in preschool children. Developmental Neuropsychology, 28 595-616

Castro, J., De Pablo, J., Gómez, J., Arrindell, W. A., \& Toro, J. (1997). Assessing rearing behaviour from the perspective of the parents: a new form of the EMBU. Social Psychiatry and Psychiatric Epidemiology, 32, 230-235.

Castro, J. R., \& Rice, K. G. (2003). Perfectionism and ethnicity: Implications for depressive symptoms and self-reported academic achievement. Cultural Diversity and Ethnic Minority Psychology, 9, 64-78. doi: 10.1037/1099-9809.9.1.64

Chang, E. C. (2000). Perfectionism as a predictor of positive and negative psychological outcomes: Examining a mediation model in younger and older adults. Journal of Counseling Psychology, 47, 18-26.

Chang, E. C., Zumberg, K. M., Sanna, L. J., Girz, L. P., Kade, A. M., Shair, S. R., . . . Srivastava, K. (2007). Relationship between perfectionism and domains of worry in a college student population: Considering the role of BIS/BAS motives. Personality and Individual Differences, 43(4), 925-936. 
Chin, W. W. (1998). The partial least squared approach to structural equation modeling. In G. A. Marcoulides (Ed.), Modern methods for business research (pp. 295-333). Mahwah, NJ: Lawrence Erlbaum Associates.

Chorpita, B. F., \& Barlow, D. H. (1998). The development of anxiety: The role of control in the early environment. Psychological Bulletin, 124, 3-21.

Cicchetti, D., \& Cohen, D.J. (1995). Perspectives on developmental psychopathology. In D. Cicchetti \& D. Cohen (Eds.), Developmental psychopathology: Vol. 1. Theory and methods (pp. 3-20). New York, NY: Wiley.

Cicchetti, D., \& Rogosch, F. A. (1996). Equifinality and multifinality in developmental psychopathology. Development and Psychopathology, 8, 597-600.

Clark, D. A. (2004). Cognitive-behavioral therapy for OCD. New York: Guilford Press.

Clark, S., \& Coker, S. (2009). Perfectionism, self-criticism and maternal criticism: A study of mothers and their children. Personality and Individual Differences, 47, 321-325.

Coles, M. E., Frost, R. O., Heimberg, R. G., \& Rhéaume, J. (2003). “Not just right experiences": Perfectionism, obsessive-compulsive features and general psychopathology. Behaviour Research and Therapy, 41, 681-700.

Coles, M. E., Frost, R. O., Heimberg, R. G., \& Steketee, G. (2003). Hoarding behaviors in a large college sample. Behaviour Research and Therapy, 41, 179-194.

Cook, L. C., \& Kearney, C. A. (2009). Parent and youth perfectionism and internalizing psychopathology. Personality and Individual Differences, 46, 325-330. 
Cook, L. C., \& Kearney, C. A. (2014). Parent perfectionism and psychopathology symptoms and child perfectionism. Personality and Individual Differences, 70, Advance online publication doi: 10.1016/j.paid.2014.06.020

Cowan, N., Saults, J. S., \& Elliott, E. M. (2002). The search for what is fundamental in the development of working memory. Advances in Child Development and Behavior, 29, 2-51.

Cox, B. J., Enns, M. W., \& Clara, I. P. (2002). The multidimensional structure of perfectionism in clinically distressed and college student samples. Psychological Assessment, 14, 365-373. doi:10.1037/1040-3590.14.3.365

Cox, B. J., Rector, N. A., Bagby, R. M., Swinson, R. P., Levitt, A. J., \& Joffe, R. T. (2000). Is self-criticism unique for depression? A comparison with social phobia. Journal of Affective Disorders, 57, 223-228.

Damian, L. E., Stoeber, J., Negru, O., \& Băban, A. (2013). On the development of perfectionism in adolescence: Perceived parental expectations predict longitudinal increases in socially prescribed perfectionism. Personality and Individual Differences, 55, 688-693.

Davidson, M. C., Amso, D., Anderson, L. C., \& Diamond, A. (2006). Development of cognitive control and executive functions from 4 to 13 years: Evidence from manipulations of memory, inhibition, and task switching. Neuropsychologia, 44, 2037-2078.

De Los Reyes, A., \& Kazdin, A. E. (2004). Measuring informant discrepancies in clinical child research. Psychological Assessment, 16, 330-334. 
de Minzi, M. C. R. (2006). Loneliness and depression in middle and late childhood: The relationship to attachment and parental styles. The Journal of Genetic Psychology, 167, 189-210.

Degnan, K. A., \& Fox, N. A. (2007). Behavioral inhibition and anxiety disorders: Multiple levels of a resilience process. Development and Psychopathology, 19, 729-746.

Derryberry, D., \& Rothbart, M. K. (1997). Reactive and effortful processes in the organization of temperament. Development and Psychopathology, 9, 633-652.

Diamond, A. (1985). Development of the ability to use recall to guide action, as indicated by infants' performance on A-not-B. Child Development, 868-883.

Diamond A. (1991). Neuropsychological insights into the meaning of object concept development. In S. Carey \& R. Gelman (Eds.), The Epigenesis of mind: Essays on biology and cognition (pp. 67-110). Hillsdale, NJ: Erlbaum.

Diamond, A. (1995). Evidence of robust recognition memory early in life even when assessed by reaching behavior. Journal of Experimental Child Psychology, 59, 419-456.

Diamond A. (2002). Normal development of prefrontal cortex from birth to young adulthood: cognitive functions, anatomy, and biochemistry. In D. T. Stuss \& R. T. Knight (Eds.), Principles of frontal lobe function (pp. 466-503). London: Oxford University Press

Diamond, A. (2012). Activities and programs that improve children's executive functions. Current Directions in Psychological Science, 21, 335-341.

Diamond, A. (2013). Executive functions. Annual Review of Psychology, 64, 135-168. 
Diamond, L. M., \& Aspinwall, L. G. (2003). Emotion regulation across the life span: An integrative perspective emphasizing self-regulation, positive affect, and dyadic processes. Motivation and Emotion, 27, 125-156.

Diamond, A., \& Taylor, C. (1996). Development of an aspect of executive control: Development of the abilities to remember what I said and to "Do as I say, not as I do". Developmental Psychobiology, 29, 315-334.

DiBartolo, P. M., \& Varner, S. P. (2012). How children's cognitive and affective responses to a novel task relate to the dimensions of perfectionism. Journal of Rational-Emotive \& Cognitive-Behavior Therapy, 30, 62-76.

DiBartolo, P. M., Frost, R. O., Chang, P., LaSota, M., \& Grills, A. E. (2004). Shedding light on the relationship between personal standards and psychopathology: The case for contingent self-worth. Journal of Rational-Emotive and CognitiveBehavior Therapy, 22, 237-250.

DiPrima, A. J., Ashby, J. S., Gnilka, P. B., \& Noble, C. L. (2011). Family relationships and perfectionism in middle-school students. Psychology in the Schools, 48, 815827.

Donaldson, D., Spirito, A., \& Farnett, E. (2000). The role of perfectionism and depressive cognitions in understanding the hopelessness experienced by adolescent suicide attempters. Child Psychiatry and Human Development, 31, 99-111. doi:10.1023/A:1001978625339

Downey, C. A., \& Chang, E. C. (2007). Perfectionism and symptoms of eating disturbances in female college students: Considering the role of negative affect and body dissatisfaction. Eating Behaviors, 8, 497-503. 
Dugas, M. J., Buhr, K., \& Ladouceur, R. (2004). The role of intolerance of uncertainty in etiology and maintenance. In R. G. Heimberg, C. L.Turk, \& D. S. Mennin (Eds.), Generalized anxiety disorder: Advances in research and practice (pp. 143-163). New York, NY: Guilford Press.

Dugas, M. J., Schwartz, A., \& Francis, K. (2004). Brief report: Intolerance of uncertainty, worry, and depression. Cognitive Therapy and Research, 28, 835-842.

Eaton, N. R., Krueger, R. F., Markon, K. E., Keyes, K. M., Skodol, A. E., Wall, M., ... \& Grant, B. F. (2013). The structure and predictive validity of the internalizing disorders. Journal of Abnormal Psychology, 122, 86-92.

Edwards, J. R., \& Lambert, L. S. (2007). Methods for integrating moderation and mediation: a general analytical framework using moderated path analysis. Psychological Methods, 12, 1-22.

Efron, B., \& Tibshirani, R. J. (1994). An introduction to the bootstrap. New York, NY: CRC Press.

Egan, S. J., van Noort, E., Chee, A., Kane, R. T., Hoiles, K. J., Shafran, R., \& Wade, T. D. (2014). A randomised controlled trial of face to face versus pure online selfhelp cognitive behavioural treatment for perfectionism. Behaviour Research and Therapy, 63, 107-113.

Egan, S. J., Wade, T. D., \& Shafran, R. (2011). Perfectionism as a transdiagnostic process: A clinical review. Clinical Psychology Review, 31, 203-212.

Eisenberg, N., Cumberland, A., Spinrad, T. L., Fabes, R. A., Shepard, S. A., Reiser, M., ... \& Guthrie, I. K. (2001). The relations of regulation and emotionality to 
children's externalizing and internalizing problem behavior. Child Development, 72, 1112-1134.

Eisenberg, N., \& Fabes, R. A. (1992). Emotion, regulation, and the development of social competence. In M. S. Glark (Ed.), Review of personality and social psychology: Vol. 14. Emotion and social behavior (pp. 119-150). Newbury Park, GA: Sage. Eisenberg, N., Fabes, R. A., Guthrie, I. K., Murphy, B. C., Maszk, P., Holmgren, R., \& Suh, K. (1996). The relations of regulation and emotionality to problem behavior in elementary school children. Development and Psychopathology, 8, 141-162.

Eisenberg, N., Fabes, R. A., Guthrie, I. K., \& Reiser, M. (2000). Dispositional emotionality and regulation: their role in predicting quality of social functioning. Journal of Personality and Social Psychology, 78, 136-157.

Eisenberg, N. \& Morris, A. M. (2002). Children's emotion-related regulation. In R. V. Kail (Ed.), Advances in child development and behavior (pp. 189-229). San Diego, CA: Academic Press.

Eisenberg, N., Sadovsky, A., Spinrad, T. L., Fabes, R. A., Losoya, S. H., Valiente, C., ... \& Shepard, S. A. (2005). The relations of problem behavior status to children's negative emotionality, effortful control, and impulsivity: concurrent relations and prediction of change. Developmental Psychology, 41, 193-211.

Eisenberg, N., Valiente, C., Spinrad, T. L., Cumberland, A., Liew, J., Reiser, M., ... \& Losoya, S. H. (2009). Longitudinal relations of children's effortful control, impulsivity, and negative emotionality to their externalizing, internalizing, and co-occurring behavior problems. Developmental Psychology, 45, 988-1008. 
Enns, M. W., Cox, B. J., \& Inayatulla, M. (2003). Personality predictors of outcome for adolescents hospitalized for suicidal ideation. Journal of the American Academy of Child \& Adolescent Psychiatry, 42, 720-727.

doi:10.1097/01.CHI.0000046847.56865.B0

Enns, M. W., Cox, B. J., Sareen, J., \& Freeman, P. (2001). Adaptive and maladaptive perfectionism in medical students: A longitudinal investigation. Medical Education, 35, 1034-1042. doi:10.1046/j.1365-2923.2001.01044.x

Erdfelder, E., Faul, F., \& Buchner, A. (1996). GPOWER: A general power analysis program. Behavior Research Methods, Instruments, \& Computers, 28, 1-11.

Essau, C. A., Conradt, J., Sasagawa, S., \& Ollendick, T. H. (2012). Prevention of anxiety symptoms in children: Results from a universal school-based trial. Behavior Therapy, 43, 450-464.

Essau, C. A., Leung, P. W. L., Conradt, J., Cheng, H., \& Wong, T. (2008). Anxiety symptoms in Chinese and German adolescents: Their relationship with early learning experiences, perfectionism, and learning motivation. Depression and Anxiety, 25, 801-810. doi:10.1002/da.20334

Evans, D. W., Leckman, J. F., Carter, A., Reznick, J. S., Henshaw, D., King, R. A., \& Pauls, D. (1997). Ritual, habit, and perfectionism: The prevalence and development of compulsive-like behavior in normal young children. Child Development, 68, 58-68.

Fan, X., Thompson, B., \& Wang, L. (1999). Effects of sample size, estimation methods, and model specification on structural equation modeling fit indexes. Structural Equation Modeling: A Multidisciplinary Journal, 6, 56-83. 
Feil, R. (2006). Environmental and nutritional effects on the epigenetic regulation of genes. Mutation Research/Fundamental and Molecular Mechanisms of Mutagenesis, 600, 46-57.

Fergus, T. A. (2014). Are "not just right experiences" (NJREs) specific to obsessivecompulsive symptoms?: Evidence that NJREs span across symptoms of emotional disorders. Journal of Clinical Psychology, 70, 353-363.

Ferrão, Y. A., Shavitt, R. G., Prado, H., Fontenelle, L. F., Malavazzi, D. M., de Mathis, M. A., ... \& do Rosario, M. C. (2012). Sensory phenomena associated with repetitive behaviors in obsessive-compulsive disorder: An exploratory study of 1001 patients. Psychiatry Research, 197, 253-258.

Ferris, C., Jacobsson, L., Lindstrom, H., von Knorring, L., \& Perris, H. (1980). Development of a new inventory for assessing memories of parental rearing behavior. Ada Psvchiatrica Scandinavica, 61, 265-274.

Flavell, J. H., Green, F. L., \& Flavell, E. R. (2004). Recent progress in cognitive developmental research: Implications for clinical practice. In H. Steiner (Ed.), Handbook of mental health interventions in children and adolescents: An integrated developmental approach (pp. 73-97). San Francisco: Jossey Bass.

Flett, G. L., Coulter, L., Hewitt, P. L., \& Nepon, T. (2011). Perfectionism, rumination, worry, and depressive symptoms in early adolescents. Canadian Journal of School Psychology, 26, 159-176. doi:10.1177/0829573511422039

Flett, G. L., Hewitt, P. L., Oliver, J. M., \& Macdonald, S. (2002). Perfectionism in children and their parents: A developmental analysis. In G. L. Flett \& P. L. Hewitt 
(Eds.), Perfectionism: Theory, research, and treatment (pp. 89-132). Washington, DC: American Psychological Association.

Flett, G. L., \& Hewitt, P. L. (1990). The Child-Adolescent Perfectionism Scale:

Development and association with measures of adjustment. In R. Frost (Chair), Perfectionism: Meaning, measurement, and relation to psychopathology.

Symposium conducted at the meeting of the Association for the Advancement of Behavior Therapy, San Francisco.

Flett, G. L., \& Hewitt, P. L. (2014). A proposed framework for preventing perfectionism and promoting resilience and mental health among vulnerable children and adolescents. Psychology in the Schools, 51, 899-912.

Flett, G. L., Molnar, D. S., Nepon, T., \& Hewitt, P. L. (2012). A mediational model of perfectionistic automatic thoughts and psychosomatic symptoms: The roles of negative affect and daily hassles. Personality and Individual Differences, 52, 565570.

Fox, N. A., \& Calkins, S. D. (2003). The development of self-control of emotion: Intrinsic and extrinsic influences. Motivation and emotion, 27, 7-26.

Fox, N. A. (1994). Dynamic cerebral process underlying emotion regulation. In N. A. Fox (Ed.), Emotion regulation: Behavioral and biological considerations, Monographs of the Society for Research in Child Development. Chicago, Ill: University of Chicago Press.

Fox, N. A. (1989). Psychophysiological correlates of emotional reactivity during the first year of life. Developmental Psychology, 25, 364-372. 
Frazier, P., Tix, A., \& Barron, K. (2004). Testing moderator and mediator effects in counseling psychology research. Journal of Counseling Psychology, 51, 115-134.

Frost, R. O., Heimberg, R. G., Holt, C. S., Mattia, J. I., \& Neubauer, A. L. (1993). A comparison of two measures of perfectionism. Personality and Individual Differences, 14, 119-126.

Frost, R. O., Lahart, C. M., \& Rosenblate, R. (1991). The development of perfectionism: A study of daughters and their parents. Cognitive Therapy and Research, 15(6), 469-489.

Frost, R. O., Marten, P., Lahart, C., \& Rosenblate, R. (1990). The dimensions of perfectionism. Cognitive Therapy and Research, 14(5), 449-468. doi:10.1007/BF01172967

Frost, R. O., \& Steketee, G. (2002). Cognitive approaches to obsessions and compulsions: Theory, assessment, and treatment. Oxford, UK: Elsevier.

Fry, A. F., \& Hale, S. (2000). Relationships among processing speed, working memory, and fluid intelligence in children. Biological Psychology, 54, 1-34.

Gable, S. L., Reis, H. T., \& Elliot, A. J. (2000). Behavioral activation and inhibition in everyday life. Journal of Personality and Social Psychology, 78, 1135-1149.

Gallagher, N. G., South, S. C., \& Oltmanns, T. F. (2003). Attentional coping style in obsessive-compulsive personality disorder: A test of the intolerance of uncertainty hypothesis. Personality and Individual Differences, 34, 41-57.

Garber, J. (2010). Vulnerability to depression in childhood and adolescence. In R. E. Ingram \& J. M. Price (Eds.), Vulnerability to psychopathology: Risk across the lifespan (pp. 189-247). New York: The Guilford Press. 
Garber, J., Robinson, N. S., \& Valentiner, D. (1997). The relation between parenting and adolescent depression self-worth as a mediator. Journal of Adolescent Research, 12, 12-33.

Garon, N., Bryson, S. E., \& Smith, I. M. (2008). Executive function in preschoolers: a review using an integrative framework. Psychological Bulletin, 134, 31-60.

Gartstein, M. A., \& Rothbart, M. K. (2003). Studying infant temperament via the revised infant behavior questionnaire. Infant Behavior and Development, 26, 64-86.

Gentes, E. L., \& Ruscio, A. M. (2011). A meta-analysis of the relation of intolerance of uncertainty to symptoms of generalized anxiety disorder, major depressive disorder, and obsessive-compulsive disorder. Clinical Psychology Review, 31, 923-933.

Ghisi, M., Chiri, L. R., Marchetti, I., Sanavio, E., \& Sica, C. (2010). In search of specificity: "Not just right experiences" and obsessive-compulsive symptoms in non-clinical and clinical Italian individuals. Journal of Anxiety Disorders, 24, $879-886$.

Ginsburg, G. S., Siqueland, L., Masia-Warner, C., \& Hedtke, K. A. (2005). Anxiety disorders in children: Family matters. Cognitive and Behavioral Practice, 11, 2843.

Glover, D. S., Brown, G. P., Fairburn, C. G., \& Shafran, R. (2007). A preliminary evaluation of cognitive-behaviour therapy for clinical perfectionism: A case series. British Journal of Clinical Psychology, 46, 85-94. 
Goldsmith, H. H., Buss, K. A., \& Lemery, K. S. (1997). Toddler and childhood temperament: expanded content, stronger genetic evidence, new evidence for the importance of environment. Developmental Psychology, 33(6), 891-905.

Graham, F. K., \& Kendall, B. S. (1960). Memory-for-designs test: Revised general manual. Perceptual and Motor Skills, 11, 147-188.

Granleese, J., \& Joseph, S. (1994). Reliability of the Harter Self-Perception Profile for Children and predictors of global self-worth. The Journal of Genetic Psychology, 155, 487-492.

Greisberg, S., \& McKay, D. (2003). Neuropsychology of obsessive-compulsive disorder: A review and treatment implications. Clinical Psychology Review, 23, 95-117.

Grills, A. E., \& Ollendick, T. H. (2002). Peer victimization, global self-worth, and anxiety in middle school children. Journal of Clinical Child and Adolescent Psychology, 31, 59-68.

Grolnick, W. S., \& Ryan, R. M. (1989). Parent styles associated with children's selfregulation and competence in school. Journal of Educational Psychology, 81, $143-154$

Gross, J. J. (1999). Emotion regulation: Past, present, future. Cognition \& Emotion, 13, $551-573$.

Grüner, K., Muris, P., \& Merckelbach, H. (1999). The relationship between anxious rearing behaviours and anxiety disorders symptomatology in normal children. Journal of Behavior Therapy and Experimental Psychiatry, 30, 27-35. 
Gunnar, M. R., Tout, K., de Haan, M., Pierce, S., \& Stanbury, K. (1997). Temperament, social competence, and adrenocortical activity in preschoolers. Developmental Psychobiology, 31, 65-85.

Hale, W. W., Engels, R., \& Meeus, W. (2006). Adolescent's perceptions of parenting behaviours and its relationship to adolescent Generalized Anxiety Disorder symptoms. Journal of Adolescence, 29, 407-417.

Hamachek, D. E. (1978). Psychodynamics of normal and neurotic perfectionism. Psychology: A Journal of Human Behavior, 15, 27-33.

Hamilton, T. K., \& Schweitzer, R. D. (2000). The cost of being perfect: Perfectionism and suicide ideation in university students. Australian and New Zealand Journal of Psychiatry, 34, 829-835. doi:10.1046/j.1440-1614.2000.00801.x

Handorf, A. (2012). Mindfulness and perfectionism. Discussions, 8(2). Retrieved from http://www.studentpulse.com/a?id=801

Hankin, B. L. (2005). Childhood maltreatment and psychopathology: Prospective tests of attachment, cognitive vulnerability, and stress as mediating processes. Cognitive Therapy and Research, 29, 645-671. doi:10.1007/s10608-005-9631-z

Harris, P. L., German, T., \& Mills, P. (1996). Children's use of counterfactual thinking in causal reasoning. Cognition, 61, 233-259.

Harris, S., Davies, M. F., \& Dryden, W. (2006). An experimental test of a core REBT hypothesis: Evidence that irrational beliefs lead to physiological as well as psychological arousal. Journal of Rational-Emotive \& Cognitive-Behavior Therapy, 24, 101-111. 
Harter, S. (1982). The perceived competence scale for children. Child Development, 53, 87-97.

Harvey, A. G., Watkins, E., Mansell, W., \& Shafran, R. (2004). Cognitive behavioural processes across psychological disorders: A transdiagnostic approach to research and treatment. Oxford, UK: Oxford University Press.

Hazen, E. P., Reichert, E. L., Piacentini, J. C., Miguel, E. C., Do Rosario, M. C., Pauls, D., \& Geller, D. A. (2008). Case series: Sensory intolerance as a primary symptom of pediatric OCD. Annals of Clinical Psychiatry, 20, 199-203.

Healey, D. M., Marks, D. J., \& Halperin, J. M. (2011). Examining the interplay among negative emotionality, cognitive functioning, and attention deficit/hyperactivity disorder symptom severity. Journal of the International Neuropsychological Society, 17, 502-510.

Heimberg, R. G., Juster, H. R., Hope, D. A., \& Mattia, J. I. (1995). Cognitive-behavioral group treatment: Description, case presentation, and empirical support. In M. Stein (Ed.), Social phobia: Clinical and research perspectives (pp. 293321). Washington, DC: American Psychiatric Press.

Herman, K. C., Trotter, R., Reinke, W. M., \& Ialongo, N. (2011). Developmental origins of perfectionism among African American youth. Journal of Counseling Psychology, 58, 321-334.

Herman, K. C., Wang, K., Trotter, R., Reinke, W. M., \& Ialongo, N. (2013). Developmental trajectories of maladaptive perfectionism among African American adolescents. Child Development, 84, 1633-1650. 
Hewitt, P. L., Caelian, C. F., Flett, G. L., Sherry, S. B., Collins, L., \& Flynn, C. A. (2002). Perfectionism in children: Associations with depression, anxiety, and anger. Personality and Individual Differences, 32(6), 1049-1061. doi:10.1016/S0191-8869(01)00109-X

Hewitt, P. L., \& Flett, G. L. (1991a). Perfectionism in the self and social contexts: Conceptualization, assessment, and association with psychopathology. Journal of Personality and Social Psychology, 60(3), 456-470. doi:10.1037/00223514.60.3.456

Hewitt, P. L., \& Flett, G. L. (1991b). Dimensions of perfectionism in unipolar depression. Journal of Abnormal Psychology, 100, 98-101.

Hewitt, P. L., Flett, G. L., \& Ediger, E. (1996). Perfectionism and depression: Longitudinal assessment of a specific vulnerability hypothesis. Journal of Abnormal Psychology, 105, 276-280.

Hewitt, P. L., Flett, G. L., Turnbull-Donovan, W., \& Mikail, S. F. (1991). The Multidimensional Perfectionism Scale: Reliability, validity, and psychometric properties in psychiatric samples. Psychological Assessment: A Journal of Consulting and Clinical Psychology, 3, 464-468. doi:10.1037/1040-3590.3.3.464

Hewitt, P. L., Newton, J., Flett, G. L., \& Callander, L. (1997). Perfectionism and suicide ideation in adolescent psychiatric patients. Journal of Abnormal Child Psychology, 25(2), 95-101. doi:10.1023/A:1025723327188

Hill, A. P., Hall, H. K., \& Appleton, P. R. (2010). Perfectionism and athlete burnout in junior elite athletes: The mediating role of coping tendencies. Anxiety, Stress, \& Coping, 23, 415-430. 
Hollender, M. H. (1978). Perfectionism, a neglected personality trait. The Journal of Clinical Psychiatry, 39, 384.

Hu, L. T., \& Bentler, P. M. (1999). Cutoff criteria for fit indexes in covariance structure analysis: Conventional criteria versus new alternatives. Structural Equation Modeling: A Multidisciplinary Journal, 6, 1-55.

Huggins, L., Davis, M. C., Rooney, R., \& Kane, R. (2008). Socially prescribed and selforiented perfectionism as predictors of depressive diagnosis in preadolescents. Australian Journal of Guidance and Counselling, 18, 182-194. doi:10.1375/ajgc.18.2.182

Hughes, C. (1998). Executive function in preschoolers: Links with theory of mind and verbal ability. British Journal of Developmental Psychology, 16, 233-253.

Huizinga, M., Dolan, C. V., \& van der Molen, M. W. (2006). Age-related change in executive function: Developmental trends and a latent variable analysis. Neuropsychologia, 44, 2017-2036.

Hymel, S., Rubin, K. H., Rowden, L., \& LeMare, L. (1990). Children's peer relationships: Longitudinal prediction of internalizing and externalizing problems from middle to late childhood. Child Development, 61, 2004-2021.

Izard, C. E. (2007). Basic emotions, natural kinds, emotion schemas, and a new paradigm. Perspectives on Psychological Science, 2, 260-280.

Jackson, T., Towson, S., \& Narduzzi, K. (1997). Predictors of shyness: A test of variables associated with self-presentational models. Social Behavior and Personality: An International Journal, 25, 149-153. 
Jacobs, R. H., Silva, S. G., Reinecke, M. A., Curry, J. F., Ginsburg, G. S., Kratochvil, C. J., \& March, J. S. (2009). Dysfunctional attitudes scale perfectionism: A predictor and partial mediator of acute treatment outcome among clinically depressed adolescents. Journal of Clinical Child \& Adolescent Psychology, 38(6), 803-813.

Kagan, J. (1997). Temperament and the reactions to unfamiliarity. Child Development, 68, 139-143.

Kamins, M. L., \& Dweck, C. S. (1999). Person versus process praise and criticism: Implications for contingent self-worth and coping. Developmental Psychology, 35, 835-847.

Kaye, M. P., Conroy, D. E., \& Fifer, A. M. (2008). Individual differences in incompetence avoidance. Journal of Sport \& Exercise Psychology, 30, 110-132.

Karreman, A., de Haas, S., van Tuijl, C., van Aken, M. A., \& Deković, M. (2010). Relations among temperament, parenting and problem behavior in young children. Infant Behavior and Development, 33, 39-49.

Kazdin, A. E., \& Peiti, T. A. (1982). Self-report and interview measures of childhood and adolescent depression. Journal of Child Psychology and Psychiatry, 23, 437-457.

Kempke, S., Van Houdenhove, B., Luyten, P., Goossens, L., Bekaert, P., \& Van Wambeke, P. (2011). Unraveling the role of perfectionism in chronic fatigue syndrome: Is there a distinction between adaptive and maladaptive perfectionism?. Psychiatry Research, 186, 373-377.

Kendall, P. C. (1994). Treating anxiety disorders in children: results of a randomized clinical trial. Journal of Consulting and Clinical Psychology, 62, 100-110. 
Kendler, K. S., Aggen, S. H., Knudsen, G. P., Røysamb, E., Neale, M. C., \& ReichbornKjennerud, T. (2011). The structure of genetic and environmental risk factors for syndromal and subsyndromal common DSM-IV axis I and all axis II disorders. Structure, 168, 29-39.

Kenney-Benson, G. A., \& Pomerantz, E. M. (2005). The role of mothers' use of control in children's perfectionism: Implications for the development of children's depressive symptoms. Journal of Personality, 73, 23-46.

Kertz, S. J., \& Woodruff-Borden, J. (2011). The developmental psychopathology of worry. Clinical Child and Family Psychology Review, 14, 174-197.

Kessler, R. C., Chiu, W. T., Demler, O., \& Walters, E. E. (2005). Prevalence, severity, and comorbidity of 12-month DSM-IV disorders in the National Comorbidity Survey Replication. Archives of General Psychiatry, 62, 617-627.

Kinzl, J. F., Traweger, C., Guenther, V., \& Biebl, W. (1994). Family background and sexual abuse associated with eating disorders. American Journal of Psychiatry, $151,1127-1131$.

Kline, R. B. (2011). Principles and Practice of Structural Equation Modeling ( $3^{\text {rd }}$ ed.). New York, NY: Guilford Press

Kobori, O., Yamagata, S., \& Kijima, N. (2005). The relationship of temperament to multidimensional perfectionism trait. Personality and Individual Differences, 38, 203-211.

Kochanska, G., \& Knaack, A. (2003). Effortful control as a personality characteristic of young children: Antecedents, correlates, and consequences. Journal of Personality, 71, 1087-1112. 
Kochanska, G., Murray, K. T., \& Harlan, E. T. (2000). Effortful control in early childhood: continuity and change, antecedents, and implications for social development. Developmental Psychology, 36, 220-232.

Kotelnikova, Y., Mackrell, S. V., Jordan, P. L., \& Hayden, E. P. (2014). Longitudinal associations between reactive and regulatory temperament traits and depressive symptoms in middle childhood. Journal of Clinical Child \& Adolescent Psychology, 44, 775-786.

Kopp, C. B. (1989). Regulation of distress and negative emotions: A developmental view. Developmental Psychology, 25, 343-354.

Kupersmidt, J. B., \& Patterson, C. J. (1991). Childhood peer rejection, aggression, withdrawal, and perceived competence as predictors of self-reported behavior problems in preadolescence. Journal of Abnormal Child Psychology, 19, 427-449.

Lagattuta, K. H. (2007). Thinking about the future because of the past: Young children's knowledge about the causes of worry and preventative decisions. Child Development, 78, 1492-1509.

Lauer, C. J. (2002). Neuropsychological findings in eating disorders. In: H. D’haenen, J. A. den Boer, H. Westenberg, P. Willner (Eds.), Biological Psychiatry (pp. 11671172). Swansey, UK: John Wiley and Sons.

Leckman, J. F., Walker, D. E., Goodman, W. K., Pauls, D. L., \& Cohen, D. J. (1994). "Just right" perceptions associated with compulsive behavior in Tourette's syndrome. American Journal of Psychiatry, 151, 675-680. 
Leekam, S., Tandos, J., McConachie, H., Meins, E., Parkinson, K., Wright, C., ... \& Couteur, A. L. (2007). Repetitive behaviours in typically developing 2-yearolds. Journal of Child Psychology and Psychiatry, 48, 1131-1138.

Lehto, J. E., \& Uusitalo, A. K. (2006). Rule detection in preschool-aged children. European Journal of Developmental Psychology, 3, 209-221.

Lengua, L. J. (2008). Anxiousness, Frustration, and Effortful Control as Moderators of the relation between Parenting and Adjustment in Middle-childhood. Social Development, 17, 554-577.

Lengua, L. J., Honorado, E., \& Bush, N. R. (2007). Contextual risk and parenting as predictors of effortful control and social competence in preschool children. Journal of Applied Developmental Psychology, 28, 40-55.

Leon, G. R., Kendall, P. C., \& Garber, J. (1980). Depression in children: Parent, teacher, and child perspectives. Journal of Abnormal Child Psychology, 8, 221-235. doi:10.1007/BF00919066

Lewis, M. (2008). The emergence of human emotion. In M. Lewis, J. M. Haviland-Jones, \& L. F. Barrett (Eds.), Handbook of emotions (3rd ed., pp. 304-319). New York: Guilford.

Libby, S., Reynolds, S., Derisley, J., \& Clark, S. (2004). Cognitive appraisals in young people with obsessive-compulsive disorder. Journal of Child Psychology and Psychiatry, 45, 1076-1084.

Lonigan, C. J., \& Vasey, M. W. (2009). Negative affectivity, effortful control, and attention to threat-relevant stimuli. Journal of Abnormal Child Psychology, 37, 387-399. 
Luciana, M., Conklin, H. M., Hooper, C. J., \& Yarger, R. S. (2005). The development of nonverbal working memory and executive control processes in adolescents. Child Development, 76, 697-712.

Lundh, L., \& Öst, L. (1996). Stroop interference, self-focus and perfectionism in social phobics. Personality and Individual Differences, 20, 725-731. doi:10.1016/01918869(96)00008-6

MacKinnon, D. P., Lockwood, C. M., Hoffman, J. M., West, S. G., \& Sheets, V. (2002). A comparison of methods to test mediation and other intervening variable effects. Psychological Methods, 7, 83-104.

MacLeod, C., \& Mathews, A. (2012). Cognitive bias modification approaches to anxiety. Annual Review of Clinical Psychology, 8, 189-217.

Maloney, G. K., Egan, S. J., Kane, R. T., \& Rees, C. S. (2014). An Etiological Model of Perfectionism. PloS one, 9(5), e94757.

Masten, A. S., \& Coatsworth, J. D. (1998). The development of competence in favorable and unfavorable environments: Lessons from research on successful children. American Psychologist, 53, 205-220.

Masten, A. S., Burt, K. B., \& Coatsworth, J. D. (2006). Competence and psychopathology in development. In D. Cicchetti \& D. J. Cohen (Eds.), Developmental psychopathology, Vol. 3: Risk, disorder, and adaptation (pp. 696738). Hoboken, NJ: John Wiley \& Sons Inc.

Maxwell, S. E., \& Cole, D. A. (2007). Bias in cross-sectional analyses of longitudinal mediation. Psychological Methods, 12, 23-44. 
McArdle, S. (2010). Exploring domain-specific perfectionism. Journal of Personality, 78, 493-508.

McCreary, B. T., Joiner, T. E., Schmidt, N. B., \& Ialongo, N. S. (2004). The structure and correlates of perfectionism in African American children. Journal of Clinical Child and Adolescent Psychology, 33, 313-324.

doi:10.1207/s15374424jecp3302_13

McHugh, M. L. (2012). Interrater reliability: The kappa statistic. Biochemia Medica, 22, 276-282.

McVey, G. L., Pepler, D., Davis, R., Flett, G. L., \& Abdolell, M. (2002). Risk and protective factors associated with disordered eating during early adolescence. The Journal of Early Adolescence, 22, 75-95.

Melnick, S. M., \& Hinshaw, S. P. (2000). Emotion regulation and parenting in AD/HD and comparison boys: Linkages with social behaviors and peer preference. Journal of Abnormal Child Psychology, 28, 73-86.

Messer, S. C., \& Beidel, D. C. (1994). Psychosocial correlates of childhood anxiety disorders. Journal of the American Academy of Child \& Adolescent Psychiatry, 33, 975-983.

Meyers, J. E., \& Meyers, K. R. (1995). Rey Complex Figure Test under four different administration procedures. The Clinical Neuropsychologist, 9, 63-67.

Mezulis, A. H., Hyde, J. S., \& Abramson, L. Y. (2006). The developmental origins of cognitive vulnerability to depression: Temperament, parenting, and negative life events in childhood as contributors to negative cognitive style. Developmental Psychology, 42, 1012-1025. 
Miguel, E. C., Rosario-Campos, M. C., Prado, H. D., Valle, R., Rauch, S. L., Coffey, ... \& Leckman, J. F. (2000). Sensory phenomena in obsessive-compulsive disorder and Tourette's Disorder. Journal of Clinical Psychiatry, 61, 150-156.

Miller-Day, M., \& Marks, J. D. (2006). Perceptions of parental communication orientation, perfectionism, and disordered eating behaviors of sons and daughters. Health Communication, 19, 153-163.

Missildine, W. H. (1963). Your inner child of the past. New York: Simon and Schuster. Mitchell, J. H., Broeren, S., Newall, C., \& Hudson, J. L. (2013a). An experimental manipulation of maternal perfectionistic anxious rearing behaviors with anxious and non-anxious children. Journal of Experimental Child Psychology. Advance online publication doi:10.1016/j.jecp.2012.12.006

Mitchell, J. H., Newall, C., Broeren, S., \& Hudson, J. L. (2013b). The role of perfectionism in cognitive behaviour therapy outcomes for clinically anxious children. Behaviour Research and Therapy. Advance online publication doi: 10.1016/j.brat.2013.05.015

Miyake, A., Friedman, N. P., Emerson, M. J., Witzki, A. H., Howerter, A., \& Wager, T. D. (2000). The unity and diversity of executive functions and their contributions to complex "frontal lobe" tasks: A latent variable analysis. Cognitive Psychology, 41, 49-100.

Morasch, K. C., \& Bell, M. A. (2011). The role of inhibitory control in behavioral and physiological expressions of toddler executive function. Journal of Experimental Child Psychology, 108, 593-606. 
Moretz, M. W., \& McKay, D. (2009). The role of perfectionism in obsessive-compulsive symptoms: "Not just right" experiences and checking compulsions. Journal of Anxiety Disorders, 23, 640-644.

Morris, A. S., Silk, J. S., Steinberg, L., Myers, S. S., \& Robinson, L. R. (2007). The role of the family context in the development of emotion regulation. Social Development, 16, 361-388.

Mueller, C. M., \& Dweck, C. S. (1998). Praise for intelligence can undermine children's motivation and performance. Journal of Personality and Social Psychology, 75, $33-52$.

Muris, P., Meesters, C., \& van Brakel, A. (2003). Assessment of anxious rearing behaviors with a modified version of "Egna Minnen Beträffande Uppfostran" questionnaire for children. Journal of Psychopathology and Behavioral Assessment, 25, 229-237.

Muris, P., van Brakel, A. M., Arntz, A., \& Schouten, E. (2011). Behavioral inhibition as a risk factor for the development of childhood anxiety disorders: A longitudinal study. Journal of Child and Family Studies, 20, 157-170.

Murray, K. T., \& Kochanska, G. (2002). Effortful control: Factor structure and relation to externalizing and internalizing behaviors. Journal of Abnormal Child Psychology, 30, 503-514.

Neal, M., \& Cavanna, A. E. (2013). "Not just right experiences" in patients with Tourette syndrome: Complex motor tics or compulsions?. Psychiatry Research, 210, 559563. 
Nigg, J. T. (2006). Temperament and developmental psychopathology. Journal of Child Psychology and Psychiatry, 47, 395-422.

Nobel, R., Manassis, K., \& Wilansky-Traynor, P. (2012). The role of perfectionism in relation to an intervention to reduce anxious and depressive symptoms in children. Journal of Rational-Emotive \& Cognitive-Behavior Therapy, 30, 77-90.

O’Connor, R. C., \& Forgan, G. (2007). Suicidal thinking and perfectionism: The role of goal adjustment and behavioral inhibition/activation systems (BIS/BAS).Journal of Rational-Emotive \& Cognitive-Behavior Therapy, 25, 321-341.

O'Connor, R. C., Rasmussen, S., \& Hawton, K. (2010). Predicting depression, anxiety and self-harm in adolescents: The role of perfectionism and acute life stress. Behaviour Research and Therapy, 48, 52-59.

Oldehinkel, A. J., Hartman, C. A., Ferdinand, R. F., Verhulst, F. C., \& Ormel, J. (2007). Effortful control as modifier of the association between negative emotionality and adolescents' mental health problems. Development and Psychopathology, 19, 523539.

Ormel, J., Oldehinkel, A. J., Ferdinand, R. F., Hartman, C. A., De Winter, A. F., Veenstra, R., ... \& Verhulst, F. C. (2005). Internalizing and externalizing problems in adolescence: General and dimension-specific effects of familial loadings and preadolescent temperament traits. Psychological Medicine, 35, $1825-1835$.

Pacht, A. R. (1984). Reflections on perfection. American Psychologist, 39, 386-390. 
Pardini, D. A. (2008). Novel insights into longstanding theories of bidirectional parentchild influences: Introduction to the special section. Journal of Abnormal Child Psychology, 36, 627-631.

Paulussen-Hoogeboom, M. C., Stams, G. J. J., Hermanns, J. M., Peetsma, T. T., \& van den Wittenboer, G. L. (2008). Parenting style as a mediator between children's negative emotionality and problematic behavior in early childhood. The Journal of Genetic Psychology, 169, 209-226.

Porges, S. W., Doussard-Roosevelt, J. A., \& Maiti, A. K. (1994). Vagal tone and the physiological regulation of emotion. Monographs of the Society for Research in Child Development, 59, 167-186.

Posner, M. I. \& DiGirolamo, G. J. (1998). Executive attention: Conflict, target detection, and cognitive control. In R. Parasuraman (Ed.), The attentive brain (pp. 401-423). Cambridge, MA: MIT Press.

Povinelli, D. J., Landau, K. R., \& Perilloux, H. K. (1996). Self-recognition in young children using delayed versus live feedback: Evidence of a developmental asynchrony. Child Development, 67, 1540-1554.

Preacher, K. J., \& Hayes, A. F. (2008). Asymptotic and resampling strategies for assessing and comparing indirect effects in multiple mediator models. Behavior research methods, 40, 879-891.

Randles, D., Flett, G. L., Nash, K. A., McGregor, I. D., \& Hewitt, P. L. (2010). Dimensions of perfectionism, behavioral inhibition, and rumination. Personality and Individual Differences, 49, 83-87. 
Rennie, D. A., Bull, R., \& Diamond, A. (2004). Executive functioning in preschoolers: Reducing the inhibitory demands of the dimensional change card sort task. Developmental Neuropsychology, 26, 423-443.

Reuther, E. T., Davis, T. E., Rudy, B. M., Jenkins, W. S., Whiting, S. E., \& May, A. C. (2013). Intolerance of uncertainty as a mediator of the relationship between perfectionism and obsessive-compulsive symptom severity. Depression and Anxiety, 30, 773-777.

Rhéaume, J., Freeston, M. H., Ladouceur, R., Bouchard, C., Gallant, L., Talbot, F., \& Vallières, A. (2000). Functional and dysfunctional perfectionists: are they different on compulsive-like behaviors?. Behaviour Research and Therapy, 38, $119-128$.

Rice, K. G., Ashby, J. S., \& Slaney, R. B. (1998). Self-esteem as a mediator between perfectionism and depression: A structural equations analysis. Journal of Counseling Psychology, 45, 304-314.

Rice, K. G., Choi, C. C., Zhang, Y., Morero, Y. I., \& Anderson, D. (2012). Self-critical perfectionism, acculturative stress, and depression among international students. The Counseling Psychologist, 40, 575-600.

Rice, K. G., Leever, B. A., Noggle, C. A., \& Lapsley, D. K. (2007). Perfectionism and depressive symptoms in early adolescence. Psychology in the Schools, 44, 139156.

Rice, K. G., \& Slaney, R. B. (2002). Clusters of perfectionists: Two studies of emotional adjustment and academic achievement. Measurement and Evaluation in Counseling and Development, 35, 35-48. 
Rimm-Kaufman, S. E., \& Kagan, J. (2005). Infant predictors of kindergarten behavior: The contribution of inhibited and uninhibited temperament types. Behavioral Disorders, 30, 331-347.

Rogers, G. M., Park, J., Essex, M. J., Klein, M. H., Silva, S. G., Hoyle, R. H., . . . Kratochvil, C. J. (2009). The Dysfunctional Attitudes Scale: Psychometric properties in depressed adolescents. Journal of Clinical Child \& Adolescent Psychology, 38, 781-789.

Rothbart, M. K. (1986). Longitudinal observation of infant temperament. Developmental Psychology, 22, 356-365.

Rothbart, M. K. (2011). Becoming who we are: Temperament and personality in development. New York: Guilford Press.

Rothbart, M. K., Ahadi, S. A., Hershey, K. L., \& Fisher, P. (2001). Investigations of temperament at three to seven years: The Children's Behavior Questionnaire. Child Development, 72, 1394-1408.

Rothbart, M. K., Derryberry, D., and Posner, M. I. (1994). A psychobiological approach to the development of temperament. In J. E. Bates \& T. D. Wachs (Eds.), Temperament: Individual differences at the interface of biology and behavior (pp. 83-116). Washington, DC: American Psychological Association.

Rothbart, M. K., Ellis, L. K., and Posner, M. I. (2004). Temperament and self-regulation. In K. D. Vohs \& R. F. Baumeister (Eds.), Handbook of self-regulation, second edition: Research, theory, and applications (pp. 441-460). New York, NY: Guilford Press. 
Rothbart, M. K., Sheese, B. E., \& Posner, M. I. (2007). Executive attention and effortful control: Linking temperament, brain networks, and genes. Child Development Perspectives, 1, 2-7.

Rudolph, S. G., Flett, G. L., \& Hewitt, P. L. (2007). Perfectionism and deficits in cognitive emotion regulation. Journal of Rational-Emotive \& Cognitive-Behavior Therapy, 25, 343-357.

Rutter, M., Kim-Cohen, J., \& Maughan, B. (2006). Continuities and discontinuities in psychopathology between childhood and adult life. Journal of Child Psychology and Psychiatry, 47, 276-295.

Saarni, C., Mumme, D., \& Campos, J. (1998). Emotional development: Action, communication, and understanding. In W. Damon \& N. Eisenberg (Eds.), Handbook of child psychology: Vol. 3. Social, emotional, and personality development (5th ed., pp. 237-311). New York, NY: Wiley.

Sabbagh, M. A., Xu, F., Carlson, S. M., Moses, L. J., \& Lee, K. (2006). The development of executive functioning and theory of mind a comparison of Chinese and US preschoolers. Psychological Science, 17, 74-81.

Sallquist, J. V., Eisenberg, N., Spinrad, T. L., Reiser, M., Hofer, C., Zhou, Q., ... \& Eggum, N. (2009). Positive and negative emotionality: trajectories across six years and relations with social competence. Emotion, 9, 15-28.

Sassaroli, S., Romero Lauro, L. J., Maria Ruggiero, G., Mauri, M. C., Vinai, P., \& Frost, R. (2008). Perfectionism in depression, obsessive-compulsive disorder and eating disorders. Behaviour Research and Therapy, 46, 757-765. 
Shafran, R., Cooper, Z., \& Fairburn, C. G. (2002). Clinical perfectionism: A cognitivebehavioural analysis. Behaviour Research and Therapy, 40, 773-791.

Shafran, R., Lee, M., \& Fairburn, C. G. (2004). Clinical perfectionism: A case report. Behavioural and Cognitive Psychotherapy, 32, 353-357.

Shelton, K. K., Frick, P. J., \& Wootton, J. (1996). Assessment of parenting practices in families of elementary school-age children. Journal of Clinical Child Psychology, 25, 317-329.

Simonds, J., Kieras, J. E., Rueda, M. R., \& Rothbart, M. K. (2007). Effortful control, executive attention, and emotional regulation in 7-10-year-old children. Cognitive Development, 22, 474-488.

Simonds, J., \& Rothbart, M. K. (2004). The temperament in middle childhood questionnaire (TMCQ): A computerized self-report measure of temperament for ages 7-10. Poster Session Presented at the Occasional Temperament Conference, Athens, GA.

Slade, P. D., Coppel, D. B., \& Townes, B. D. (2009). Neurocognitive correlates of positive and negative perfectionism. International Journal of Neuroscience, 119, $1741-1754$.

Slaney, R. B., \& Ashby, J. S. (1996). Perfectionists: Study of a criterion group. Journal of Counseling \& Development, 74, 393-398.

Smith, E. E., \& Jonides, J. (1999). Storage and executive processes in the frontal lobes. Science, 283, 1657-1661. 
Sobel, M. E. (1982). Asymptotic confidence intervals for indirect effects in structural equation models. In S. Leinhart (Ed.), Sociological methodology 1982 (pp. 290312). San Francisco, CA: Jossey-Bass

Soenens, B., Elliot, A. J., Goossens, L., Vansteenkiste, M., Luyten, P., \& Duriez, B. (2005). The intergenerational transmission of perfectionism: Parents' psychological control as an intervening variable. Journal of Family Psychology, 19, 358-366.

Soenens, B., Luyckx, K., Vansteenkiste, M., Luyten, P., Duriez, B., \& Goossens, L. (2008). Maladaptive perfectionism as an intervening variable between psychological control and adolescent depressive symptoms: a three-wave longitudinal study. Journal of Family Psychology, 22, 465-474.

Soreni, N., Streiner, D., McCabe, R., Bullard, C., Swinson, R., Greco, A., ... \& Szatmari, P. (2014). Dimensions of perfectionism in children and adolescents with obsessive-compulsive disorder. Journal of the Canadian Academy of Child and Adolescent Psychiatry, 23, 136-143.

Sowislo, J. F., \& Orth, U. (2013). Does low self-esteem predict depression and anxiety? A meta-analysis of longitudinal studies. Psychological Bulletin, 139, 213-240.

Steele, A. L., Waite, S., Egan, S. J., Finnigan, J., Handley, A., \& Wade, T. D. (2013). Psycho-education and group cognitive-behavioural therapy for clinical perfectionism: a case-series evaluation. Behavioural and Cognitive Psychotherapy, 41, 129-143.

Steinberg, L. (2005). Cognitive and affective development in adolescence. Trends in Cognitive Sciences, 9, 69-74. 
Stornelli, D., Flett, G. L., \& Hewitt, P. L. (2009). Perfectionism, achievement, and affect in children: A comparison of students from gifted, arts, and regular programs. Canadian Journal of School Psychology, 24, 267-283. doi:10.1177/0829573509342392

Stright, A. D., Gallagher, K. C., \& Kelley, K. (2008). Infant temperament moderates relations between maternal parenting in early childhood and children's adjustment in first grade. Child Development, 79, 186-200.

Sullivan, P. J., Keller, M., Paternostro, J., \& Friedberg, R. D. (2015). Treating emotionally dysregulated and perfectionistic youth with transdiagnostic cognitive behavioral procedures. Journal of Contemporary Psychotherapy, 45, 151-158.

Tangney, J. P. (2002). Perfectionism and the self-conscious emotions: Shame, guilt, embarrassment, and pride. In G. L. Flett \& P. L. Hewitt (Eds.), Perfectionism: Theory, research, and treatment (pp. 199-215). Washington, DC: American Psychological Association.

Tangney, J. P., Baumeister, R. F., \& Boone, A. L. (2004). High self-control predicts good adjustment, less pathology, better grades, and interpersonal success. Journal of Personality, 72, 271-324.

Taylor, S., Afifi, T. O., Stein, M. B., Asmundson, G. J., \& Jang, K. L. (2010). Etiology of obsessive beliefs: A behavioral-genetic analysis. Journal of Cognitive Psychotherapy, 24, 177-186.

Tchanturia, K., Morris, R., Anderluh, M. B., Collier, D. A., Nikolaou, V., \& Treasure, J. (2004). Set shifting in anorexia nervosa: An examination before and after weight 
gain, in full recovery and relationship to childhood and adult OCPD traits. Journal of Psychiatric Research, 38, 545-552.

Thompson, R. A. (1994). Emotion regulation: A theme in search of definition. Monographs of the Society for Research in Child Development, 59, 25-52.

Thornton, L. M., Mazzeo, S. E., Bulik, C. M. (2011). The heritability of eating disorders: Methods and current findings. Current Topics in Behavioral Neuroscience, 6 , 141-156. doi: 10.1007/7854_2010_91

Tobin, D. L., \& Griffing, A. S. (1996). Coping, sexual abuse, and compensatory behavior. International Journal of Eating Disorders, 20, 143-148.

Tolin, D. F., Abramowitz, J. S., Brigidi, B. D., \& Foa, E. B. (2003). Intolerance of uncertainty in obsessive-compulsive disorder. Journal of Anxiety Disorders, 17, $233-242$.

Tozzi, F., Aggen, S. H., Neale, B. M., Anderson, C. B., Mazzeo, S. E., Neale, M. C., \& Bulik, C. M. (2004). The structure of perfectionism: A twin study. Behavior Genetics, 34, 483-494.

Turner, L. A., \& Turner, P. E. (2011). The relation of behavioral inhibition and perceived parenting to maladaptive perfectionism in college students. Personality and Individual Differences, 50, 840-844.

Ursache, A., Blair, C., Stifter, C., \& Voegtline, K. (2013). Emotional reactivity and regulation in infancy interact to predict executive functioning in early childhood. Developmental Psychology, 49, 127-137.

Van de Mortel, T. F. (2008). Faking it: Social desirability response bias in self-report research. Australian Journal of Advanced Nursing, 25, 40-48. 
Vasey, M. W., \& Dadds, M. R. (2001). The developmental psychopathology of anxiety. New York, NY: Oxford University Press.

Verstraeten, K., Vasey, M. W., Raes, F., \& Bijttebier, P. (2009). Temperament and risk for depressive symptoms in adolescence: Mediation by rumination and moderation by effortful control. Journal of Abnormal Child Psychology, 37, 349361.

Vieth, A. Z., \& Trull, T. J. (1999). Family patterns of perfectionism: An examination of college students and their parents. Journal of Personality Assessment, 72, 49-67.

Wade, T. D., Tiggemann, M., Bulik, C. M., Fairburn, C. G., Wray, N. R., \& Martin, N. G. (2008). Shared temperament risk factors for anorexia nervosa: a twin study. Psychosomatic Medicine, 70, 239-244.

Wallace, M., \& Rabin, A. I. (1960). Temporal experience. Psychological Bulletin, 57, 213-236.

Wheeler, H. A., Blankstein, K. R., Antony, M. M., McCabe, R. E., \& Bieling, P. J. (2011). Perfectionism in anxiety and depression: Comparisons across disorders, relations with symptom severity, and role of comorbidity. International Journal of Cognitive Therapy, 4, 66-91.

Wirtz, P. H., Elsenbruch, S., Emini, L., Rüdisüli, K., Groessbauer, S., \& Ehlert, U. (2007). Perfectionism and the cortisol response to psychosocial stress in men. Psychosomatic Medicine, 69, 249-255.

Wood, J. J., McLeod, B. D., Sigman, M., Hwang, W. C., \& Chu, B. C. (2003). Parenting and childhood anxiety: Theory, empirical findings, and future directions. Journal of Child Psychology and Psychiatry, 44, 134-151. 
Ye, H. J., Rice, K. G., \& Storch, E. A. (2008). Perfectionism and peer relations among children with obsessive-compulsive disorder. Child Psychiatry and Human Development, 39, 415-426. doi:10.1007/s10578-008-0098-5

Zelazo, P. D., Frye, D., \& Rapus, T. (1996). An age-related dissociation between knowing rules and using them. Cognitive Development, 11, 37-63.

Zeman, J., Penza, S., Shipman, K., \& Young, G. (1997). Preschoolers as functionalists: The impact of social context on emotion regulation. Child Study Journal, 27, 4167.

Zhao, X., Lynch, J. G., \& Chen, Q. (2010). Reconsidering Baron and Kenny: Myths and truths about mediation analysis. Journal of Consumer Research, 37, 197-206.

Zlomke, K. R., \& Young, J. N. (2009). A retrospective examination of the role of parental anxious rearing behaviors in contributing to intolerance of uncertainty. Journal of Child and Family Studies, 18, 670-679. 
APPENDIX A 
Figure copy task instructions

Instructions to child:

I am going to show you some pictures. I want you to copy them so that your drawing looks like the picture I show you. Copy only what is inside the boxes. Try to make everything the same: the same size, the same shape, and the same design. There are 3 groups of pictures. I will give you 1 group of pictures at a time. After you have finished all the pictures in a group, let me know, and I will give you the next group.

You can use these pencils and paper to draw the picture. I will also give you some erasers and rulers to use however you want to. You can use them to help you draw your picture, but you don't have to use them.

The drawings will be marked later on to see how much your drawing looks like my picture, and to see how you do compared to other children your age. But I can't tell you how you do today. I will need to videotape today's task so that what you do can be watched later on. Do you have any questions?

Remember, I'd like you to copy these pictures so that your drawing looks like the pictures I show you. Copy only what is in the box. You can use rulers and erasers however you want, but you don't have to use them. I will time you and let you know when your time is up. Let me know if you finish before the time is up. Okay, ready? Go.

[start the timer]

Instructions for the examiner:

*If the child does not complete all pictures from that trial, stop the trial after 3 minutes.

*If the child does complete all pictures from a trial, note the time it took for them to complete the trial.

Remove the old pictures, present the next trial's pictures. Make sure the child is ready, tell him/her to begin and start the timer. 


\section{CAPS}

This is a chance to find out about yourself. It is not a test. There are no right answers and everyone will have different answers. Be sure that your answers show how you actually are. Please do not talk about your answers with anyone else. We will keep your answers private and not show them to anyone.

When you are ready to begin, please read each sentence below and pick your answer by circling a number from " 1 " to " 5 ". The five possible answers for each sentence are listed below.

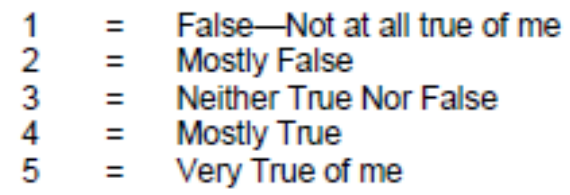

For example, if you were given the sentence "I like to read comic books," you would circle a " 5 " if this is very true of you. If you were given the sentence "I like to keep my room neat and tidy," you would circle a " $1^{n}$ if this was false and not at all true of you. You are now ready to begin.

Please be sure to answer all of the sentences.

\section{False True}

1. I try to be perfect in every thing I do.

$\begin{array}{lllll}1 & 2 & 3 & 4 & 5\end{array}$

2. I want to be the best at everything I do $\begin{array}{lllll}1 & 2 & 3 & 4 & 5\end{array}$

3. My parents don't always expect me to be perfect in everything I do $\begin{array}{lllll}1 & 2 & 3 & 4 & 5\end{array}$

4. I feel that I have to do my best all the time. $\begin{array}{lllll}1 & 2 & 3 & 4 & 5\end{array}$

5. There are people in my life who expect me to be perfect. $\begin{array}{lllll}1 & 2 & 3 & 4 & 5\end{array}$

6. I always try for the top score on a test. $\begin{array}{lllll}1 & 2 & 3 & 4 & 5\end{array}$

7. It really bothers me if I don't do my best all the time. $\begin{array}{lllll}1 & 2 & 3 & 4 & 5\end{array}$

8. My family expects me to be perfect. $\begin{array}{lllll}1 & 2 & 3 & 4 & 5\end{array}$

9. I don't always try to be the best. $\begin{array}{lllll}1 & 2 & 3 & 4 & 5\end{array}$

10. People expect more from me than I am able to give. $\begin{array}{lllll}1 & 2 & 3 & 4 & 5\end{array}$

11. I get mad at myself when I make a mistake. 


\section{CAPS}

12. Other people think that I have failed if I do not do my very best

all the time.

$\begin{array}{lllll}1 & 2 & 3 & 4 & 5\end{array}$

13. Other people always expect me to be perfect.

$\begin{array}{lllll}1 & 2 & 3 & 4 & 5\end{array}$

14. I get upset if there is even one mistake in my work.

$\begin{array}{lllll}1 & 2 & 3 & 4 & 5\end{array}$

15. People around me expect me to be great at everything.

$\begin{array}{lllll}1 & 2 & 3 & 4 & 5\end{array}$

16. When I do something, it has to be perfect. $\begin{array}{lllll}1 & 2 & 3 & 4 & 5\end{array}$

17. My teachers expect my work to be perfect. $\begin{array}{lllll}1 & 2 & 3 & 4 & 5\end{array}$

18. I do not have to be the best at everything I do. $\begin{array}{lllll}1 & 2 & 3 & 4 & 5\end{array}$

19. I am always expected to do better than others. $\begin{array}{lllll}1 & 2 & 3 & 4 & 5\end{array}$

20. Even when I pass, I feel that I have failed if I didn't get one of the highest marks in the class. $\begin{array}{lllll}1 & 2 & 3 & 4 & 5\end{array}$

21. I feel that people ask too much of me. $\begin{array}{lllll}1 & 2 & 3 & 4 & 5\end{array}$

22. I can't stand to be less than perfect. $\begin{array}{lllll}1 & 2 & 3 & 4 & 5\end{array}$

Copyright (c) Gordon L. Flett, Fh.D. \& Paul L. Hewitt, Ph.D. 
Q 2004 Jennlfer Simonds and Mary K. Rothoart, Unlversity of Oregon All FIghts Reserved

\section{Temperament in Middle Childhood Questionnaire (Version 3.0)}

\begin{tabular}{|c|c|c|c|c|c|}
\hline \multirow{3}{*}{$\begin{array}{l}\text { Today's Date } \\
\text { Child's Height }\end{array}$} & \multirow[b]{2}{*}{1} & \multirow{3}{*}{$\begin{array}{l}\text { Sex of Child } \\
\text { Child's Date of Birth }\end{array}$} & $\mathrm{N}$ & $\mathrm{F}$ & \multirow[t]{2}{*}{ (circle one) } \\
\hline & & & & & \\
\hline & Feet / Inches & & Month & Day & Year \\
\hline Staff Use: Subj. No & & Age of Child & \multicolumn{2}{|c|}{ Years I } & Months \\
\hline
\end{tabular}

Race/Ethnicity of Child: European American/White Hispanic

African-American Asian/Pacific Islander Native American/Indian

Multiracial Other (please specify)

Your Relationship to Child:

Mother _ Father

Other: (please indicate relationship)

Instructions: Please read carefully before starting:

On the next pages you will see a set of statements that describe children's reactions to a number of situations. We would like you to tell us what your child's reaction is likely to be in those situations. There are of course no "correct" ways of reacting; children differ widely in their reactions, and it is these differences we are trying to learn about. Please read each statement and decide whether it is a "true" or "untrue" description of your child's reaction within the past six months. Use the following scale to indicate how well a statement describes your child:

\begin{tabular}{ll} 
Circle \# & If the statement is: \\
\hline 1 & Almost always untrue of your child \\
2 & Usually untrue of your child \\
3 & Sometimes true, sometimes untrue of your child \\
4 & Usually true of your child \\
5 & Almost always true of your child
\end{tabular}

If you cannot answer one of the items because you have never seen the child in that situation, for example, if the statement is about the child playing wildly and recklessly and you have never seen your child play that way, then circle $\mathrm{NA}$ (not applicable).

Please be sure to respond by circling a number or NA for every item. If you find an item objectionable or upsetting, you may make an exception to this instruction and skip the item.

Temperament in Middle Childhood Questionnaire 3.0 - Page 1 


\begin{tabular}{|c|c|c|c|c|c|c|c|}
\hline & My Child... & $\begin{array}{l}\text { Almost } \\
\text { always } \\
\text { untrue }\end{array}$ & $\begin{array}{l}\text { Usually } \\
\text { untrue }\end{array}$ & $\begin{array}{c}\text { Sometimes } \\
\text { true } \\
\text { sometimes } \\
\text { untrue }\end{array}$ & $\begin{array}{c}\text { Usually } \\
\text { true }\end{array}$ & $\begin{array}{c}\text { Almost } \\
\text { always } \\
\text { true }\end{array}$ & $\begin{array}{l}\text { Does } \\
\text { Not } \\
\text { Apply }\end{array}$ \\
\hline 1 & Likes poems. & 1 & 2 & 3 & 4 & 5 & NA \\
\hline 2 & Likes to be physically active. & 1 & 2 & 3 & 4 & 5 & NA \\
\hline 3 & $\begin{array}{l}\text { Likes going down high slides or other } \\
\text { adventurous activities. }\end{array}$ & 1 & 2 & 3 & 4 & 5 & NA \\
\hline 4 & $\begin{array}{l}\text { Greatly enjoys playing games where s/he can } \\
\text { win. }\end{array}$ & 1 & 2 & 3 & 4 & 5 & NA \\
\hline 5 & Is bothered by pain when s/he falls down. & 1 & 2 & 3 & 4 & 5 & NA \\
\hline 6 & Can stop him/herself when s/he is told to stop. & 1 & 2 & 3 & 4 & 5 & NA \\
\hline 7 & Is easily distracted when listening to a story. & 1 & 2 & 3 & 4 & 5 & NA \\
\hline 8 & $\begin{array}{l}\text { Has a hard time settling down after an exciting } \\
\text { activity. }\end{array}$ & 1 & 2 & 3 & 4 & 5 & NA \\
\hline 9 & Likes rough and rowdy games. & 1 & 2 & 3 & 4 & 5 & NA \\
\hline 10 & Likes the crunching sound of leaves in the fall. & 1 & 2 & 3 & 4 & 5 & NA \\
\hline 11 & Is afraid of fire. & 1 & 2 & 3 & 4 & 5 & NA \\
\hline 12 & Likes to think of new ideas. & 1 & 2 & 3 & 4 & 5 & NA \\
\hline 13 & Is afraid of heights. & 1 & 2 & 3 & 4 & 5 & NA \\
\hline 14 & $\begin{array}{l}\text { Can't help touching things without getting } \\
\text { permission. }\end{array}$ & 1 & 2 & 3 & 4 & 5 & NA \\
\hline 15 & Is always on the move. & 1 & 2 & 3 & 4 & 5 & NA \\
\hline 16 & $\begin{array}{l}\text { Tends to say the first thing that comes to mind, } \\
\text { without stopping to think about it. }\end{array}$ & 1 & 2 & 3 & 4 & 5 & NA \\
\hline 17 & Looks around the room when doing homework. & 1 & 2 & 3 & 4 & 5 & NA \\
\hline 18 & Would like to be friends with lots of people. & 1 & 2 & 3 & 4 & 5 & NA \\
\hline 19 & $\begin{array}{l}\text { Is very difficult to soothe when s/he has become } \\
\text { upset. }\end{array}$ & 1 & 2 & 3 & 4 & 5 & NA \\
\hline 20 & $\begin{array}{l}\text { Can make him/herself do homework, even when } \\
\text { s/he wants to play. }\end{array}$ & 1 & 2 & 3 & 4 & 5 & NA \\
\hline 21 & $\begin{array}{l}\text { Prefers playing outdoors to indoors when weather } \\
\text { permits. }\end{array}$ & 1 & 2 & 3 & 4 & 5 & NA \\
\hline 22 & Interrupts others when they are talking. & 1 & 2 & 3 & 4 & 5 & NA \\
\hline 23 & Would rather play a sport than watch TV. & 1 & 2 & 3 & 4 & 5 & NA \\
\hline 24 & Tends to become sad if plans don't work out. & 1 & 2 & 3 & 4 & 5 & NA \\
\hline 25 & Says the first thing that comes to mind. & 1 & 2 & 3 & 4 & 5 & NA \\
\hline 26 & $\begin{array}{l}\text { Can say hello to a new child in class, even when } \\
\text { feeling shy. }\end{array}$ & 1 & 2 & 3 & 4 & 5 & NA \\
\hline 27 & $\begin{array}{l}\text { Sometimes appears to be downcast for no } \\
\text { reason. }\end{array}$ & 1 & 2 & 3 & 4 & 5 & NA \\
\hline 28 & $\begin{array}{l}\text { Has a hard time speaking when scared to answer } \\
\text { a question. }\end{array}$ & 1 & 2 & 3 & 4 & 5 & NA \\
\hline 29 & Cheers up quickly. & 1 & 2 & 3 & 4 & 5 & NA \\
\hline 30 & Cries when given an injection. & 1 & 2 & 3 & 4 & 5 & NA \\
\hline 31 & $\begin{array}{l}\text { Becomes sad when told to do something s/he } \\
\text { does not want to do. }\end{array}$ & 1 & 2 & 3 & 4 & 5 & NA \\
\hline
\end{tabular}

Temperament in Middle Childhood Questionnaire 3.0 - Page 2 
Q 2004 Jennifer Simonds and Mary K. Rothioart, Unlversity of Oregon All Fights Reserved

\begin{tabular}{|c|c|c|c|c|c|c|c|}
\hline & My Child... & $\begin{array}{l}\text { Almost } \\
\text { always } \\
\text { untrue }\end{array}$ & $\begin{array}{l}\text { Usually } \\
\text { untrue }\end{array}$ & $\begin{array}{c}\text { Sometimes } \\
\text { true. } \\
\text { sometimes } \\
\text { untrue }\end{array}$ & $\begin{array}{c}\text { Usually } \\
\text { true }\end{array}$ & $\begin{array}{c}\text { Almost } \\
\text { always } \\
\text { true }\end{array}$ & $\begin{array}{l}\text { Does } \\
\text { Not } \\
\text { Apply }\end{array}$ \\
\hline 32 & Likes to play quiet games. & 1 & 2 & 3 & 4 & 5 & NA \\
\hline 33 & $\begin{array}{l}\text { Would like to spend time with a good friend every } \\
\text { day. }\end{array}$ & 1 & 2 & 3 & 4 & 5 & NA \\
\hline 34 & Likes the sound of poems. & 1 & 2 & 3 & 4 & 5 & NA \\
\hline 35 & Cries sadly when a favorite toy gets lost or broken. & 1 & 2 & 3 & 4 & 5 & NA \\
\hline 36 & Notices the color of people's eyes. & 1 & 2 & 3 & 4 & 5 & NA \\
\hline 37 & $\begin{array}{l}\text { Likes to get out of the house and do something } \\
\text { physical. }\end{array}$ & 1 & 2 & 3 & 4 & 5 & NA \\
\hline 38 & Becomes quite uncomfortable when cold or wet. & 1 & 2 & 3 & 4 & 5 & NA \\
\hline 39 & $\begin{array}{l}\text { Can take a Band-AidB off when needed, even when } \\
\text { painful. }\end{array}$ & 1 & 2 & 3 & 4 & 5 & NA \\
\hline 40 & Can stop him/herself from doing things too quickly. & 1 & 2 & 3 & 4 & 5 & NA \\
\hline 41 & Enjoys exciting and suspenseful TV shows. & 1 & 2 & 3 & 4 & 5 & NA \\
\hline 42 & $\begin{array}{l}\text { Usually stops and thinks things over before deciding } \\
\text { to do something. }\end{array}$ & 1 & 2 & 3 & 4 & 5 & NA \\
\hline 43 & Likes to run. & 1 & 2 & 3 & 4 & 5 & NA \\
\hline 44 & Notices the sound of birds. & 1 & 2 & 3 & 4 & 5 & NA \\
\hline 45 & Likes exploring new places. & 1 & 2 & 3 & 4 & 5 & NA \\
\hline 46 & Can make him/herself run fast, even when tired. & 1 & 2 & 3 & 4 & 5 & NA \\
\hline 47 & Becomes self conscious when around people. & 1 & 2 & 3 & 4 & 5 & NA \\
\hline 48 & Likes to make up stories. & 1 & 2 & 3 & 4 & 5 & NA \\
\hline 49 & Becomes tearful when tired. & 1 & 2 & 3 & 4 & 5 & NA \\
\hline 50 & Enjoys making her/his own decisions. & 1 & 2 & 3 & 4 & 5 & NA \\
\hline 51 & Is warm and friendly. & 1 & 2 & 3 & 4 & 5 & NA \\
\hline 52 & Would find moving to a new, big city exciting. & 1 & 2 & 3 & 4 & 5 & NA \\
\hline 53 & $\begin{array}{l}\text { Gets very angry when another child takes his/her toy } \\
\text { away. }\end{array}$ & 1 & 2 & 3 & 4 & 5 & NA \\
\hline 54 & Likes reading or listening to make believe stories. & 1 & 2 & 3 & 4 & 5 & NA \\
\hline 55 & Is shy with new people. & 1 & 2 & 3 & 4 & 5 & NA \\
\hline 56 & Has an easy time waiting to open a present. & 1 & 2 & 3 & 4 & 5 & NA \\
\hline 57 & $\begin{array}{l}\text { Notices odors like perfume, smoke, and cooking } \\
\text { smells. }\end{array}$ & 1 & 2 & 3 & 4 & 5 & NA \\
\hline 58 & Likes to make others feel good. & 1 & 2 & 3 & 4 & 5 & NA \\
\hline 59 & $\begin{array}{l}\text { Can generally think of something to say, even with } \\
\text { strangers. }\end{array}$ & 1 & 2 & 3 & 4 & 5 & NA \\
\hline 60 & Is followed by other children. & 1 & 2 & 3 & 4 & 5 & NA \\
\hline 61 & $\begin{array}{l}\text { Gets angry when called in from play before } s / \text { he is } \\
\text { ready to quit. }\end{array}$ & 1 & 2 & 3 & 4 & 5 & NA \\
\hline 62 & $\begin{array}{l}\text { Can tell if another person is sad or angry by the look } \\
\text { on their face. }\end{array}$ & 1 & 2 & 3 & 4 & 5 & NA \\
\hline 63 & Is scared of injections by the doctor. & 1 & 2 & 3 & 4 & 5 & NA \\
\hline 64 & $\begin{array}{l}\text { When s/he cries, tends to cry for more than a couple } \\
\text { of minutes at a time. }\end{array}$ & 1 & 2 & 3 & 4 & 5 & NA \\
\hline
\end{tabular}

Temperament in Midolle Childhood Questionnaire 3.0 - Page 3 
Q 2004 Jennifer Simonds and Mary K. Rothoart, Unlversity of Oregon All Fights Reserved

\begin{tabular}{|c|c|c|c|c|c|c|c|}
\hline & My Child... & $\begin{array}{l}\text { Almost } \\
\text { always } \\
\text { untrue }\end{array}$ & $\begin{array}{l}\text { Usually } \\
\text { untrue }\end{array}$ & $\begin{array}{c}\text { Sometimes } \\
\text { true. } \\
\text { sometimes } \\
\text { untrue }\end{array}$ & $\begin{array}{c}\text { Usually } \\
\text { true }\end{array}$ & $\begin{array}{c}\text { Almost } \\
\text { always } \\
\text { true }\end{array}$ & $\begin{array}{c}\text { Does Not } \\
\text { Apply }\end{array}$ \\
\hline 65 & Enjoys exciting places with big crowds. & 1 & 2 & 3 & 4 & 5 & NA \\
\hline 66 & Is energetic. & 1 & 2 & 3 & 4 & 5 & NA \\
\hline 67 & Likes listening to music. & 1 & 2 & 3 & 4 & 5 & NA \\
\hline 68 & $\begin{array}{l}\text { Remains upset for hours when someone hurts } \\
\text { his/her feelings. }\end{array}$ & 1 & 2 & 3 & 4 & 5 & NA \\
\hline 69 & Is bothered by loud or scratchy sounds. & 1 & 2 & 3 & 4 & 5 & NA \\
\hline 70 & Has a hard time making him/herself clean own room. & 1 & 2 & 3 & 4 & 5 & NA \\
\hline 71 & Enjoys drawing pictures. & 1 & 2 & 3 & 4 & 5 & NA \\
\hline 72 & $\begin{array}{l}\text { Calls out answers before being called on by a } \\
\text { teacher or group leader. }\end{array}$ & 1 & 2 & 3 & 4 & 5 & NA \\
\hline 73 & Enjoys looking at books. & 1 & 2 & 3 & 4 & 5 & NA \\
\hline 74 & Makes up mind suddenly. & 1 & 2 & 3 & 4 & 5 & NA \\
\hline 75 & Is afraid of burglars or the "boogie man." & 1 & 2 & 3 & 4 & 5 & NA \\
\hline 76 & When a child is left out, can ask that child to play. & 1 & 2 & 3 & 4 & 5 & NA \\
\hline 77 & Touches fabric or other soft material. & 1 & 2 & 3 & 4 & 5 & NA \\
\hline 78 & $\begin{array}{l}\text { When working on an activity, has a hard time } \\
\text { keeping her/his mind on it. }\end{array}$ & 1 & 2 & 3 & 4 & 5 & NA \\
\hline 79 & $\begin{array}{l}\text { Has a hard time waiting his/her tum to talk when } \\
\text { excited. }\end{array}$ & 1 & 2 & 3 & 4 & 5 & NA \\
\hline 80 & Has a hard time paying attention. & 1 & 2 & 3 & 4 & 5 & NA \\
\hline 81 & Is bothered by light or color that is too bright. & 1 & 2 & 3 & 4 & 5 & NA \\
\hline 82 & Needs to be told by teacher to pay attention. & 1 & 2 & 3 & 4 & 5 & NA \\
\hline 83 & Often rushes into doing new things. & 1 & 2 & 3 & 4 & 5 & NA \\
\hline 84 & Is first to speak up in a group. & 1 & 2 & 3 & 4 & 5 & NA \\
\hline 85 & Is afraid of sleeping over at someone's house. & 1 & 2 & 3 & 4 & 5 & NA \\
\hline 86 & Likes quiet reading time. & 1 & 2 & 3 & 4 & 5 & NA \\
\hline 87 & $\begin{array}{l}\text { Gets angry when s/he can't find something s/he is } \\
\text { looking for. }\end{array}$ & 1 & 2 & 3 & 4 & 5 & NA \\
\hline 88 & $\begin{array}{l}\text { Is very careful and cautious when crossing the } \\
\text { street. }\end{array}$ & 1 & 2 & 3 & 4 & 5 & NA \\
\hline 89 & $\begin{array}{l}\text { Has a hard time working on an assignment s/he finds } \\
\text { boring. }\end{array}$ & 1 & 2 & 3 & 4 & 5 & NA \\
\hline 90 & Is afraid of loud noises. & 1 & 2 & 3 & 4 & 5 & NA \\
\hline 91 & $\begin{array}{l}\text { Goes to school nurse's office for very minor } \\
\text { complaints. }\end{array}$ & 1 & 2 & 3 & 4 & 5 & NA \\
\hline 92 & Likes the feel of warm water in a bath or shower. & 1 & 2 & 3 & 4 & 5 & NA \\
\hline 93 & $\begin{array}{l}\text { Does a fun activity when s/he is supposed to do } \\
\text { homework instead. }\end{array}$ & 1 & 2 & 3 & 4 & 5 & NA \\
\hline 94 & Gets angry when s/he has trouble with a task. & 1 & 2 & 3 & 4 & 5 & NA \\
\hline 95 & Likes to look at trees. & 1 & 2 & 3 & 4 & 5 & NA \\
\hline 96 & $\begin{array}{l}\text { Likes to play so wildly and recklessly that s/he might } \\
\text { get hurt. }\end{array}$ & 1 & 2 & 3 & 4 & 5 & NA \\
\hline
\end{tabular}

Temperament in Middle Childhood Questionnaire 3.0 - Page 4 


\begin{tabular}{|c|c|c|c|c|c|c|c|}
\hline & My Child .... & $\begin{array}{l}\text { Almost } \\
\text { always } \\
\text { untrue }\end{array}$ & $\begin{array}{l}\text { Usually } \\
\text { untrue }\end{array}$ & $\begin{array}{l}\text { Sometimes } \\
\text { true } \\
\text { sometimes } \\
\text { untrue }\end{array}$ & $\begin{array}{c}\text { Usually } \\
\text { true }\end{array}$ & $\begin{array}{c}\text { Almost } \\
\text { always } \\
\text { true }\end{array}$ & $\begin{array}{l}\text { Does Not } \\
\text { Apply }\end{array}$ \\
\hline 97 & Is told by others to "cheer up" and be happier. & 1 & 2 & 3 & 4 & 5 & NA \\
\hline 98 & $\begin{array}{l}\text { When with other children, is the one to choose } \\
\text { activities or games. }\end{array}$ & 1 & 2 & 3 & 4 & 5 & NA \\
\hline 99 & Gets angry when s/he makes a mistake. & 1 & 2 & 3 & 4 & 5 & NA \\
\hline 100 & Her/his feelings are easily hurt. & 1 & 2 & 3 & 4 & 5 & NA \\
\hline 101 & $\begin{array}{l}\text { Can make him/herself get out of bed, even when } \\
\text { tired. }\end{array}$ & 1 & 2 & 3 & 4 & 5 & NA \\
\hline 102 & Likes active games. & 1 & 2 & 3 & 4 & 5 & NA \\
\hline 103 & Can apologize or shake hands after a fight. & 1 & 2 & 3 & 4 & 5 & NA \\
\hline 104 & Has a big imagination. & 1 & 2 & 3 & 4 & 5 & NA \\
\hline 105 & $\begin{array}{l}\text { When angry about something. s/he tends to stay } \\
\text { upset for five minutes or longer. }\end{array}$ & 1 & 2 & 3 & 4 & 5 & NA \\
\hline 106 & Places great importance on friends. & 1 & 2 & 3 & 4 & 5 & NA \\
\hline 107 & $\begin{array}{l}\text { Seems to feel down when unable to accomplish a } \\
\text { task. }\end{array}$ & 1 & 2 & 3 & 4 & 5 & NA \\
\hline 108 & $\begin{array}{l}\text { Gets into trouble because s/he does things without } \\
\text { thinking first. }\end{array}$ & 1 & 2 & 3 & 4 & 5 & NA \\
\hline 109 & $\begin{array}{l}\text { Notices small changes in the environment, like } \\
\text { lights getting brighter in a room. }\end{array}$ & 1 & 2 & 3 & 4 & 5 & NA \\
\hline 110 & $\begin{array}{l}\text { Has temper tantrums when s/he doesn't get what } \\
\text { s/he wants. }\end{array}$ & 1 & 2 & 3 & 4 & 5 & NA \\
\hline 111 & Notices things others don't notice. & 1 & 2 & 3 & 4 & 5 & NA \\
\hline 112 & $\begin{array}{l}\text { Has a hard time going back to sleep after waking in } \\
\text { the night. }\end{array}$ & 1 & 2 & 3 & 4 & 5 & NA \\
\hline 113 & Likes to sit under a blanket. & 1 & 2 & 3 & 4 & 5 & NA \\
\hline 114 & Notices even little specks of dirt on objects. & 1 & 2 & 3 & 4 & 5 & NA \\
\hline 115 & Enjoys playing chase. & 1 & 2 & 3 & 4 & 5 & NA \\
\hline 116 & Likes to pretend. & 1 & 2 & 3 & 4 & 5 & NA \\
\hline 117 & Gets nervous about going to the dentist. & 1 & 2 & 3 & 4 & 5 & NA \\
\hline 118 & Is shy. & 1 & 2 & 3 & 4 & 5 & NA \\
\hline 119 & Likes to go high and fast on the swings. & 1 & 2 & 3 & 4 & 5 & NA \\
\hline 120 & Needs to be told to pay attention. & 1 & 2 & 3 & 4 & 5 & NA \\
\hline 121 & $\begin{array}{l}\text { Would think that sking or snowboarding fast } \\
\text { sounds scary. }\end{array}$ & 1 & 2 & 3 & 4 & 5 & NA \\
\hline 122 & Usually wins arguments with other children. & 1 & 2 & 3 & 4 & 5 & NA \\
\hline 123 & $\begin{array}{l}\text { Likes to run his/her hand over things to see if they } \\
\text { are smooth or rough. }\end{array}$ & 1 & 2 & 3 & 4 & 5 & NA \\
\hline 124 & Grabs what s/he wants. & 1 & 2 & 3 & 4 & 5 & NA \\
\hline 125 & Becomes upset when hair is combed. & 1 & 2 & 3 & 4 & 5 & NA \\
\hline 126 & Enjoys riding bicycle fast and recklessly. & 1 & 2 & 3 & 4 & 5 & NA \\
\hline 127 & Likes to run around outside. & 1 & 2 & 3 & 4 & 5 & NA \\
\hline 128 & $\begin{array}{l}\text { Decides what s/he wants very quickly and then } \\
\text { goes after it. }\end{array}$ & 1 & 2 & 3 & 4 & 5 & NA \\
\hline
\end{tabular}

Temperament in Middle Childhood Questionnaire 3.0 - Page 5 


\begin{tabular}{|c|c|c|c|c|c|c|c|}
\hline & My Child... & $\begin{array}{l}\text { Almost } \\
\text { always } \\
\text { untrue }\end{array}$ & $\begin{array}{l}\text { Usually } \\
\text { untrue }\end{array}$ & $\begin{array}{l}\text { Sometimes } \\
\text { true. } \\
\text { sometimes } \\
\text { untrue }\end{array}$ & $\begin{array}{l}\text { Usually } \\
\text { true }\end{array}$ & $\begin{array}{c}\text { Almost } \\
\text { always } \\
\text { true }\end{array}$ & $\begin{array}{l}\text { Does } \\
\text { Not } \\
\text { Apply }\end{array}$ \\
\hline 129 & Would like to confide in others. & 1 & 2 & 3 & 4 & 5 & NA \\
\hline 130 & $\begin{array}{l}\text { Usually rushes into an activity without thinking } \\
\text { about it. }\end{array}$ & 1 & 2 & 3 & 4 & 5 & NA \\
\hline 131 & Likes to be in charge. & 1 & 2 & 3 & 4 & 5 & NA \\
\hline 132 & $\begin{array}{l}\text { Can make himherself take medicine or eat food } \\
\text { that s/he knows tastes bad. }\end{array}$ & 1 & 2 & 3 & 4 & 5 & NA \\
\hline 133 & Feels sad frequently. & 1 & 2 & 3 & 4 & 5 & NA \\
\hline 134 & Likes hugs and kisses. & 1 & 2 & 3 & 4 & 5 & NA \\
\hline 135 & Likes to plan carefully before doing something. & 1 & 2 & 3 & 4 & 5 & NA \\
\hline 136 & Acts insecure with others. & 1 & 2 & 3 & 4 & 5 & NA \\
\hline 137 & Feels nervous for a long time after being scared. & 1 & 2 & 3 & 4 & 5 & NA \\
\hline 138 & Is quite upset by a little cut or bruise. & 1 & 2 & 3 & 4 & 5 & NA \\
\hline 139 & $\begin{array}{l}\text { Can make himherself pick up something dirty in } \\
\text { order to throw it away. }\end{array}$ & 1 & 2 & 3 & 4 & 5 & NA \\
\hline 140 & Is afraid of the dark. & 1 & 2 & 3 & 4 & 5 & NA \\
\hline 141 & Is able to keep secrets. & 1 & 2 & 3 & 4 & 5 & NA \\
\hline 142 & $\begin{array}{l}\text { Is bothered by bath water that is too hot or too } \\
\text { cold. }\end{array}$ & 1 & 2 & 3 & 4 & 5 & NA \\
\hline 143 & $\begin{array}{l}\text { Has a hard time slowing down when rules say to } \\
\text { walk. }\end{array}$ & 1 & 2 & 3 & 4 & 5 & NA \\
\hline 144 & Tends to feel sad even when others are happy. & 1 & 2 & 3 & 4 & 5 & NA \\
\hline 145 & Loves pets and other small animals. & 1 & 2 & 3 & 4 & 5 & NA \\
\hline 146 & Gets mad when provoked by other children. & 1 & 2 & 3 & 4 & 5 & NA \\
\hline 147 & $\begin{array}{l}\text { When s/he sees a toy or a game s/he wants, is } \\
\text { eager to have it right away. }\end{array}$ & 1 & 2 & 3 & 4 & 5 & NA \\
\hline 148 & Likes to feel close to other people. & 1 & 2 & 3 & 4 & 5 & NA \\
\hline 149 & $\begin{array}{l}\text { Gets distracted when trying to pay attention in } \\
\text { class. }\end{array}$ & 1 & 2 & 3 & 4 & 5 & NA \\
\hline 150 & Notices when parents are wearing new clothing. & 1 & 2 & 3 & 4 & 5 & NA \\
\hline 151 & Likes to make things. & 1 & 2 & 3 & 4 & 5 & NA \\
\hline 152 & Has a hard time getting moving when tired. & 1 & 2 & 3 & 4 & 5 & NA \\
\hline 153 & Is very frightened by nightmares. & 1 & 2 & 3 & 4 & 5 & NA \\
\hline 154 & Is likely to cry when even a little bit hurt. & 1 & 2 & 3 & 4 & 5 & NA \\
\hline 155 & Enjoys winning arguments. & 1 & 2 & 3 & 4 & 5 & NA \\
\hline 156 & Likes just being with other people. & 1 & 2 & 3 & 4 & 5 & NA \\
\hline 157 & $\begin{array}{l}\text { Can make him/herself smile at someone, even } \\
\text { when s/he dislikes them. }\end{array}$ & 1 & 2 & 3 & 4 & 5 & NA \\
\hline
\end{tabular}

Temperament in Middle Childhood Questionnaire 3.0 - Page 6 
The EMBU -C

Read each sentence below. Circle the number that shows how often each event happens in your family.

$1=$ No,never $\quad 2=$ Yes, but seldom $\quad 3=$ Yes, often $\quad 4=$ Yes, most of the time

\begin{tabular}{|c|c|c|c|c|}
\hline & Never & Seldom & Often & $\begin{array}{l}\text { Most of } \\
\text { the time }\end{array}$ \\
\hline When you come home, you have to tell your parents what you have been doing. & 1 & 2 & 3 & 4 \\
\hline When you are unhappy, your parents console you and cheer you up. & 1 & 2 & 3 & 4 \\
\hline Your parents want you to reveal your secrets to them. & 1 & 2 & 3 & 4 \\
\hline Your parents tell you that they don't like your behavior at home. & 1 & 2 & 3 & 4 \\
\hline Your parents like you just the way you are. & 1 & 2 & 3 & 4 \\
\hline Your parents worry about what you are doing after school. & 1 & 2 & 3 & 4 \\
\hline Your parents play with you and are interested in your hobbies. & 1 & 2 & 3 & 4 \\
\hline Your parents treat you unfairly. & 1 & 2 & 3 & 4 \\
\hline Your parents are afraid that something might happen to you. & 1 & 2 & 3 & 4 \\
\hline Your parents listen to you and consider your opinion. & 1 & 2 & 3 & 4 \\
\hline 1. Your parents wish that you were like somebody else. & 1 & 2 & 3 & 4 \\
\hline $\begin{array}{l}\text { 2. Your parents want to decide how you should be dressed or } \\
\text { how you should look. }\end{array}$ & 1 & 2 & 3 & 4 \\
\hline Your parents worry about you getting into trouble. & 1 & 2 & 3 & 4 \\
\hline
\end{tabular}


ID\#:

$1=$ No,never

$3=$ Yes, often

$4=$ Yes, most of the time

14. You are blamed for everything that goes wrong.

15. Your parents punish you for no reason.

16. Your parents tell you what you should do after school hours.

17. Your parents want to be with you.

18. Your parents worry about you doing dangerous things.

19. Your parents show that they love you.

20. Your parents criticize you in front of others.

21. Your parents know exactly what you are allowed to do and what you are not.

22. Your parents worry about you making a mistake.

23. You feel disappointed because your parents don't give you what you want.

24. Your parents allow you to decide what you want to do.

25. Your parents take care that you behave by the rules.

26. Your parents are afraid when you do something on your own.

27. Your parents and you like each other.

28. Your parents are mean and grudging toward you.

29. Your parents do not allow you to do as many things as other children.

\begin{tabular}{|c|c|c|c|}
\hline Never & Seldom & Often & $\begin{array}{l}\text { Most of } \\
\text { the time }\end{array}$ \\
\hline 1 & 2 & 3 & 4 \\
\hline 1 & 2 & 3 & 4 \\
\hline 1 & 2 & 3 & 4 \\
\hline 1 & 2 & 3 & 4 \\
\hline 1 & 2 & 3 & 4 \\
\hline 1 & 2 & 3 & 4 \\
\hline 1 & 2 & 3 & 4 \\
\hline 1 & 2 & 3 & 4 \\
\hline 1 & 2 & 3 & 4 \\
\hline 1 & 2 & 3 & 4 \\
\hline 1 & 2 & 3 & 4 \\
\hline 1 & 2 & 3 & 4 \\
\hline 1 & 2 & 3 & 4 \\
\hline 1 & 2 & 3 & 4 \\
\hline 1 & 2 & 3 & 4 \\
\hline 1 & 2 & 3 & 4 \\
\hline
\end{tabular}




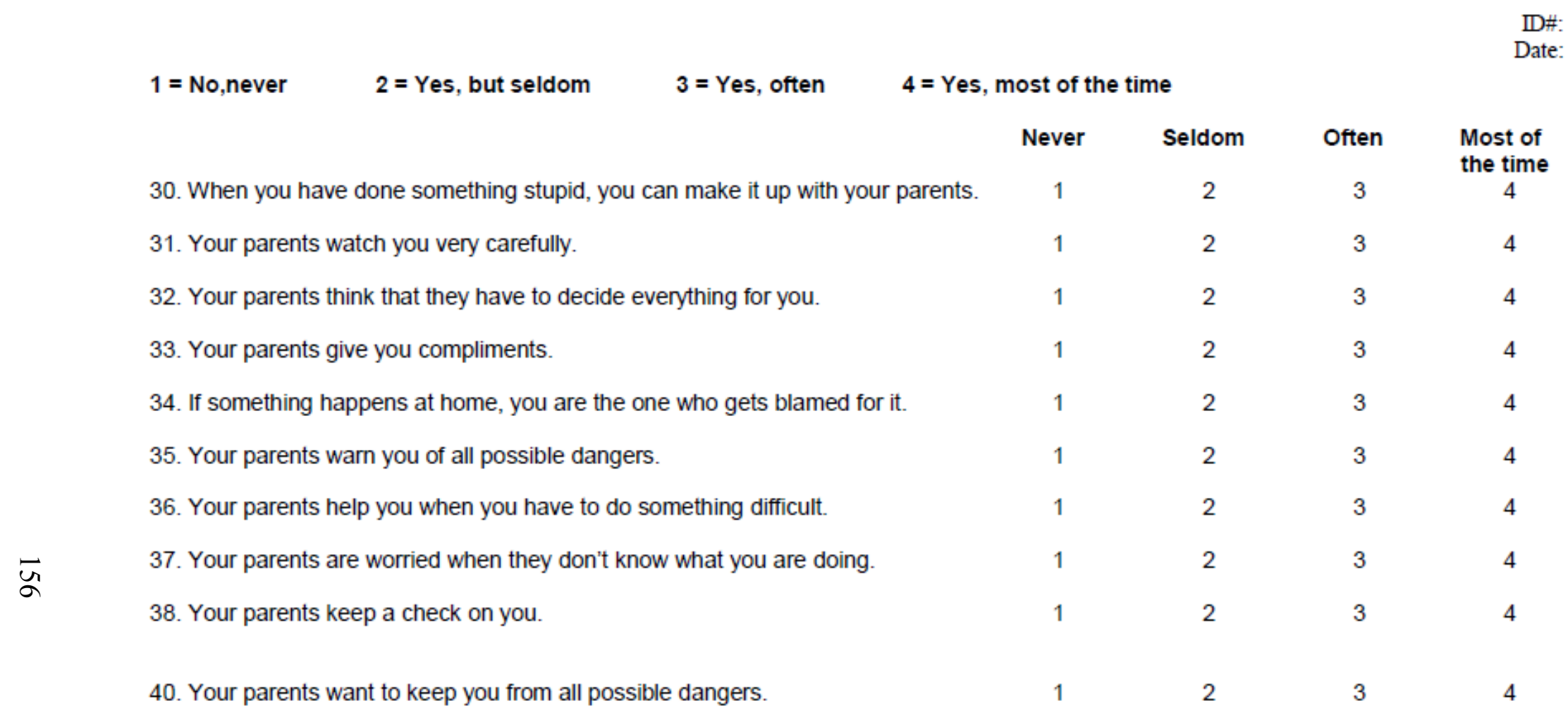


The EMBU - P

Read each sentence below. Circle the number that shows how often each event happens in your family.

\section{$1=$ No,never \\ $2=$ Yes, but seldom \\ $3=$ Yes, often}

1. When my child comes home, I ask my child about what he/she has been doing.

2. When my child is unhappy, I console my child and cheer him/her up.

3. I want my child to reveal his/her secrets to me.

4. I tell my child that I don't like his/her behavior at home.

5. I like my child just the way he/she is.

$\bar{v}$

6. I worry about what my child is doing after school

7. I play with my child and am interested in his/her hobbies.

8. I treat my child unfairly.

9. I am afraid that something might happen to my child.

10. I listen to my child and consider his/her opinion.

11. I wish that my child was like somebody else.

12. I want to decide how my child should be dressed or how he/she should look.

13. I worry about my child getting into trouble.
$4=$ Yes, most of the time

\section{Never Seldom}

Often

Most of the time

4

4

4

4

4

4

4

4

4

4

4

4

4 
14. I blame my child for everything that goes wrong.

\section{Never Seldom}

Often

Most of the time

15. I punish my child for no reason.

16. I tell my child what he/she should do after school hours.

17. I want to be with my child

18. I worry about my child doing dangerous things.

19. I show that I love my child.

20. I criticize my child in front of others

21. I know exactly what my child is allowed to do and what not to do.

22. I worry about my child making a mistake.

23. My child feels disappointed because I don't give him/her what they want.

24. I allow my child to decide what he/she wants to do.

25. I take care that my child behaves by the rules.

26. I am afraid when my child does something on their own

27. My child and I like each other

28. I am mean and grudging toward my child.

4

4

4

4

4

4 
$4=$ Yes, most of the time

29. I do not allow my child to do as many things as other children.

Never

30. When my child has done something stupid, he/she can make it up with me.

31. I watch my child very carefully.

32. I think that I have to decide everything for my child.

33. I give my child compliments.

34. If something happens at home, my child is the one who gets blamed for it.

35. I warn my child of all possible dangers.

36. I help my child when he/she has to do something difficult.

37. I am worried when I don't know what my child is doing.

38. I keep a check on my child.

40. I want to keep my child from all possible dangers.

$\begin{array}{ll}1 & 2 \\ 1 & 2 \\ 1 & 2 \\ 1 & 2 \\ 1 & 2 \\ 1 & 2 \\ 1 & 2 \\ 1 & 2 \\ 1 & 2 \\ 1 & 2 \\ 1 & 2\end{array}$

\section{Often}

3

3

3

3

3

3

3

3

3

Most of the time

4

4

4

4

4

4

4

4

4

4

4 


\section{CURRICULUM VITAE}

NAME: $\quad$ Nicholas William Affrunti

ADDRESS: 1212 S. Michigan Ave., 32307

Chicago, IL 60605

naffrun@uic.edu

860-930-9933

DOB: $\quad$ Hartford, Connecticut - September 24, 1985

EDUCATION \& TRAINING:

B.S., Psychology

Fordham University

2003-2007

M.A., Psychology

Catholic University of America

2008-2010

Ph.D., Clinical Psychology

University of Louisville

2012-2017 (expected)

Dissertation title: The roles of anxious rearing, negative affect, and effortful control in a model of risk for child perfectionism

Chair: Janet Woodruff-Borden, Ph.D.

Predoctoral Psychology Internship

University of Chicago-Illinois Department of Psychiatry

2016-present

HONORS \& AWARDS:

2007 Psychology Honors Graduate, Fordham University, New York, NY 
2010 Comprehensive Exam Honors, Catholic University of America, Washington, DC

2012 Graduate Student Travel Award, University of Louisville, Louisville, KY

2012 University Fellowship, University of Louisville, Louisville, KY

2013 Graduate Student Travel Award, University of Louisville, Louisville, KY

2013 University Fellowship, University of Louisville, Louisville, KY

2015 Nominee, Program for Excellence in Science, American Association for the Advancement of Science

2015 Excellence in Research Award, University of Louisville, Louisville, KY

2015 Nominee, Distinguished Student Research Award, APA Division 12

2016 Nominee, Stanley A. Murrell Scientist Practitioner Award, University of Louisville, Louisville, KY

2016 Excellence in Research Award, University of Louisville, Louisville, KY

\section{EDITORIAL POSITIONS:}

2015-Present Ad hoc Reviewer

Behavior Therapy

Child Care and Youth Forum

Child Psychiatry and Human Development

Clinical Child and Family Psychology Review

Clinical Psychology Review

Comprehensive Psychiatry

Journal of Anxiety Disorders

Journal of Child and Family Studies

Journal of Early Adolescence

Personality and Individuals Differences

PLOS one

Psychological Reports

Scandinavian Journal of Psychology

\section{PUBLICATIONS:}

Chapters in books

Ginsburg, G.S. \& Affrunti, N.W. (2013) Generalized anxiety disorder in children and adolescents. In Vasa, R. \& Roy, A.K. (Eds.) Pediatric Anxiety Disorders: A Clinical Guide. New York: Springer.

Affrunti, N.W. \& Woodruff-Borden, J. (in press) Perfectionism and anxiety in children. In Stoeber, J. (Ed.) The Psychology of Perfectionism: Theory, Research, Applications. New York: Routledge. 
Published manuscripts:

Affrunti, N.W. \& Ginsburg, G.S. (2012) Maternal overcontrol and child anxiety: The mediating role of perceived competence. Child Psychiatry and Human Development, 43, 102-112. doi:10.1007/s10578-011-0248-Z

Affrunti, N.W. \& Ginsburg, G.S. (2012) Exploring parental predictors of child anxiety: The mediating role of child interpretation bias. Child and Youth Care Forum, 41, 517-527. doi:10.1007/s10566-012-9186-6

Affrunti, N.W., Geronimi, E.M.C., \& Woodruff-Borden, J. (2014) Temperament, peer victimization, and nurturing parenting in child anxiety: A moderated mediation model. Child Psychiatry and Human Development, 45, 483492. doi: 10.1007/s10578-013-0418-2

Affrunti, N.W. \& Woodruff-Borden, J. (2014) Perfectionism in pediatric anxiety and depressive disorders. Clinical Child and Family Psychology Review, 17, 299-317. doi: 10.1007/s10567-014-0164-4

Affrunti, N.W. \& Woodruff-Borden, J. (2015) The association of executive function and temperament in a model of risk for childhood anxiety. Journal of Child and Family Studies, 24, 715-724. doi: 10.1007/s10826013-9881-4

Affrunti, N.W. \& Woodruff-Borden, J. (2015) Parental perfectionism and overcontrol: Examining mechanisms in the development of child anxiety. Journal of Abnormal Child Psychology, 43, 517-529. doi: 10.1007/s10802-014-9914-5

Affrunti, N.W. \& Woodruff-Borden, J. (2015) The effect of parental psychopathology on parent-child agreement of child anxiety symptoms: A hierarchical linear modeling approach. Journal of Anxiety Disorders, 32, 56-65. doi: 10.1016/j.janxdis.2015.03.010

Affrunti, N.W., Geronimi, E.M.C., \& Woodruff-Borden, J. (2015) Language of perfectionistic parents predicting child anxiety diagnostic status. Journal of Anxiety Disorders, 30, 94-102. doi: 10.1016/j.janxdis.2015.01.001

Affrunti, N.W. \& Woodruff-Borden, J. (2016) Negative affect and child internalizing symptoms: The mediating role of perfectionism. Child Psychiatry and Human Development, 47, 358-368. doi: 10.1007/s10578015-0571-X

Affrunti, N.W., Gramszlo, C., \& Woodruff-Borden, J. (2016) Executive function moderates the association between fearful temperament and dimensions of perfectionism. Personality and Individual Differences, 89, 117-122. doi: 10.1016/j.paid.2015.10.012

Affrunti, N.W. \& Woodruff-Borden, J. (2016) Emotional control mediates the association between dimensions of perfectionism and worry in children. 
Child Psychiatry and Human Development. doi: 10.1007/s10578-0160654-3

Manuscripts under review:

Geronimi, E.M.C., Affrunti, N.W., Jones, M., \& Woodruff-Borden, J. (under review) Anxiety and parental overcontrol: Examining linguistic elements of overcontrolling behaviors. Journal of Child and Family Studies.

Affrunti, N.W. \& Woodruff-Borden, J. (under review) An integrative review of the development of perfectionism. Child and Youth Care Forum.

Manuscripts in preparation:

Affrunti, N.W. \& Woodruff-Borden, J. Perfectionism and intolerance of uncertainty predicts child anxiety diagnostic status.

Affrunti, N.W. \& Woodruff-Borden, J. Perfectionism in child worry and obsessive-compulsive symptoms.

PRESENTATIONS:

Affrunti, N.W. \& MacDonall, J.S. (March, 2007). Concurrent schedules: Is responding at one alternative independent of reinforcers arranged at the other alternative?. Poster presented at the meeting of the Eastern Psychological Association, Philadelphia, PA.

Affrunti, N.W. \& Ginsburg, G.S. (April, 2011). Maternal overcontrol and child anxiety: The mediating role of perceived competence. Poster presented at the meeting of the Anxiety and Depression Association of America, New Orleans, LA.

Teetsel, R., Affrunti, N.W. \& Ginsburg, G.S. (April, 2012). Anxious parenting behaviors of mothers versus fathers. Poster presented at the meeting of the Anxiety and Depression Association of America, Arlington.

Affrunti, N.W., Teetsel, R.., Vasa, R., \& Ginsburg, G.S. (April, 2012). The relation between anxious parenting behaviors and children's threat interpretation biases. Poster presented at the meeting of the Anxiety and Depression Association of America, Arlington, VA.

Bortoleto, E.M.C., Williams, S.R., Affrunti, N.W., Carrico, K., Kertz, S.J., \& Woodruff-Borden, J. (November, 2012). Autonomic responsiveness, intolerance of uncertainty and behavior control in child worry and anxiety. Poster presented at the meeting of the Association for Behavioral and Cognitive Therapies, Washington, D.C.

Bortoleto, E.M.C., Affrunti, N.W., \& Woodruff-Borden, J. (November, 2013) Investigating Linguistic Features of GAD Parents versus Controls. Poster 
presented at the meeting of the Association for Behavioral and Cognitive Therapies, Nashville, TN.

Affrunti, N.W., Bortoleto, E.M.C., \& Woodruff-Borden, J. (November, 2013) Executive function and temperament in a model of risk in the familial transmission of anxiety. Poster presented at the meeting of the Association for Behavioral and Cognitive Therapies, Nashville, TN.

Bortoleto, E.M.C., Affrunti, N.W., \& Woodruff-Borden, J. (November, 2013) Linguistic expressions of worry models in individuals with GAD. Poster presented at the meeting of the Association for Behavioral and Cognitive Therapies, Nashville, TN.

Affrunti, N.W., Laun, A., Bortoleto, E.M.C., \& Woodruff-Borden, J. (November, 2013) The effects of perfectionism in parents and children on child anxiety and worry. Poster presented at the meeting of the Association for Behavioral and Cognitive Therapies, Nashville, TN.

Affrunti, N.W., Bortoleto, E.M.C., \& Woodruff-Borden, J. (March, 2014) Parent anxiety, perfectionism and overcontrolling parenting in child anxiety. Poster presented at the meeting of the Anxiety and Depression Association of America, Chicago, IL.

Affrunti, N.W., Bortoleto, E.M.C., \& Woodruff-Borden, J. (March, 2014) Temperament, peer victimization, and nurturing parenting in child anxiety: A moderated mediation model. In W. Chiaying (Chair), Family factors in the development, maintenance, and treatment for childhood anxiety. Symposium presented at the Anxiety and Depression Association of America, Chicago, IL.

Bortoleto, E.M.C., Affrunti, N.W., Jones, M.A., \& Woodruff-Borden, J. (November, 2014) Verb tense patterns in individuals with GAD versus controls. Poster presented at the meeting of the Association for Behavioral and Cognitive Therapies, Philadelphia, PA.

Bortoleto, E.M.C., Affrunti, N.W., Jones, M.A., \& Woodruff-Borden, J. (November, 2014) Language of controlling parental behaviors. Poster presented at the meeting of the Association for Behavioral and Cognitive Therapies, Philadelphia, PA.

Bortoleto, E.M.C., Affrunti, N.W., Williams, S.R., \& Woodruff-Borden, J. (November, 2014) Cardiac modulation as a predictor of worry in children. Poster presented at the meeting of the Association for Behavioral and Cognitive Therapies, Philadelphia, PA.

Affrunti, N.W., Bortoleto, E.M.C., \& Woodruff-Borden, J. (November, 2014) Executive functioning mediates the relation between child perfectionism, anxiety, and worry. Poster presented at the meeting of the Association for Behavioral and Cognitive Therapies, Philadelphia, PA. 
Geronimi, E.M.C., Gramszlo, C., Patterson, H., Affrunti, N.W., Richards, A., \& Woodruff-Borden, J. (2015). Understanding Worry in Adolescents: Linguistic Features of Theoretical Worry Models. Poster presented in the ABCT Annual Convention, Chicago, IL.

Affrunti, N.W., Bortoleto, E.M.C., Gramszlo, C., Patterson, H., Richards, A., \& Woodruff-Borden, J. (November, 2015) Fearful temperament moderates the relation between perfectionism and child worry and anxiety. Poster presented at the meeting of the Association for Behavioral and Cognitive Therapies, Chicago, IL.

Affrunti, N.W., Bortoleto, E.M.C., Gramszlo, C., Patterson, H., Richards, A., \& Woodruff-Borden, J. (November, 2015) The effect of maternal psychopathology on parent-child agreement of child anxiety symptoms: A hierarchical linear modeling approach. Poster presented at the meeting of the Association for Behavioral and Cognitive Therapies, Chicago, IL.

Patterson, H., Affrunti, N.W., Geronimi, E.M.C., Richards, A., Szabo-Long, C. \& Woodruff-Borden, J. (2015). Preliminary evidence for a physiological avoidance mechanism in children: Comparison with adult research on heart rate variability and worry. Poster presented at the Association for Behavioral and Cognitive Therapies Annual Convention, Chicago, IL.

Affrunti, N.W., Bortoleto, E.M.C., Gramszlo, C., Arellano, B. \& WoodruffBorden, J. (October, 2016). Negative affect, perfectionism, and intolerance of uncertainty in a model of risk for child anxiety diagnostic status. Poster presented at the meeting of the Association for Behavioral and Cognitive Therapies, New York, NY.

FUNDING:

2014 American Psychological Association of Graduate Students Basic Psychological Science Research Grant Principal Investigator Study Title: Autonomic markers in child worry and perfectionism Amount: $\$ 1,000.00$

PROFESSIONAL SERVICE:

2014-2015 University of Louisville Department of Psychological and Brain Sciences Student Representative

2015 APAGS Basic Psychological Science Grant reviewer

\section{PROFESSIONAL AFFILIATIONS:}


2012-2014 Association of Psychological Science, Student Member

2014-2016 American Psychological Association, Student Affiliate

2012-Present Association for Behavior and Cognitive Therapy, Student Member

2010-Present Anxiety and Depression Association of America, Student Member

2015-Present Society of Clinical Psychology, Division 12, APA, Student Affiliate

2015-Present Society for a Science of Clinical Psychology, Student Member

\section{PROFESSIONAL TALKS:}

10/5/2015 "Helping your anxious child." Presented at the Crescent Hill Library

10/13/2015 “Helping your anxious child.” Presented at the Middletown Library

11/13/2016 "Anxiety at school: How you can help anxious students." Presentation at Jefferson County Public School Counselor Continuing Education training

3/29/2016 "Reducing perfectionism and stress in children" Workshop presented for parents at Meyzeek Middle School Family Symposium

\section{TEACHING \& MENTORSHIP:}

2009-2010 Saylor Foundation, Educational research consultant

In charge of developing curriculum and individual course outlines for an online undergraduate psychology degree. Researched current course

topics, readings and publications to match with specific course areas 2010-2012 Johns Hopkins University

Undergraduate mentorship:

Jovan Custis, Morgan State University, Research Assistant

Melissa Love, Johns Hopkins University, Research Assistant

Kevin Cochran, Johns Hopkins University, Research Assistant

Colette Szabo-Long, Johns Hopkins University, Research Assistant

2012-2016 University of Louisville

Undergraduate mentorship:

Kaitlin Hancock, University of Louisville, Research Assistant

Allison Laun, University of Louisville, Research Assistant

Brittany Ruehling, University of Louisville, Research Assistant

Meghan Jones, University of Louisville, Honors Research Assistant 
Elizabeth Niehaus, University of Louisville, Research Assistant

Ammenah Ikram, University of Louisville, Research Assistant

\section{CLINICAL EXPERIENCE:}

2010-2012 Diagnostic Interviewer, Child and Adolescent Psychiatry, Johns Hopkins University School of Medicine, Baltimore, MD Supervisors: Golda S. Ginsburg, Ph.D.; Kelly L. Drake, Ph.D.; Mark A. Riddle, M.D.

Responsible for administering and scoring Kiddie-Schedule of Affective Disorders and Schizophrenia (K-SADS-PL), Anxiety Disorders Interview Schedule for Parents and Children (ADIS$\mathrm{P} / \mathrm{C}$ ) and Client Lifetime interview (ADIS-IV-L)

2012-Present Diagnostic Interviewer, Developmental Psychopathology Lab, University of Louisville, Louisville, KY Supervisor: Janet Woodruff-Borden, Ph.D.

Responsible for administering and scoring Anxiety Disorders Interview Schedule for Parents and Children (ADIS-P/C) and Client Lifetime interview (ADIS-IV-L)

2012-Present Graduate Student Therapist, Psychological Services Center, University of Louisville, Louisville, KY

Supervisors: Paul J. Rosen, Ph.D., Bernadette Walter, Ph.D., David Winsch, Ph.D., Janet Woodruff-Borden, Ph.D.

Child experience:

Conducted therapy intake interviews

Utilized Cognitive Behavioral Therapy modules, including Coping Cat manualized treatment for children with anxiety disorders Utilized Collaborative Problem Solving program for parents of severely dysregulated children

Taught problem solving strategies and coping skills to children with anxiety disorders, ADHD, and emotion dysregulation Led child group therapy using the "Managing Frustration for Children: A Group Based Intervention for Emotion Dysregulation in Children" protocol for children with emotion regulation difficulties Led parent psychoeducation group using the "Understanding and Managing ADHD: A Course for Parents" protocol for parents of children with emotion dysregulation and ADHD Administered diagnostic assessments including use of WISC-IV, Woodcock-Johnson Achievement Test-III, and ADIS-IV-P/C 
Consulted on creation of individualized education plan (IEP) with school personnel

Supervision and observation of therapy conducted by other students

Adult experience:

Utilized Cognitive Behavioral Therapy modules for adults with anxiety and depressive disorders

Utilized Dialectical Behavior Therapy modules for adults with emotion dysregulation difficulties

Administered neuropsychological assessments, including the WAIS-IV, Woodcock-Johnson Achievement Test Administered personality assessments, including MMPI-II and MCMI

Supervision and observation of therapy conducted by other students 